\title{
A viscoplastic SANICLAY model for natural soft soils
}

Mohammad Rezania ${ }^{\mathrm{a}}$, Mahdi Taiebat ${ }^{\mathrm{b}, \mathrm{c},}$, and Elisa Poletti ${ }^{\mathrm{d}}$

${ }^{a}$ Department of Civil Engineering, University of Nottingham, Nottingham, UK

${ }^{\mathrm{b}}$ Department of Civil Engineering, University of British Columbia, Vancouver, BC, Canada

${ }^{c}$ Department of Civil \& Environmental Engineering, Massachusetts Institute of Technology, Cambridge, MA, USA

${ }^{\mathrm{d}}$ Department of Civil Engineering, University of Minho, Azurém, Guimarães, Portugal

(1)

\section{Abstract}

This paper focuses on constitutive and numerical modeling of strain-rate dependency in natural clays while also accounting for anisotropy and destructuration. For this purpose the SANICLAY model that accounts for the fabric anisotropy with the additional destructuration feature that accounts for sensitivity of natural clays, is considered as the reference model. An associated flow rule is adopted for simplicity. The model formulation is refined to also account for the important feature of strain-rate dependency using the Perzyna's overstress theory. The model is then implicitly integrated in finite element program PLAXIS. Performance of the developed and implemented model is explored by comparing the simulation results of several element tests and a boundary value problem to the available experimental data. The element tests include the constant strain-rate under one-dimensional and triaxial conditions on different clays. The boundary value problem includes a test embankment, namely embankment D constructed at Saint Alban, Quebec. For comparison, the test embankment is also analysed using the Modified CamClay (MCC) model, the SANICLAY model, and the viscoplastic model but without destructuration. Results demonstrate the success of the developed and implemented viscoplastic SANICLAY in reproducing the strain-rate dependent behavior of natural soft soils.

Keywords: viscoplasticity; strain-rate dependency; anisotropy; destructuration; clay

${ }^{*}$ Corresponding author. Tel.: +1 6048223279 .

E-mail addresses: mohammad.rezania@nottingham.ac.uk (M. Rezania), mtaiebat@civil.ubc.ca (M. Taiebat), elisapoletti@civil.uminho.pt (E. Poletti). 


\section{Introduction}

Modeling the stress-strain response of natural soft soils constitutes a challenge in practical geotechnical engineering; it is governed by a series of factors that are not always included in conventional constitutive models. In particular, the three main inherent features that influence their response are a) anisotropy, b) destructuration (degradation of the inter-particle bonds), and c) strain-rate dependency.

Since modeling the full anisotropy of natural clay behavior is not practical due to the number of parameters involved, efforts have been mainly focused on development of models with reduced number of parameters while maintaining the capacity of the model [1]. Historically, for practical model development purposes, the initial orientation of soil fabric is considered to be of cross-anisotropic nature, which is a realistic assumption as natural soils have been generally deposited only one-dimensionally in a vertical direction. It is also a well-established fact that the yield surfaces obtained from experimental tests on undisturbed samples of natural clays are inclined in the stress space due to the inherent fabric anisotropy in the clay structure (e.g., [2-4]). Based on the above, a particular line of thought has become popular in capturing the effects of anisotropy on clayey soil behavior, by development of elasto-plastic constitutive models involving an inclined yield surface that is either fixed (e.g., [2]), or can changed it inclination by adopting a rotational hardening $(\mathrm{RH})$ law in order to simulate the development or erasure of anisotropy during plastic straining (e.g., [5-6]). For obvious reasons a model accounting for both inherent and evolving anisotropy would be more representative of the true nature of response in clays; hence, since the first proposal of such model by Dafalias [5-6] similar framework has been adopted by a number of other researchers for development of anisotropic elasto-plastic constitutive models (e.g., [7-11]). Based on the original model, Dafalias et al. [12] proposed what they called SANICLAY model, altering the original RH law and introducing a non-associated flow rule. A destructuration theory was later applied to the SANICLAY model [13] to account for both isotropic and frictional destructuration processes. In these works, the SANICLAY has been shown to provide successful simulation of both undrained and drained rate-independent behaviour of normally consolidated sensitive clays, and to a satisfactory degree of accuracy of overconsolidated clays.

Past experimental studies have also shown that soft soils exhibit time-dependent response (e.g., [1417]). Time-dependency is usually related to the soil viscosity that could lead to particular effects such as creep, stress relaxation, and strain-rate dependency of response. Time-dependency of soil response can be 54 observed experimentally by means of creep tests, stress relaxation tests, or constant rate of strain (CRS) tests [18]. Rate-sensitivity is a particular aspect of time effect that has been investigated extensively; it 
influences both strength and stiffness of soils. Various studies using CRS tests have shown how faster strain rates for a certain strain level lead to higher effective stresses; also, the general observation, particularly in soft soils, is that higher undrained strengths can be achieved by increasing the loading rate

59 (e.g., [16-17,19-20]). The reported observations from laboratory studies all imply that consideration of soil viscosity effects could be key for correct prediction of long term deformations in field conditions; although, neglecting soil viscosity seemingly provide sufficiently correct predictions in short-term [21]. Landslides or long-term deformations of tunnels and embankments on soft soils are examples of common practical problems where a sustainable remediation and/or design solution can only be achieved if time-dependent behavior of soil is taken into consideration.

In order to account for the time-dependency of soft clays' behavior, various frameworks can be found in the literature. Among a number of popular frameworks such as the isotache theory of Šuklje [22] or the non-stationary surface theory of Naghdi and Murch [23], the overstress theory of Perzyna [24-25] is a common framework often used in geomechanics for this purpose due to its relative simplicity. The first overstress-type viscoplastic models were based on isotropic Cam-Clay or modified Cam-Clay models (e.g., [26-32]). More recently, several models accounting for either only the fabric anisotropy (e.g., [33]), or both anisotropy and destructuration [34] have also been introduced. A shortcoming of these models is the absence of bounds for the evolution of rotational hardening variables which could eventually lead to an excessive rotation of the yield surface for loading at very high values of stress-ratio [35-36]. Furthermore, destructuration theories have so far only addressed isotropic destructuration (usually constituting a destructuration. model is proposed. The model is a new member of the SANICLAY family of models, which are based on the classical modified Cam-Clay model and include rotational hardening and destructuration features for simulation of anisotropy and sensitivity, respectively. Perzyna's overstress theory [24-25] is employed to account for soil viscosity effects. Being based on the SANICALY model, the new viscoplastic model restricts the rotation to within bounds necessary to guarantee the existence of real-valued solutions for the analytical expression of the yield surface [12]. In the following sections, the theoretical formulation of 84 the model will be discussed, followed by the details of its numerical implementation based on an algorithm proposed by Katona [28]. The validation of the new model is done by comparing the model 
87 boundary value problem. In particular, at element level the measured behavior observed from CRS and 88 undrained triaxial tests over a number of different soft clays are used. Within these examples, 89 determination of model parameter values is also discussed. For the boundary value problem, a well-

90 studied test embankment, namely St. Alban embankment, is modeled and the predicted deformations 91 using the EVP-SANICLAY model are compared with the recorded in-situ values. In order to better

92 highlight the merits of the newly proposed constitutive model, the simulation results are also compared 93 with those obtained using the MCC model, the SANCILAY model, and also the EVP-SANICLAY model 94 but without the destructuration feature. Note that in this paper all stress components are effective 95 stresses and as usual in geomechanics, both stress and strain quantities are assumed positive in 96 compression.

97

\section{EVP-SANICLAY}

\subsection{Model formulation}

According to Perzyna's theory, the total strain increment, $\Delta \boldsymbol{\varepsilon}$, associated with a change in effective stress, $\Delta \boldsymbol{\sigma}$, during a time increment of $\Delta t$, is additively decomposed to elastic and viscoplastic parts

$$
\Delta \varepsilon=\Delta \boldsymbol{\varepsilon}^{e}+\Delta \boldsymbol{\varepsilon}^{v p}
$$

102 where the superscripts $e$ and $v p$ represent the elastic and the viscoplastic components, respectively. The elastic strain increment, $\Delta \boldsymbol{\varepsilon}^{e}$, is time-independent; whereas, the viscoplastic strain increment, $\Delta \boldsymbol{\varepsilon}^{v p}$, is

104 irreversible and time-dependent. Adopting the isotropic hypoelastic relations for simplicity [12], the elastic 105 part of the total strain can be shown as

$$
\Delta \varepsilon^{e}=D^{-1}: \Delta \sigma
$$

where $\boldsymbol{D}$ is the elastic stiffness matrix with more details presented in the Appendix, and symbol : in

107 implies the trace of the product of two tensors.

108 The time-dependent viscoplastic strain increment is evaluated as

$$
\Delta \boldsymbol{\varepsilon}^{v p}=\dot{\boldsymbol{\varepsilon}}^{v p} \cdot \Delta t
$$

109

where $\dot{\boldsymbol{\varepsilon}}^{v p}$ is the viscoplastic strain rate tensor (a superposed dot denotes the time derivative), and following the original proposal by Perzyna [24-25], it can be defined as

$$
\dot{\boldsymbol{\varepsilon}}^{v p}=\mu \cdot\langle\Phi(F)\rangle \cdot \frac{\partial g}{\partial \boldsymbol{\sigma}}
$$


111

112

113

114

115

116

117

118

119

120

121

122

123

124

125

126

127

128

129

130

where $\mu$ is referred to as the fluidity parameter, $g$ is the viscoplastic potential function represented by the dynamic loading surface (DLS - explained in the sequel), and $\Phi(F)$ is the so-called overstress that is the normalised distance between the current static yield surface (SYS) and the DLS (see Figure 1). The application of Macauley brackets in Equation (4) ensures that

$$
\langle\Phi(F)\rangle= \begin{cases}0 & \text { for } \Phi(F) \leq 0 \\ \Phi(F) & \text { for } \Phi(F)>0\end{cases}
$$

Several different relationships for $\Phi(F)$ have been proposed in the literature (e.g. [26,37]). In this work the following exponential function proposed by Fodil et al. [38] is employed

$$
\Phi(F)=\exp (F)-1=\exp \left[N\left(\frac{p_{0}^{d}}{p_{0}^{s}}-1\right)\right]-1
$$

where $p_{0}^{S}$ and $p_{0}^{d}$ are the size of the SYS and the DLS, respectively (see Figure 1), $N$ is the strain-rate coefficient that together with $\mu$ are the two viscous parameters of this model. 
In the above expression, $\boldsymbol{s}=\boldsymbol{\sigma}-p \boldsymbol{I}$ is the deviatoric component of stress tensor $\boldsymbol{\sigma}$ (I being the fourth order identity tensor). $\boldsymbol{\alpha}$ is the deviatoric fabric tensor that accounts for anisotropy by coupling the deviatoric and volumetric plastic strain rates. $p_{0}^{* S}=S_{i} p_{0}^{S}$ defines the size of the structured SYS where $S_{i} \geq 1$ is an isotropic destructuration factor and $p_{0}^{S}$ is the size of the intrinsic SYS. $M^{*}(\theta)=S_{f} M(\theta)$ where $S_{f} \geq 1$ is a frictional destructuration factor and $M(\theta)$ is the critical stress-ratio that in the general stress space its value is interpolated between $M_{c}$ and $M_{e}$ by means of a Lode angle $\theta$. In the stress space illustrated in Figure 1 the scalar $\alpha=\sqrt{(3 / 2) \boldsymbol{\alpha}: \boldsymbol{\alpha}}$ defines the rotation of the SYS and DLS. As shown in Figure 1, the DLS has the same shape and orientation as the smaller SYS, and following the adoption of associate flow rule it coincides the viscoplastic potential surface too. A summary of the hardening equations and the Lode angle formulation are presented in the Appendix for the sake of completeness.

The model constants of EVP-SANICLAY can be divided into 4 categories: (1) the elasticity constants $\kappa$ and $v$ and the critical state constants $M_{c}, M_{e}$ and $\lambda$ which are the same as those in the MCC model (with the exception that in MCC we have $M_{e}=M_{c}$ ); (2) the rotational hardening (RH) constants $C$ and $x$, which are specific to the SANICLAY model; (3) the destructuration constants $k_{i}, k_{f}$ and $A$; and (4) the viscosity parameters $N$ and $\mu$, which constitute the two new additional parameters of the EVPSANICLAY and they can be determined as discussed in Yin and Hicher [31]. Furthermore, similar to the SANICLAY, $\alpha$ and $p_{0}^{s}$ constitute the hardening internal variables in the EVP-SANICLAY model. It should be noted that despite the large number of model parameters, they have clear physical meaning and can be determined following straightforward processes. The detailed procedure for evaluating the initial values of the model state variables, and hardening and destructuration parameters can be found in Taiebat et al. [13].

\subsection{Numerical Integration}

The numerical solution algorithm for the elasto-viscoplastic model can be developed by using a stepby-step time integration algorithm with a Newton-Raphson iteration procedure [28]. In this scheme it is assumed at the beginning of a certain defined time interval and strain increment, the values of stresses, strains, and state variables are known. The objective is to determine the subsequent elastic and viscoplastic strain components, which in turn allow finding the subsequent stresses and internal variables. From Equations $(1,2)$ the incremental constitutive relationship for a time step can be expressed as

$$
\Delta \sigma=D\left(\Delta \varepsilon-\Delta \varepsilon^{v p}\right)
$$


For approximation of $\Delta \boldsymbol{\varepsilon}^{v p}$, a finite difference scheme is employed as:

$$
\Delta \boldsymbol{\varepsilon}^{v p}=\Delta t\left[(1-\beta) \dot{\boldsymbol{\varepsilon}}_{t}^{v p}+\beta \dot{\boldsymbol{\varepsilon}}_{t+\Delta t}^{v p}\right]
$$

161

162

163

where $\dot{\varepsilon}_{t}^{v p}$ is the value of viscoplastic strain rate at time $t$, and $\beta$ is a time interpolation parameter $(0 \leq \beta \leq 1) ; \beta=0$ represents an explicit forward (Euler) interpolation, $\beta=0.5$ represents central (CrankNicolson) interpolation, and $\beta=1$ implies an implicit backward interpolation. Lewis and Schrefler [39] showed that in this scheme the solution is conditionally stable for $0 \leq \beta<0.5$ and $\beta=1$, and unconditionally stable for $0.5 \leq \beta<1$. Substituting Equation (9) into Equation (8) and rearranging the terms give:

$$
D^{-1} \boldsymbol{\sigma}_{t+\Delta t}+\Delta t \cdot \beta \cdot \dot{\boldsymbol{\varepsilon}}_{t+\Delta t}^{v p}=\Delta \boldsymbol{\varepsilon}-\Delta t \cdot(1-\beta) \dot{\boldsymbol{\varepsilon}}_{t}^{v p}+D^{-1} \boldsymbol{\sigma}_{t}
$$

where the terms on the right hand side are known (at time $t$ ), while the left hand side terms are unknowns (at time $t+\Delta t$ ) and they are to be solved in an iterative procedure. A Modified NewtonRaphson approach is used for the iterative solution of Equation (10). To do this, a limited Taylor series is applied to the unknown quantities $\boldsymbol{\sigma}_{t+\Delta t}$ and $\dot{\boldsymbol{\varepsilon}}_{t+\Delta t}^{v p}$ :

$$
\left\{\begin{array}{c}
\boldsymbol{\sigma}_{t+\Delta t}=\boldsymbol{\sigma}_{i}+d \boldsymbol{\sigma}_{i} \\
\dot{\boldsymbol{\varepsilon}}_{t+\Delta t}^{v p}=\dot{\boldsymbol{\varepsilon}}_{i}^{v p}+\frac{\partial \dot{\boldsymbol{\varepsilon}}_{i}^{v p}}{\partial \boldsymbol{\sigma}} d \boldsymbol{\sigma}_{i}
\end{array}\right.
$$

Note that subscript $i$ refers to the $i$-th iteration at the current time step. Substituting Equations (11a) and (11b) into Equation (10) and successive rearrangements result in the following form for computation of stress increment:

$$
d \boldsymbol{\sigma}_{i}=\left[\boldsymbol{D}^{-1}+\Delta t \cdot \beta \cdot \frac{\partial \dot{\varepsilon}_{i}^{v p}}{\partial \boldsymbol{\sigma}}\right]^{-1}:\left[\left(\Delta \boldsymbol{\varepsilon}-\Delta t \cdot(1-\beta) \dot{\boldsymbol{\varepsilon}}_{t}^{v p}+\boldsymbol{D}^{-1}: \boldsymbol{\sigma}_{t}\right)-\left(\boldsymbol{D}^{-1} \boldsymbol{\sigma}_{i}+\Delta t \cdot \beta \cdot \dot{\boldsymbol{\varepsilon}}_{i}^{v p}\right)\right]
$$

If it is assumed that function $K$ represents the term $\left(\Delta \boldsymbol{\varepsilon}-\Delta t \cdot(1-\beta) \dot{\boldsymbol{\varepsilon}}_{t}^{v p}+\boldsymbol{D}^{-1} \boldsymbol{\sigma}_{t}\right)$ with known quantities remaining constant during the iteration, and that function $U$ represents the iterative term $\left(\boldsymbol{D}^{-1} \boldsymbol{\sigma}_{i}+\Delta t \cdot \beta \cdot \dot{\boldsymbol{\varepsilon}}_{i}^{v p}\right)$, then Equation (12) can be presented in a short form as:

$d \boldsymbol{\sigma}_{i}=\left[\frac{\partial U}{\partial \boldsymbol{\sigma}}\right]^{-1} \cdot\left[K_{t}-U_{i}\right]$

The most efficient solution scheme for continuum problems using overstress-type elasto-viscoplastic constitutive equations can be obtained with $\beta=0.5$ [40]; hence, this value is adopted for the time interpolation parameter in the present work. For the solution algorithm, at every time step Equation (13) is iteratively solved. At each iteration $d \boldsymbol{\sigma}_{i}$ is calculated and subsequently $\boldsymbol{\sigma}_{i}$ is updated as $\boldsymbol{\sigma}_{i}=\boldsymbol{\sigma}_{i-1}+$ $d \boldsymbol{\sigma}_{i}$. When convergence is achieved (i.e. when $d \boldsymbol{\sigma}_{i}<$ tolerance $\sim 10^{-7}$ ), the iterative procedure stops and 
the incrementally accumulated stress values will become the stresses at the corresponding time step (i.e., $\left.\boldsymbol{\sigma}_{t+\Delta t}\right)$; subsequently, viscoplastic strain tensor can be calculated as $\boldsymbol{\varepsilon}_{t+\Delta t}^{v p}=\boldsymbol{\varepsilon}_{t+\Delta t}-\boldsymbol{D}^{-1} \boldsymbol{\sigma}_{t+\Delta t}$. The implementation makes it possible to apply the whole strain increment through a number of subincrements, not all at once. After the completion of the integration process at a time increment the procedure advances to the next time step.

The EVP-SANICLAY model has been implemented into PLAXIS finite element program as a userdefined soil model in order to be used for both element level and boundary value problem simulations. In the following, first the performance of the model is validated by simulation of a number of element test data on various clays. The model is then used for settlement study of a real instrumented test embankment and the simulation results are discussed in detail. The embankment simulation also aims to compare details of the predicted response using the proposed model and also using an isotropic and rateindependent model that is often used in practice.

\section{Model validation based on element level tests}

For the element test simulations the implemented user-defined model has been employed through the PLAXIS Soil Test application [41] to simulate several undrained triaxial shear and CRS test data on four different soft soils reported in the literature, namely Kawasaki clay, Haney clay, St. Herblain clay, and Batiscan clay $[14,16,42-43]$. The values of model constants and state variables used for the four soil types analysed in this paper are summarised in Tables 1 and 2. In accordance with the natural or reconstituted state of the clay sample being simulated the destructuration feature of the model has been switched on or off by setting respective values to the structuration parameters. 


\begin{tabular}{lccccc}
\hline \multirow{2}{*}{ Model constant } & & & & & \\
& & Kawasaki & Haney & St. Herblain & Batiscan \\
\hline Elasticity & $\kappa$ & 0.021 & 0.05 & 0.022 & 0.037 \\
Critical state & $v$ & 0.2 & 0.25 & 0.3 & 0.3 \\
Rotational hardening & $M_{c}\left(M_{e}\right)$ & $1.65(1.24)$ & 1.28 & 1.25 & 0.98 \\
& $\lambda$ & 0.16 & 0.32 & 0.41 & 0.41 \\
Destructuration & $C$ & 12 & 12 & 10 & 12 \\
& $x$ & 2.6 & 2.4 & 1.5 & 1.7 \\
\multirow{2}{*}{ Viscosity } & $k_{i}$ & 0 & 1.5 & 0 & 1.4 \\
& $k_{f}$ & 0 & 1.4 & 0 & 1.3 \\
& $A$ & 0 & 0.3 & 0 & 0.5 \\
& $N$ & 12 & 17 & 9 & 12 \\
& $\mu\left[\mathrm{s}^{-1}\right]$ & $7 \times 10^{-6}$ & $5 \times 10^{-11}$ & $5 \times 10^{-9}$ & $2 \times 10^{-9}$ \\
\hline
\end{tabular}

Table 2. Initial values of state variables adopted for four types of clays

\begin{tabular}{lccccc}
\hline Model state variable & & Kawasaki & Haney & St. Herblain & Batiscan \\
\hline Initial void ratio & $e$ & 1.07 & 2 & 2.26 & 1.92 \\
$\begin{array}{l}\text { Initial size of the SYS } \\
\text { Initial rotation of the }\end{array}$ & $p_{0}[\mathrm{kPa}]$ & 250 & 340 & 30 & 50 \\
SYS & $\alpha$ & 0.60 & 0.43 & 0.46 & 0.36 \\
$\begin{array}{l}\text { Initial isotropic } \\
\text { structuration factor }\end{array}$ & $S_{i}$ & 1 & 6 & 1 & 3 \\
$\begin{array}{l}\text { Initial frictional } \\
\text { structuration factor }\end{array}$ & $S_{f}$ & 1 & 1.3 & 1 & 1.5 \\
\hline
\end{tabular}

\subsection{Kawasaki clay}

211 To evaluate the strain-rate dependency, Nakase and Kamei [42] performed undrained triaxial 212 compression and extension tests with various shearing rates on anisotropically consolidated reconstituted

213 Kawasaki clay specimens. The index properties of Kawasaki clay samples were reported as plasticity index

$214 I_{P}=29.4$, specific gravity $G_{S}=2.69$, liquid limit $w_{L}=55.3 \%$, plastic limit $w_{P}=25.9 \%$, and clay content

$21522.3 \%$. All tests were conducted under a vertical effective consolidation pressure of $392 \mathrm{kPa}$ with a back-

216 pressure of $196 \mathrm{kPa}$ in the consolidation stage. The samples were consolidated under a $K_{0}$ value of 0.42 ,

217 and then the samples were sheared in both compression and extension with axial strain rates of $0.7,0.07$, 218 and $0.007 \% / \mathrm{min}$.

219 Kamei and Sakajo [44] reported the values of conventional soil parameters, such as $\kappa, \lambda, M$ and 220 initial void ratio, for the samples of Kawasaki clay. Based on the test data, the critical stress ratio in 221 triaxial compression and extension were measured as 1.65 and 1.24, respectively. Rotational hardening 222 parameters were determined according to Dafalias et al. [12]. For the simulations, the destructuration 
feature of the model was switched off by setting $S_{i}=S_{f}=1$, as the soil specimens were reconstituted.

224 Viscosity parameters were determined through calibration based on data from tests at only two strain225 rates.

Figure 2 shows the comparison between experimental and numerical results obtained using the EVPSANICLAY model. The tests were simulated considering the consolidation stage. As it is seen in the figure, the response during triaxial compression has been captured very well by the model, while for the extension part the results are less accurate, even though the Lode angle dependency was considered in order to better reproduce the clay behavior in extension. As illustrated in Figure 3 of Taiebat et al. [13] this could be in part due to adoption of an associated flow rule in the EVP model.

232

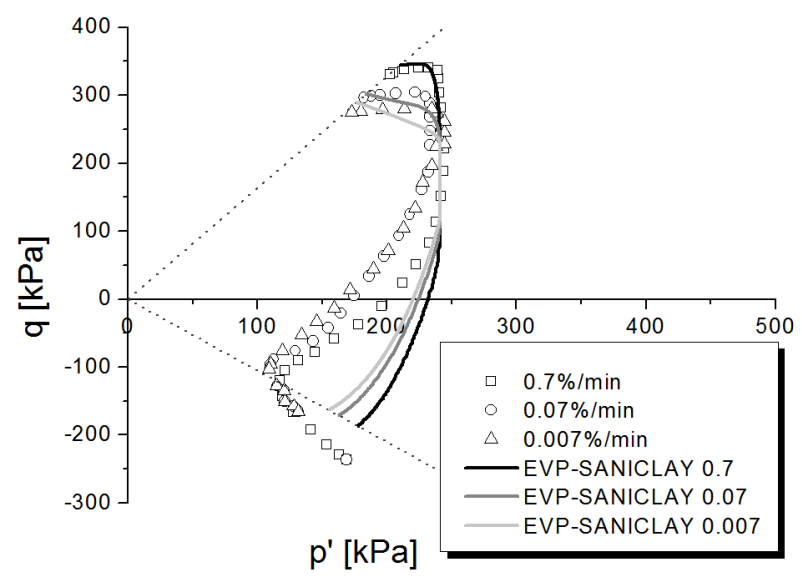

(a)

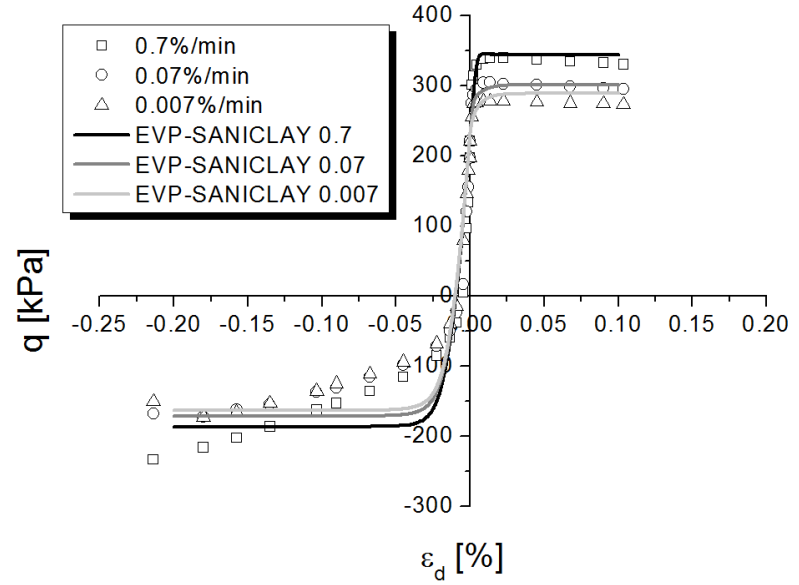

(b)

Figure 2. Undrained triaxial test: (a) effective stress path; (b) deviator stress versus axial strain paths tend to be more lenient towards the critical state. As no destructuration was considered for this simulation and also associated flow rule was employed, the modeling results did not reproduce a noticeable softening behavior (Figure 2b). This is observed in both compression and extension. The initial stiffness of the curve was also well represented. The Lode angle dependency of the model allows capturing the anisotropy in strength as it was observed by Nakase and Kamei [42]. 


\subsection{Haney clay}

Vaid and Campanella [14] carried out undrained triaxial tests on undisturbed saturated sensitive marine clay known as Haney clay. It is a silty clay with $w_{L}=44 \%, w_{P}=26 \%$ and a sensitivity within the range of 6 to 10. All test samples were normally consolidated, with an all-around confining pressure of $515 \mathrm{kPa}$. Consolidation was allowed for a period of $36 \mathrm{hr}$ after which the samples were left undrained for $12 \mathrm{hr}$ under the consolidation stresses prior to shearing. In order to study the rate dependency of undisturbed clay response, the undrained shearing stage of the tests was performed at different constant strain rates, varying from $10^{-3}$ to $1.1 \% / \mathrm{min}$.

Values of conventional soil parameters listed in Tables 1 and 2 were reported by Vermeer and Neher [45]. After determination of the initial value of $\alpha$, the values of anisotropy constants, $C$ and $x$, were obtained via curve fitting. Destructuration parameter values were also calibrated via trial runs.

254 Structuration factor and destructuration constants influence the softening behavior after peak strength, and to a lesser degree, the shear strength achieved. Figure 3a and 3b show the influence of frictional destructuration in soft clay behavior. An increase of the frictional structuration factor leads to a larger softening behavior and a noticeable decrease in shear strength (Figure 3a).

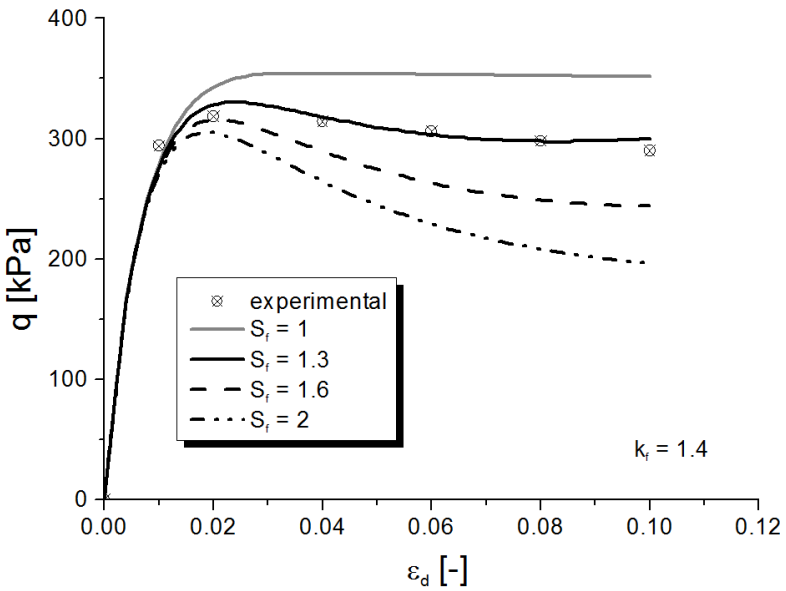

(a)

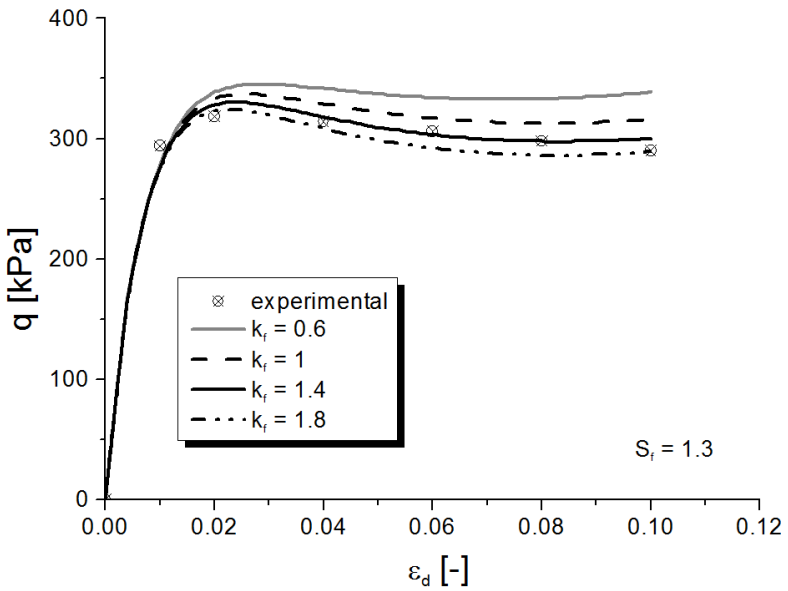

(b) 


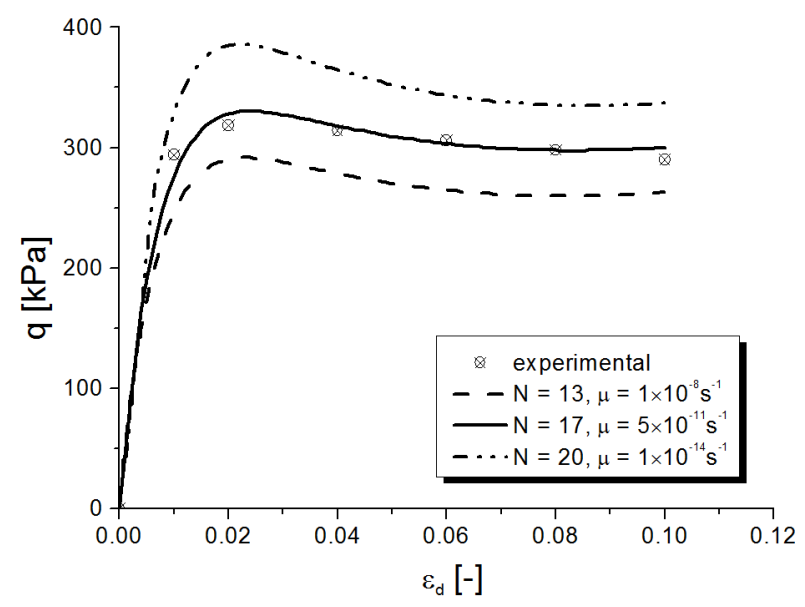

(c)

Figure 3. Calibration of structuration and viscosity parameters for Haney clay: (a) influence of frictional structuration parameter $S_{f}$ for a constant rate $k_{f}=1.4$; (b) influence of rate of frictional destructuration $k_{f}$ for a constant value of $S_{f}=1.3$; (c) combined influence of viscosity parameters $N$ and $\mu$

A similar, if less marked, behavior is seen in relation to the rate of frictional destructuration (Figure 3b), with larger softening observed for higher destructuration rates. Viscosity parameter values were calibrated based on the results of two tests (i.e. at two strain rates) only. As it is shown in Figure 3c, viscosity parameters play an important role in the overall calibration of the model, particularly with regards to the shear strengths achieved. In order to obtain an improved match with the experimental results, instead of the default value of 0.5 , a value of 0.3 was adopted for the destructuration parameter $A$.

For model simulations using EVP-SANICLAY, three specific strain rates, at $0.00094 \% / \mathrm{min}$, $0.15 \% / \mathrm{min}$ and $1.1 \% / \mathrm{min}$, have been taken into account to reproduce the observed shear stress-shear strain curves. Also the peak strengths achieved at different strain rates were considered to evaluate the model performance. The experimental versus numerical results are shown in Figure 4. It can be seen from the figure that the model simulations compare very well with the observed behavior. The model, with its destructuration function on, is able to simulate the softening behavior of natural clay response after peak (Figure 4a). Also Figure 4b indicates that the model provides a reasonably good representation for the variations of maximum shear strength with loading rate. 


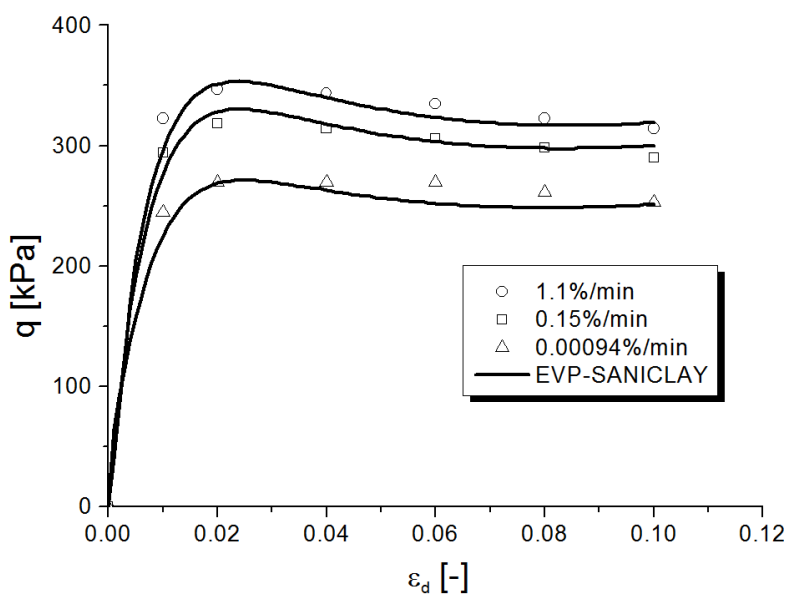

(a)

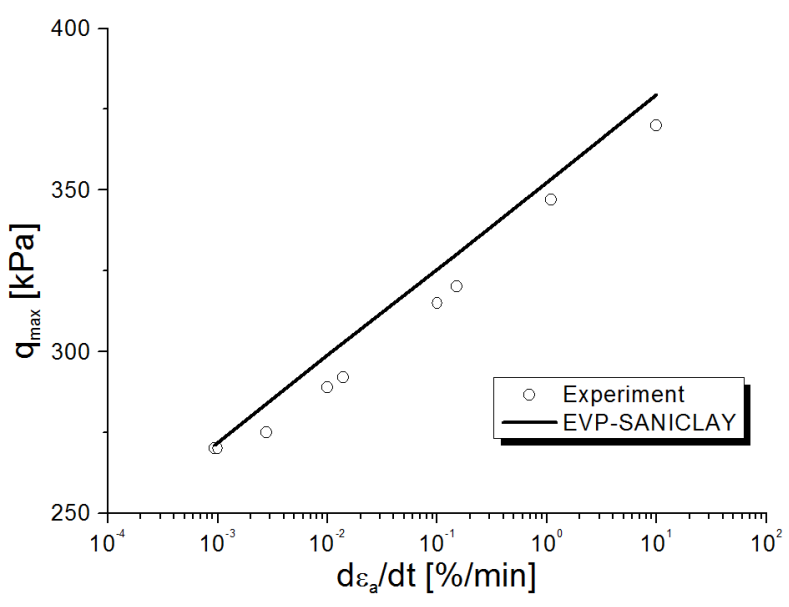

(b)

Figure 4. Undrained triaxial compression tests: (a) deviator stress versus axial strain; (b) evolution of maximum deviator stress with strain rate

\subsection{St. Herblain clay}

A particular CSR oedometer test was performed by Rangeard [43] on St. Herblain clay, a clayey river alluvial deposit. Two different strain rates were considered during the test. The test was started with a strain rate of $3.3 \times 10^{-6} \mathrm{~s}^{-1}$ until an axial strain of $12 \%$, at this strain the loading rate was lowered to a strain rate of $6.6 \times 10^{-7} \mathrm{~s}^{-1}$ and was kept at that until a vertical strain of $15.5 \%$, then again the rate was switched back to the initial strain rate and was kept constant until the end of the test.

Soil parameter values, obtained from oedometer and triaxial tests, were also reported by Rangeard [43]. The clay sample used for the experiments was taken from a depth of 6.5-7.5 m, it had a bulk unit weight $\gamma=14.85 \mathrm{kN} / \mathrm{m}^{3}$ and a water content of $87 \%$. A vertical pre-consolidation pressure of $52 \mathrm{kPa}$ was determined from the oedometer tests. The model parameters adopted are summarised in Tables 1 and 2.

Given that the clay was slightly structured, for the simulations the destructuration feature of the model was switched off. Figure 5 shows the experimental data versus simulation results. It can be seen that the model predictions are in good agreement with the data, particularly with regards to vertical stresses. The model also captures the indentation due to the change in strain-rate during the test. 


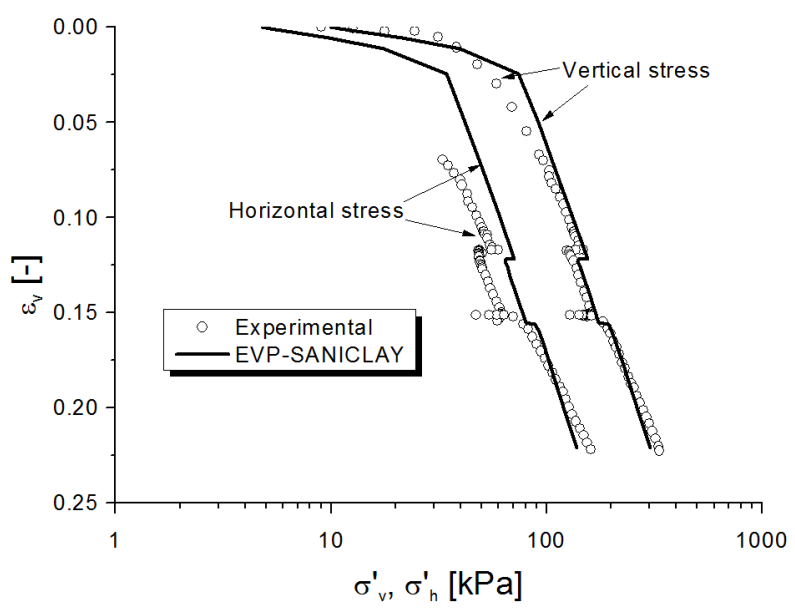

Figure 5. Simulations of CRS oedometer test results over St. Herblain clay

\subsection{Batiscan clay}

CSR oedometer tests were performed on Batiscan clay by Leroueil et al. [16]. The clay samples were taken from a depth of $7.25-7.46 \mathrm{~m}$; the samples reportedly had a water content of $80 \%$, liquidity index $I_{L}$ $=2.7, I_{P}=21$, and $\gamma=17.5 \mathrm{kN} / \mathrm{m}^{3}$. The pre-consolidation pressure, determined from conventional oedometer tests, was evaluated as $88 \mathrm{kPa}$. The strain-rates for the CRS tests varied between $1.7 \times 10^{-8} \mathrm{~s}^{-1}$ and $4 \times 10^{-5} \mathrm{~s}^{-1}$. The initial vertical effective stress was taken equal to $65 \mathrm{kPa}$, corresponding to a size of the initial yield surface of $50 \mathrm{kPa}$. Conventional soil parameter values reported in Tables 1 and 2 were obtained from Leroueil et al. [16] and Rocchi et al. [46]. best coupled values were chosen for the numerical simulations. As it is shown in Figure 6a, larger values of initial structuration $S_{i}$ result in a larger reduction of final vertical stress due to the higher softening

310 occurring. For a constant value of $\mathrm{S}_{\mathrm{i}}$, the value of the rate of destructuration does not appear to have as 311 much influence, but it follows the same trend (Figure 6b), with higher rates leading to a higher vertical

312 stress reduction. Viscosity parameters are typically obtained from long-term oedometer tests via curve 313 fitting. The calibration of the coupled values is showed in Figure 6c. Note that viscosity parameters 314 greatly change the stress value at the end of the initial stiff elastic regime. The calibrated model parameter values are summarised in Tables 1 and 2 . 


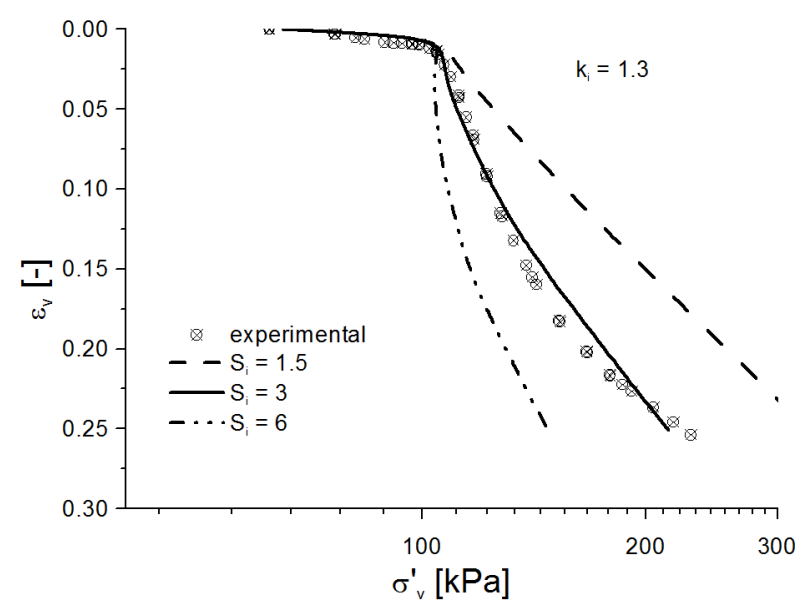

(a)

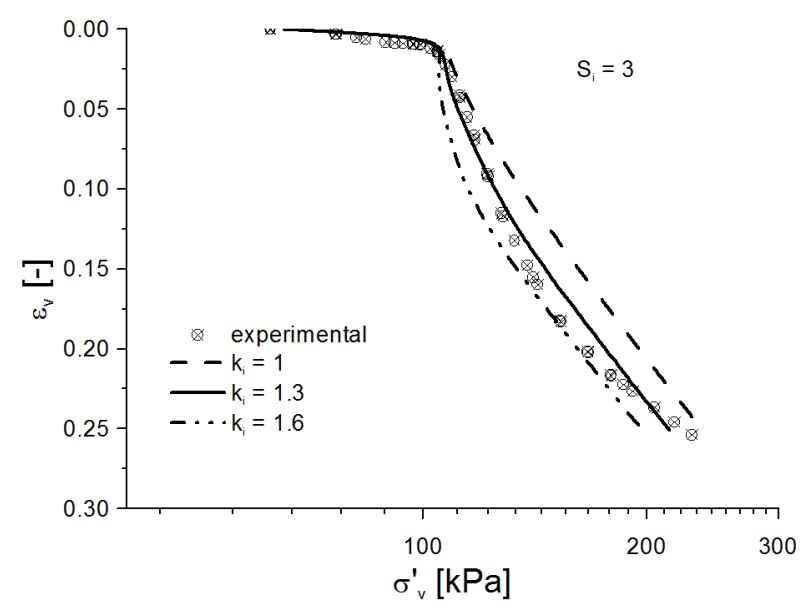

(b)

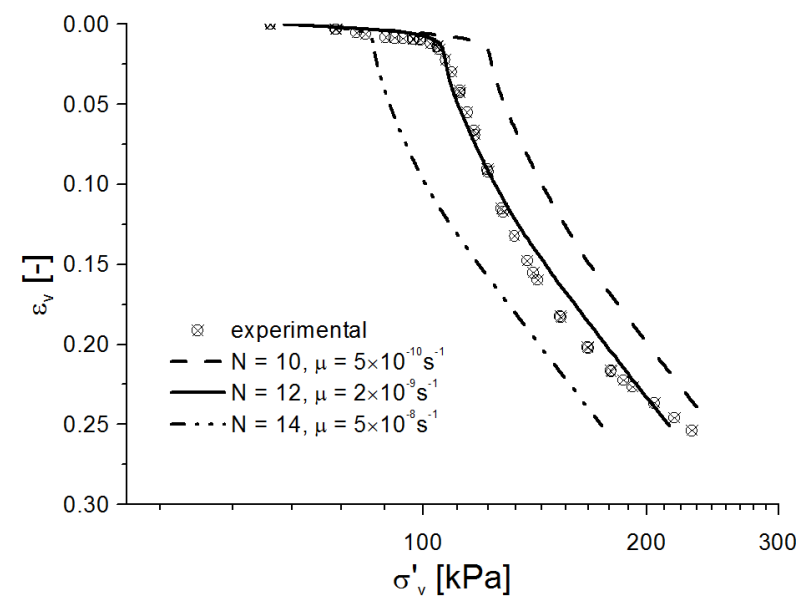

(c)

Figure 6. Calibration of structuration and viscosity parameters for Batiscan clay: (a) influence of isotropic structuration factor $S_{i}$ for a constant rate $k_{i}=1.3$; (b) influence of rate of isotropic destructuration $k_{i}$ for a constant structuration value of $S_{i}=3$; (c) combined influence of viscosity parameters $N$ and $\mu$

Model simulations using EVP-SANICLAY are shown in Figure 7. It is seen that a good correlation is obtained between the numerical results and experimental data. Also clearly the strain-rate effects are well captured; the exponential trend of the curves indicates the progress of destructuration at large strains. 


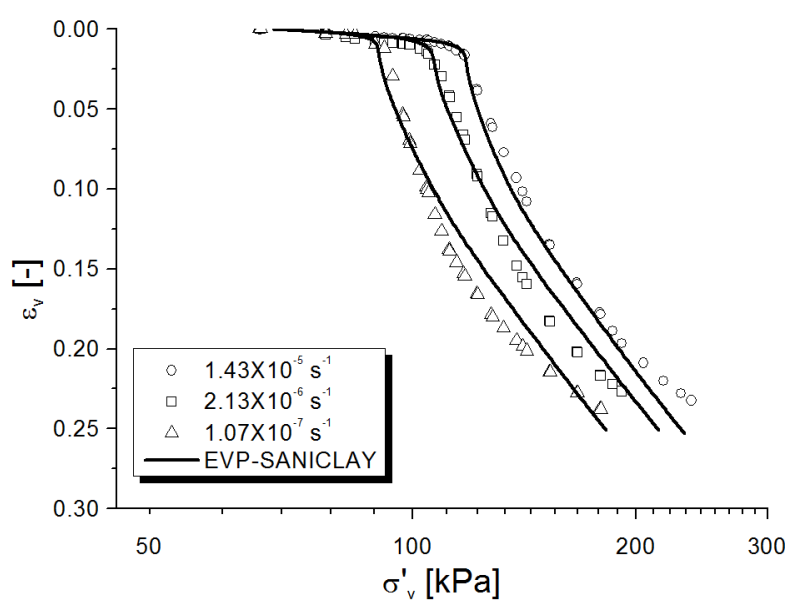

Considering that all above element test simulations performed using EVP-SANICLAY, it appears that in addition to the anisotropy and destructuration effects, the model is able to reasonably capture the strain-rate dependency in behavior of natural clays. Also for the simulations preformed above, the model implementation proved to be sufficiently robust.

\section{Boundary value level modeling}

In order to study the performance of the proposed elasto-viscoplastic constitutive model at the boundary value level, the simulation of a test embankment was carried out. In particular, embankment D of a set of four test embankments built on a soft, sensitive and cemented clay in Saint-Alban, Quebec, Canada was selected [47-48]. This is a well-known and well-instrumented embankment for which soil parameters are readily available in the literature.

\subsection{Model description}

Embankment D has a height of $3.28 \mathrm{~m}$, a uniform crest width of $7.6 \mathrm{~m}$ and slope angles of $13.75^{\circ}$. The embankment material consists of uniform medium sand compacted to a unit weight of $18.56 \mathrm{kN} / \mathrm{m}^{3}$. It was constructed on $13.7 \mathrm{~m}$ deep natural clay deposit known as Champlain clay, underlain by a dense fine to medium sand layer down to a depth of $24.4 \mathrm{~m}$ [49]. The soft deposit is overlain by approximately $1.5 \mathrm{~m}$ thick weathered crust. In order not to disturb the very soft and sensitive clay deposit at the site, the embankment was built directly on the existing natural ground, without excavating the thin dry crust

344 layer at the top. In this work a two-dimensional plane strain finite element model of the embankment was 
created using PLAXIS AE [41], and taking advantage of the symmetry, only half of the embankment was modeled. A finite element mesh with 1723 15-noded triangular elements (Figure 8.a) was used for the 347 analyses. Each element has pore water pressure (PWP) degrees of freedom at corner nodes. Mesh 348 sensitivity studies were carried out to ensure that the mesh was dense enough to produce accurate results. 349 The geometry of the finite element model is shown in Figure 8a. The far right boundary of the model was 350 assumed at distance of $40 \mathrm{~m}$ from the embankment centerline. The bottom boundary of the clay deposit 351 was assumed to be completely fixed in both horizontal and vertical directions, whereas, the left and right vertical boundaries were only restrained horizontally. Drainage was allowed at the ground level, while the 353 bottom boundary was considered impermeable. Impermeable drainage boundaries were also assigned to 354 the lateral boundaries. Based on ground data, the water table was assumed at $0.7 \mathrm{~m}$ depth.

The embankment was built in stages, with an initial layer of $0.6 \mathrm{~m}$ and after 6 days the normal construction began (Figure 8.b), with an average rate of $0.24 \mathrm{~m} /$ day [48]. The same construction pace was 357 adopted in the numerical model. For the calculation phases, plastic analyses were carried out corresponding to the construction process of the embankment, after which the consolidation analysis was performed.

For the numerical analysis, the embankment itself was modeled with the simple linear elasticperfectly plastic Mohr-Coulomb model using the following reported values for the embankment material: Young's modulus $E=40,000 \mathrm{kPa}$, Poisson's ratio $v=0.3$, friction angle $\phi=44^{\circ}$, and cohesion $c=0 \mathrm{kPa}$.

363 The dry crust layer above the water table was also modeled with the Mohr-Coulomb model using shear 364 modulus $G=880 \mathrm{kPa}$, Poisson's ratio $v=0.3, \phi=27^{\circ}, c=1 \mathrm{kPa}$. Unit weight $\gamma=19 \mathrm{kN} / \mathrm{m}^{3}$ is used for 365 both $[47,50]$. The sensitive Champlain clay deposit below the water table was modeled using the 366 implemented user-defined EVP-SANICLAY model, with a unit weight $\gamma=16 \mathrm{kN} / \mathrm{m}^{3}$ [47]. 


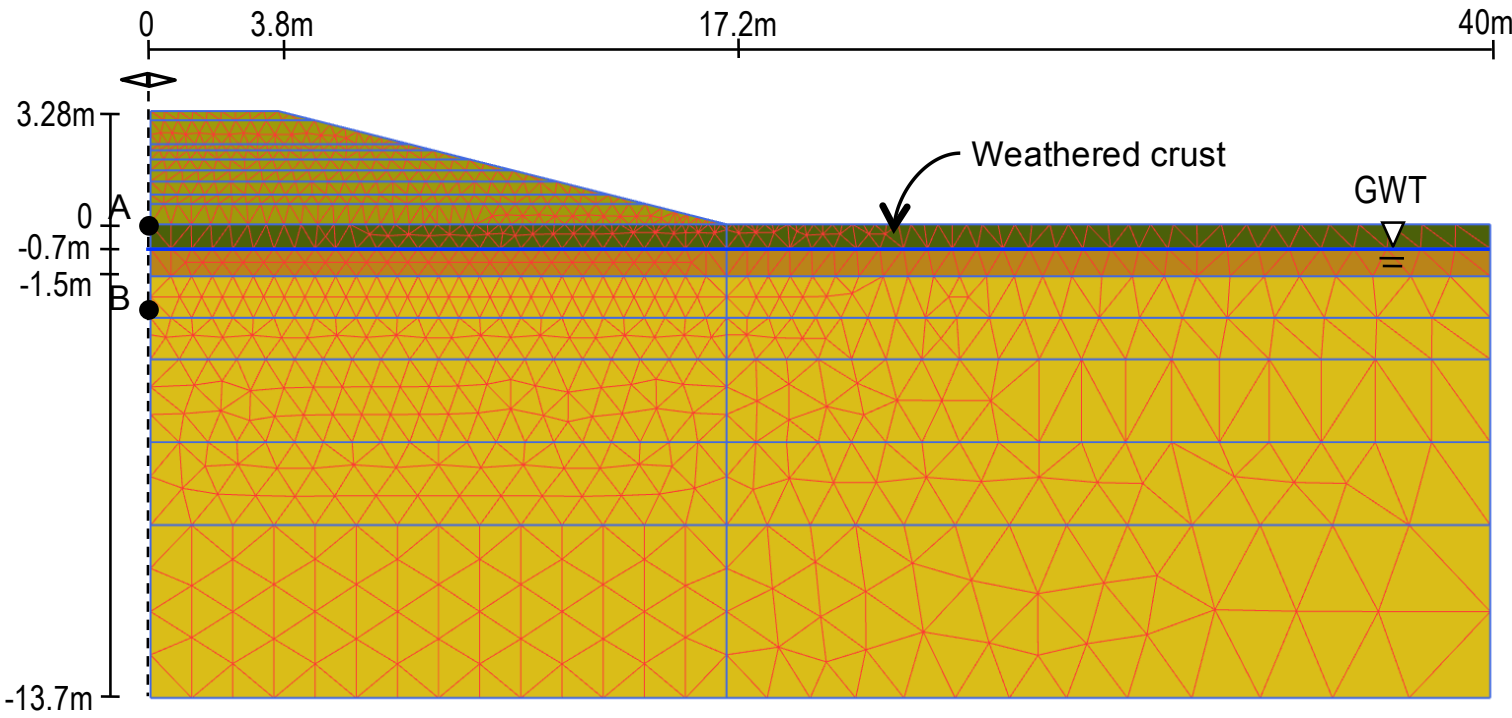

(a)

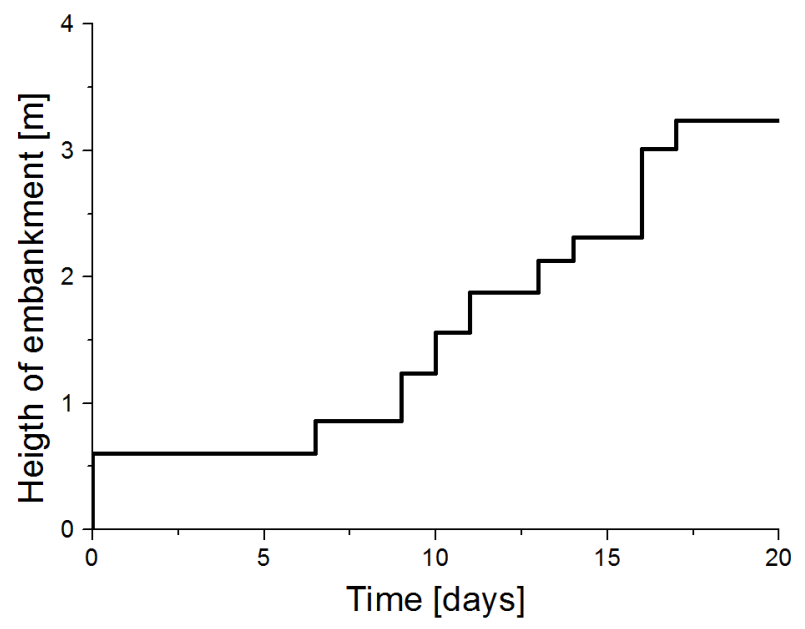

(b)

Figure 8. (a) Geometry of the model embankment and the finite element mesh adopted; (b) construction history of the St. Alban embankment D

The material parameter values for the Champlain clay layers were determined using the available 371 data obtained from testing of samples taken at a depth of $6 \mathrm{~m}$ below the ground surface [15]. Conventional 372 parameter values were derived from existing studies based on soil element test results [47-48,50]. Similar 373 to the section on element level simulations, the anisotropy parameter values were determined following 


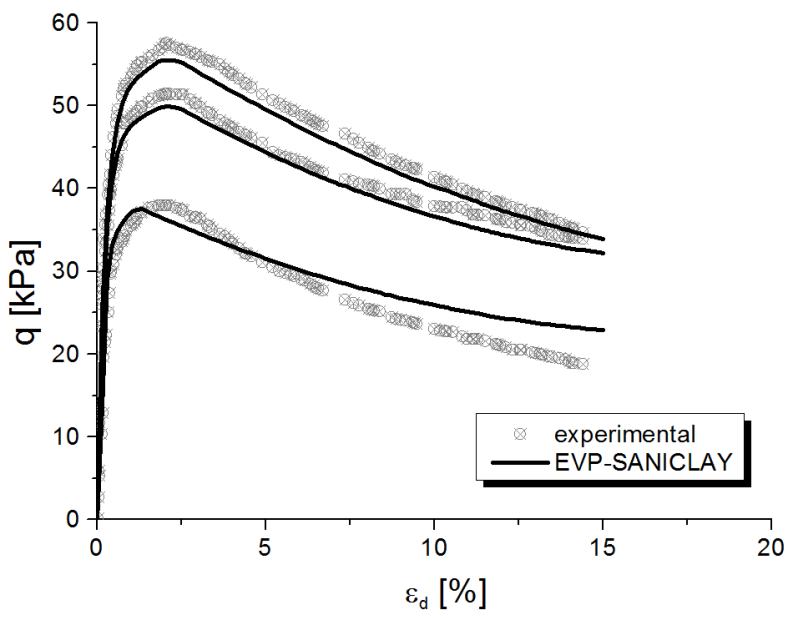

(a)

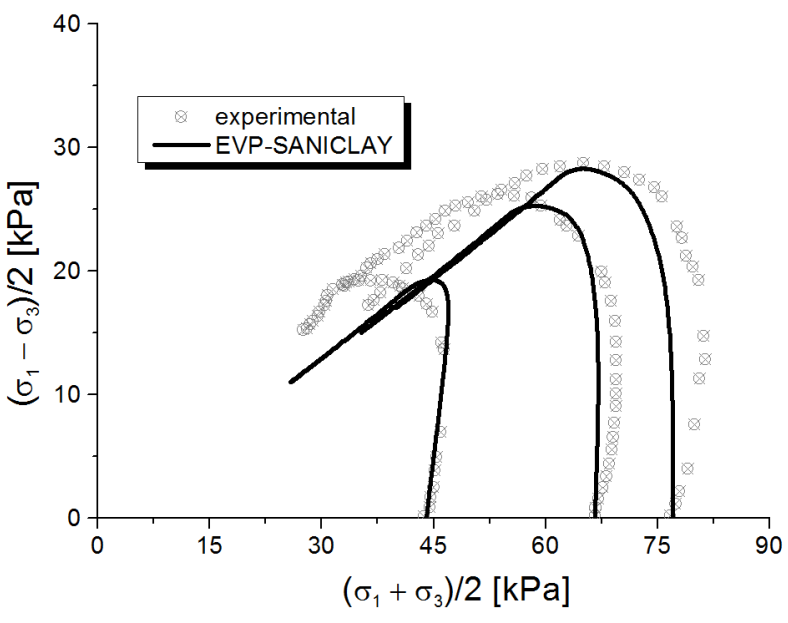

(b)

Figure 9. Validation of numerical simulations versus experimental results for undrained triaxial compression tests: (a) deviator stress versus axial strain; (b) effective stress paths different strain rates, viscosity parameters were calibrated using trial runs.

Table 3 summarises the soil and state parameters adopted for the simulation of St. Alban test embankment, and Table 4 lists the calibrated anisotropy and destructuration parameter values. The permeability, $k$, of the clay, assumed to be isotropic, was reported to be equal to $3.46 \times 10^{-4} \mathrm{~m} /$ day. It should also be added that the initial state of stress was generated by adopting $K_{0}$-procedure [41] where the reported $K_{0}$ value of 0.8 was employed [52]. Results from oedometer tests performed on Champlain clay reported that over-consolidation ratio (OCR) varied between 1.8 and 2.2 [47]; a mean value of 2.0 was assumed for the analyses performed here. 
Table 3 - Constants of the EVP-SANICLAY model adopted for St. Alban test embankment D

\begin{tabular}{lccc}
\hline Model constant & & $\begin{array}{c}\text { Top Champlain clay } \\
\text { layer }(0.7-1.5 \mathrm{~m})\end{array}$ & $\begin{array}{c}\text { Bottom Champlain } \\
\text { clay layer }(1.5-13.7 \mathrm{~m})\end{array}$ \\
\hline Elasticity & $\kappa$ & 0.012 & 0.013 \\
\multirow{2}{*}{ Critical state } & $v$ & 0.3 & 0.3 \\
& $M_{c}$ & 1.07 & 1.07 \\
Rotational hardening & $\left.M_{e}\right)$ & 0.36 & 0.25 \\
\multirow{2}{*}{ Destructuration } & $\lambda$ & 10 & 10 \\
& $\boldsymbol{C}$ & 1.7 & 1.7 \\
& $k_{i}$ & 1.5 & 1.5 \\
Viscosity & $k_{f}$ & 1.4 & 1.4 \\
& $A$ & 0.5 & 0.5 \\
& $N$ & 13 & $5 \times 10^{-9}$ \\
\hline
\end{tabular}

397

Table 4 - Initial values of state variables adopted for St. Alban test embankment D

\begin{tabular}{lccc}
\hline Model state variable & & $\begin{array}{c}\text { Top Champlain } \\
\text { clay layer } \\
(0.7-1.5 \mathrm{~m})\end{array}$ & $\begin{array}{c}\text { Bottom Champlain } \\
\text { clay layer } \\
(1.5-13.7 \mathrm{~m})\end{array}$ \\
\hline Initial void ratio & $e$ & 1.7 & 1.8 \\
$\begin{array}{l}\text { Overconsolidation ratio } \\
\text { Initial rotation of the }\end{array}$ & $\alpha$ & 2.0 & 2.0 \\
SYS & 0.41 & 0.41 \\
$\begin{array}{l}\text { Initial isotropic } \\
\text { structuration factor }\end{array}$ & $S_{i}$ & 4.5 & 4.5 \\
$\begin{array}{l}\text { Initial frictional } \\
\text { structuration factor }\end{array}$ & $S_{f}$ & 1.2 & 1.2 \\
\hline
\end{tabular}

In order to assess the performance of EVP-SANICLAY model, the finite element analysis of the embankment was repeated twice where instead of the EVP-SANICLAY model the MCC model and the EVP-SANICLAY model without destructuration (i.e., with $S_{i}=S_{f}=1$ ) were used.

\subsection{Simulations results}

The results from numerical analyses were compared with the available field measurement data for the time period following the construction $[47,50,53]$. Figure 10 shows settlement predictions versus time at the node on the centerline at the base of the embankment (point $\mathrm{A}$ in Figure 8a), using different models. From the figure it is clear that the proposed EVP-SANICLAY model gives a rather good prediction when compared to the in-situ measurements. When destructuration is switched off, the model 
significantly underestimates the settlement over time. The underestimation of settlement is even more

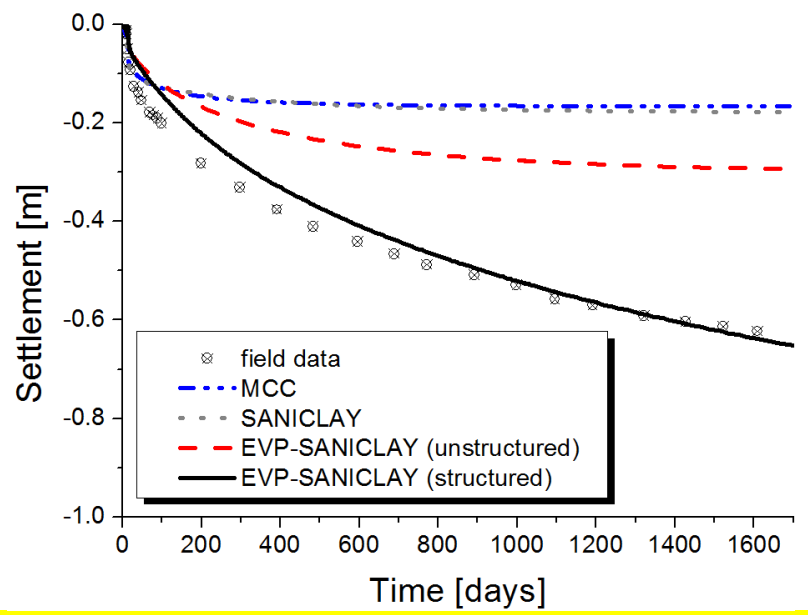
comparison between the numerical results adopting different soil constitutive models can be made. Such

418 numerical simulation results are shown in Figure 11. Generally they all show a typical behavior, with the 419 main vertical settlements at the centerline of the embankment and diminishing values at larger distances 420 from the centerline. However, as consideration of soil viscosity during plastic deformation delays the 421 consolidation process, settlements through using EVP-SANICLAY (Figure 11d) represent more realistic 422 deformation pattern with time. The simulation performed using the MCC and SANICLAY (Figure 11a,b) clearly shows that with the time-independent models the consolidation process completes rapidly after 424 which the vertical deformation stops. When the effect of soil structure is ignored (Figure 11c) a behavior 425 similar to the complete EVP-SANICLAY model is obtained, but with significantly lower values for the 426 vertical settlement. This is expected, given that Champlain clay is highly structured clay with a 427 sensitivity value of about of $22[15]$. 


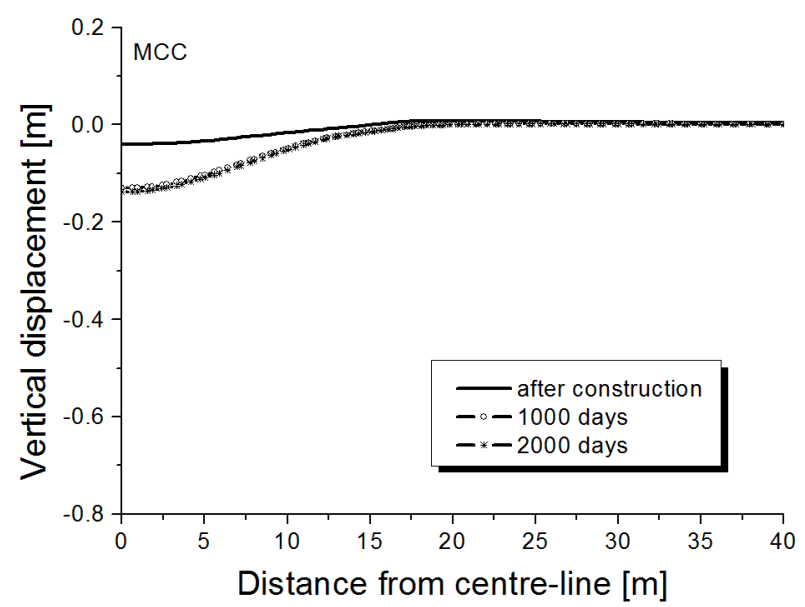

(a)

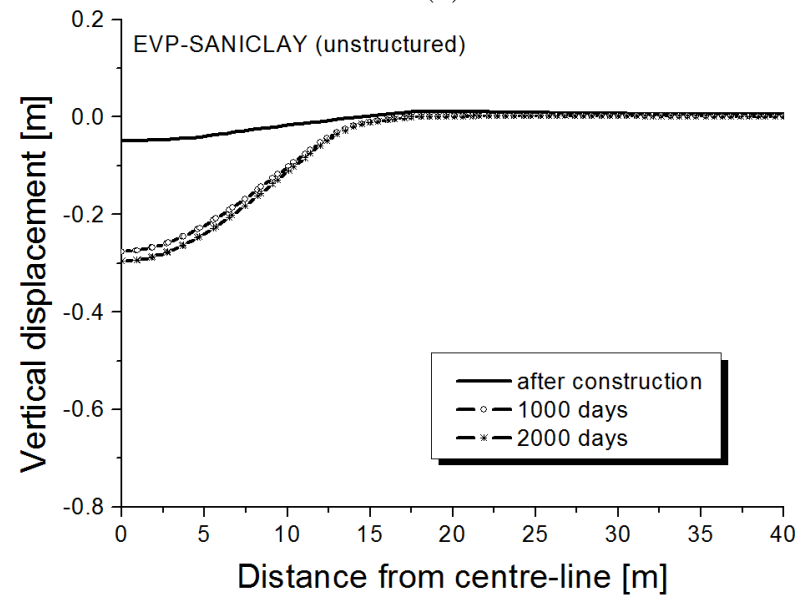

(c)

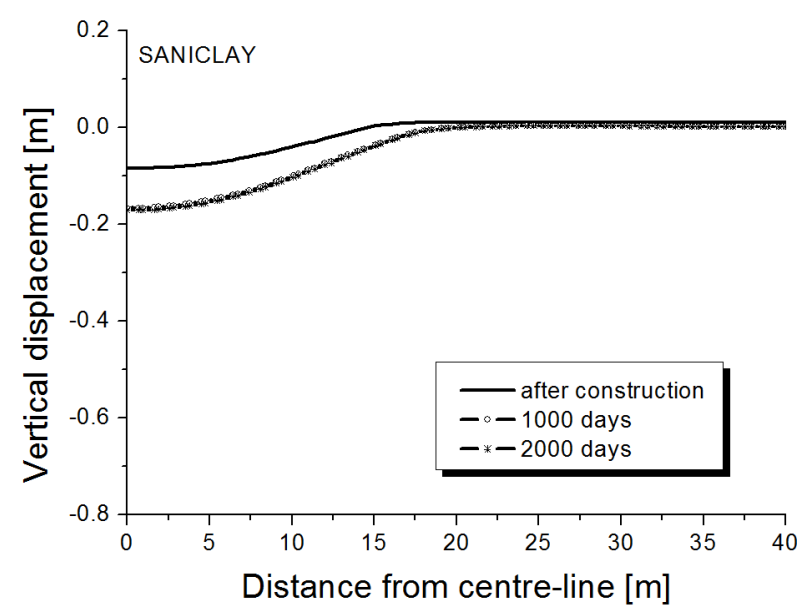

(b)

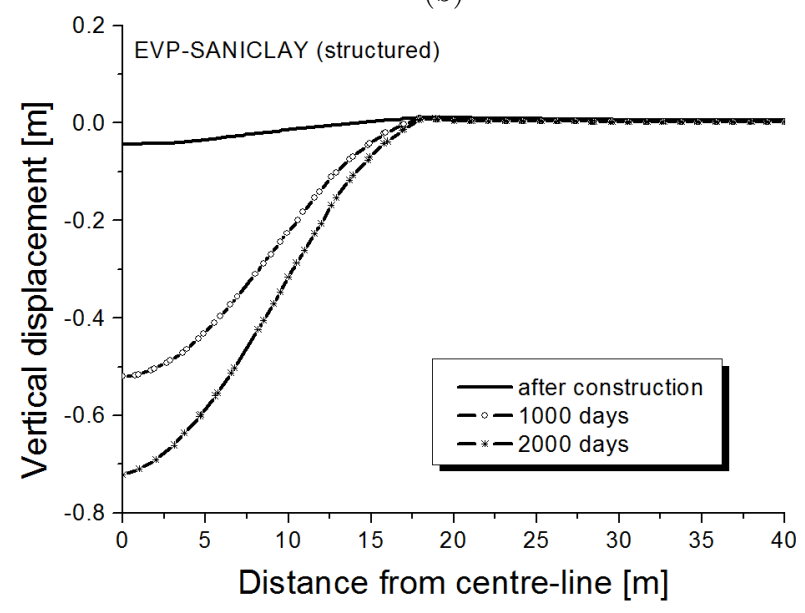

(d)

Figure 11. Numerical simulation results for surface settlement using: (a) MCC model; (b) SANICLAY model; (c) EVP-SANICLAY model without structure; (d) EVP-SANICLAY model

Pneumatic piezometers were installed at different depths underneath the embankment to monitor the excess pore water pressure variations with time $[48,50]$. Figure 12 shows the in-situ measurements related to a piezometer located on the centerline at a depth of $2.6 \mathrm{~m}$ under the base of the embankment (point B in Figure 8a). The excess PWP initially increased during the embankment construction and then gradually dissipated with time. The figure also shows the results of numerical simulations with the models. As it can be seen, a better approximation of the excess PWP variation is obtained with the EVPSANICLAY model, in comparison with the MCC, SANICLAY, and the anisotropic EVP model without structure. Interestingly, for the SANICLAY and both of the EVP-SANICLAY model simulations, with and without structure, the maximum PWP value is reasonably close to the field measurement, but when the initial structure and degradation of bonds are not taken into consideration, a faster dissipation of 
excess PWP is observed. MCC model underestimates the maximum excess PWP immediately after the

construction; additionally, after the construction excess PWP is dissipated very quickly, contrary to the observed in-situ scenario. The observed delayed pore pressure dissipation can be captured only when the viscosity of soil behavior is taken into consideration.

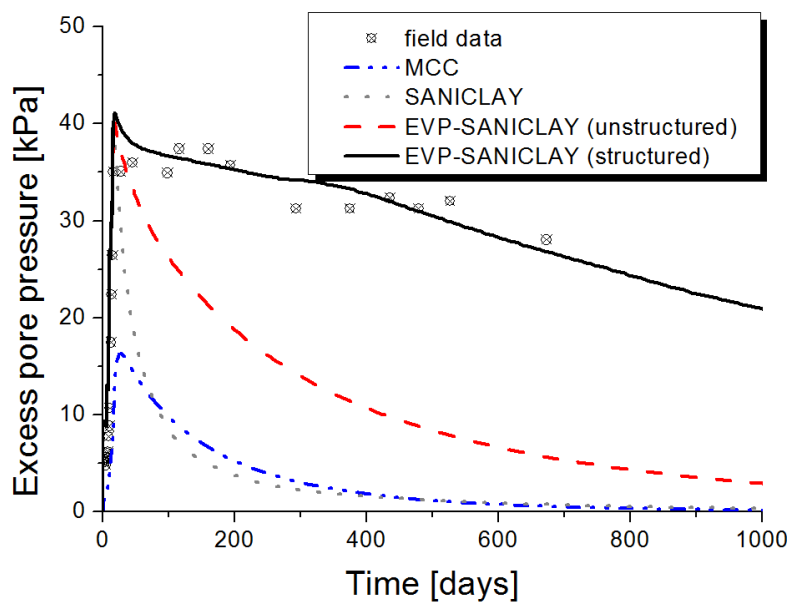

Figure 12. Excess PWP predictions at point B in Figure 8a

Field data for lateral displacements at depth are not available for the embankment [54]; therefore, simulation results presented in Figure 13, for the lateral deformation profiles at the toe of the embankment, could not be compared with the actual measurements. From Figure 13d, EVP-SANICLAY model simulations show deformation profiles similar in shape to what was reported for other embankment sites. For example in case of St. Alban embankment B, the maximum lateral displacement was reported to have more than doubled during the initial 4.5 years of consolidation [54], and the maximum value was at a depth of about $1 \mathrm{~m}$. The MCC and SANCILAY models led to smaller lateral displacement near the surface (Figure 13a,b). For the EVP simulations in Figure 13c,d, the lateral displacements increased near the surface, and delayed deformation became more pronounced. When structure effects were ignored in the EVP model (Figure 13c), the general shape of the lateral deformation profiles did not change much compared to Figure 13d but the predicted values became smaller, without noticeable difference between the profiles at 1000 and 2000 days. Clearly consideration of the soil initial structure and its degradation result in a greater pace of viscoplastic strain developments. For example, monitoring the development of viscoplastic strains at point B under the embankment, i.e. the position of the piezometer, it can be seen in Figure 14 that after an initial elastic response, the viscoplastic strains begin to develop while still in the 

observed in previous figures.

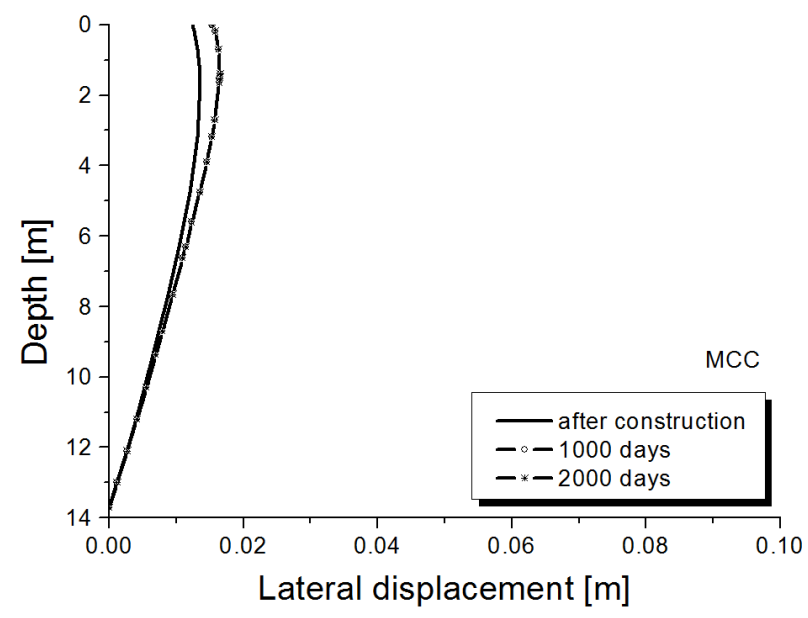

(a)

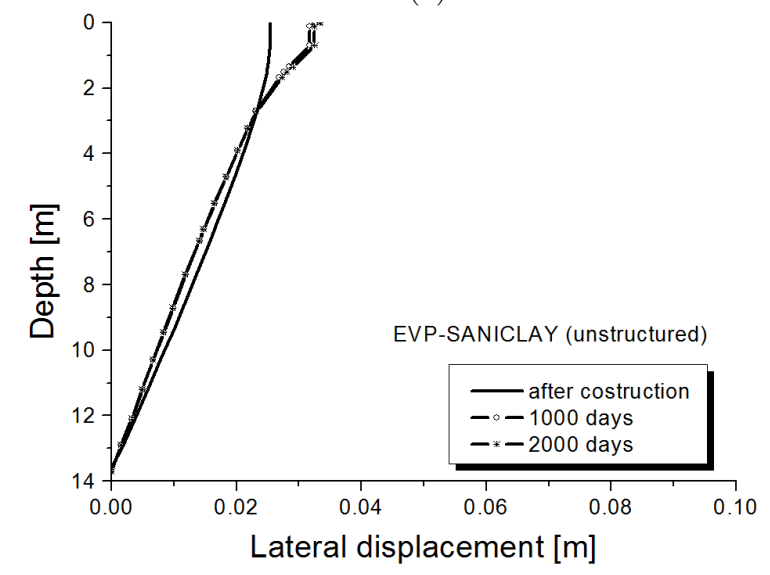

(c)

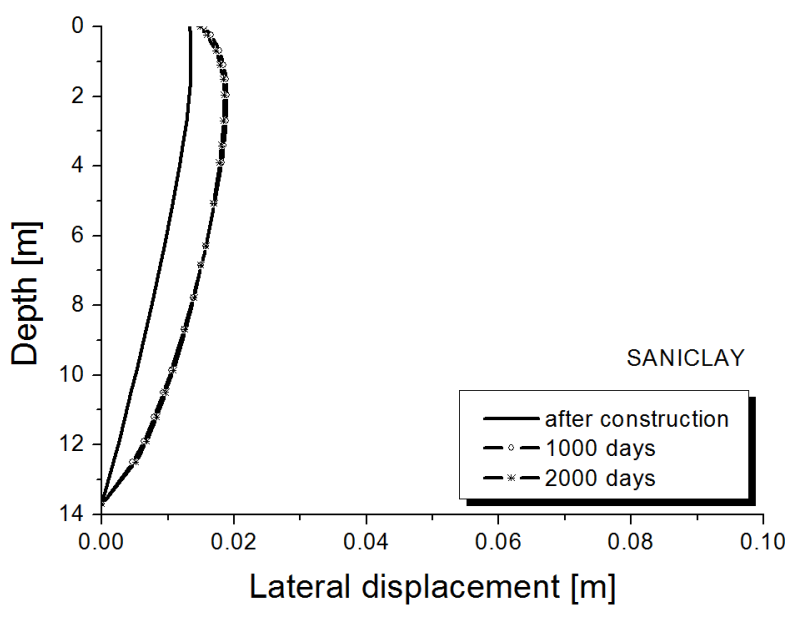

(b)

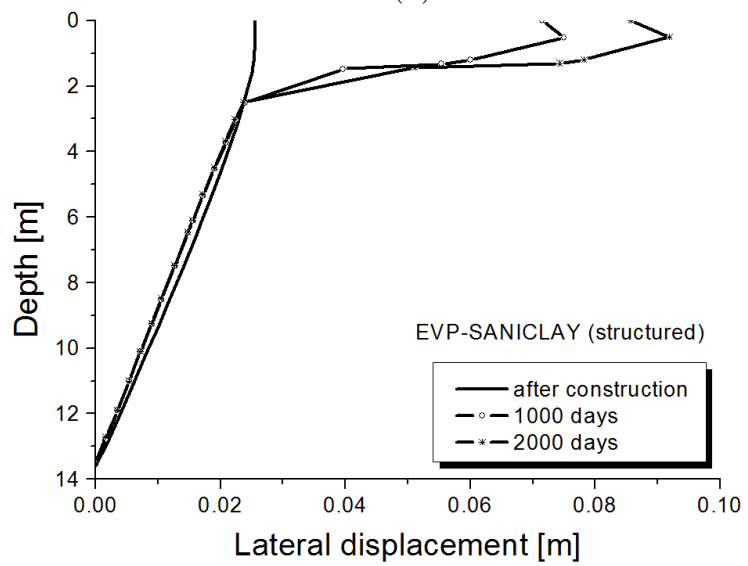

(d)

Figure 13. Numerical simulation results for lateral displacement under the toe using: (a) MCC model; (b)

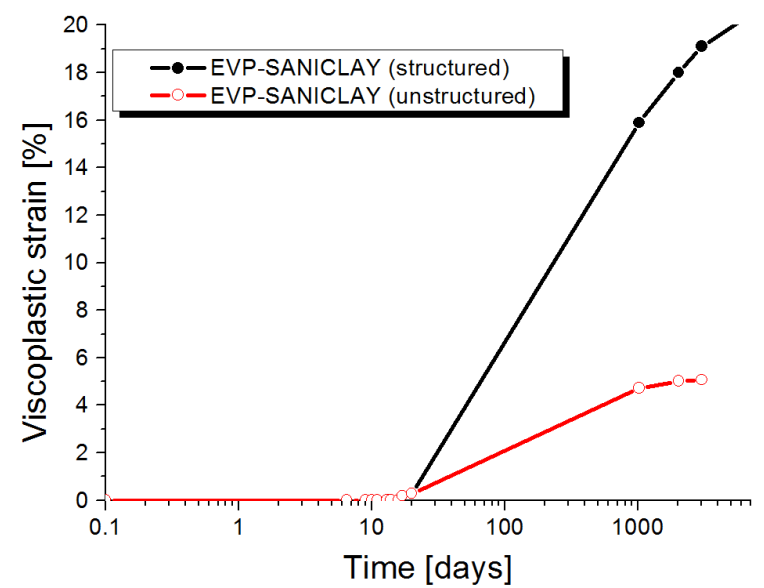

Figure 14. Development of viscoplastic strains at point B in Figure 8a 


\subsection{Non-uniqueness of viscosity parameters}

As already mentioned, calibration of viscosity parameters $N$ and $\mu$ has been done directly on the embankment model as no appropriate test data has been available for the foundation soil. It should be pointed out that the Perzyna-type viscosity parameters for a particular clay are not necessarily a unique set and more than one combination of the two viscosity parameters can be found for a clay, depending on how one wants to fit the experimental data [55]. Figure 15 shows an example of how for three different sets of viscosity parameter values it is still possible to obtain a good approximation of the field observation for settlements at point A under the embankment. For these particular sets, a maximum difference of only $3 \%$ was found among the vertical settlement results, and similar minor variations were observed among the corresponding lateral displacement and excess PWP predictions.

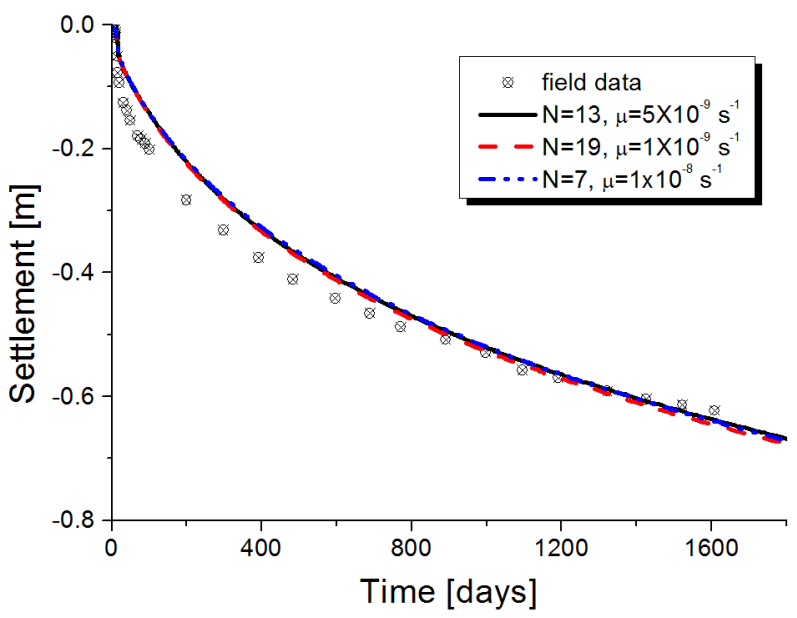

Figure 15. Illustrating the non-uniqueness of viscosity parameters for prediction of time-settlement at point A in Figure 8a

\subsection{Discussion on behavior during construction}

Additional field measurement data on settlement and excess pore pressure generation during embankment construction process is also available [48]. The data could be used to assess the performance of the developed model in reproducing the short-term response of the embankment. Simulation results during the construction are shown in Figure 16.

Figure 16a shows that at point $\mathrm{A}$ in Figure 8a, EVP-SANICLAY model somewhat underestimates the results; although, as it was observed in Figure 7a, it is then able to gain accuracy during consolidation. MCC and SANCILAY, on the contrary, overestimates short-term settlements during the 
construction. In terms of excess PWP at point B in Figure 8a, EVP-SANICLAY is able to give a good prediction of the pore pressure generation during the embankment construction (Figure 16b). Based on EVP-SANICLAY predictions, PWP develops rapidly during the construction until embankment reaches a height of approximately $2.31 \mathrm{~m}$ (corresponding to 16 days after the start of construction) when the excess PWP generation slightly decelerates. From the figure, it is clear that the MCC model underestimates excess PWP generation during the construction. Compared to the full EVP model, EVP-SANICLAY without structure provides lower predictions of excess PWP generation after the stage at which the embankment reaches a height of $2.31 \mathrm{~m}$.

501

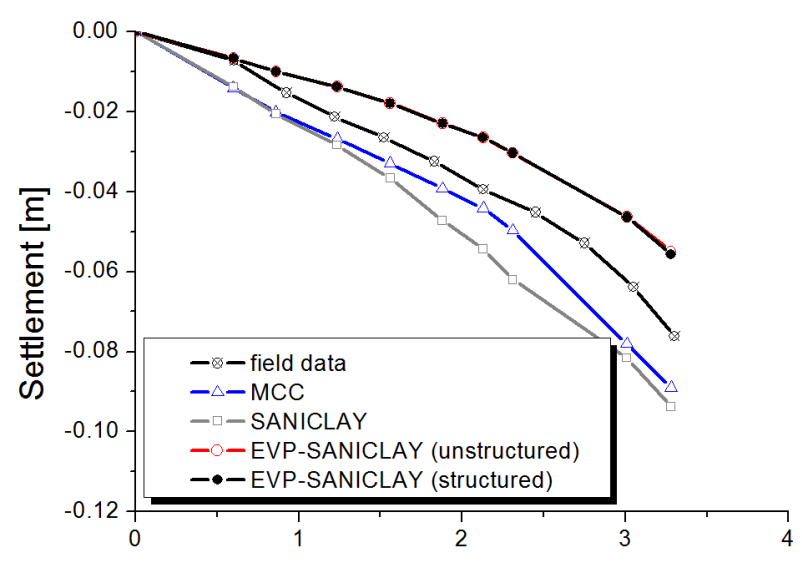

Fill height [m]

(a)

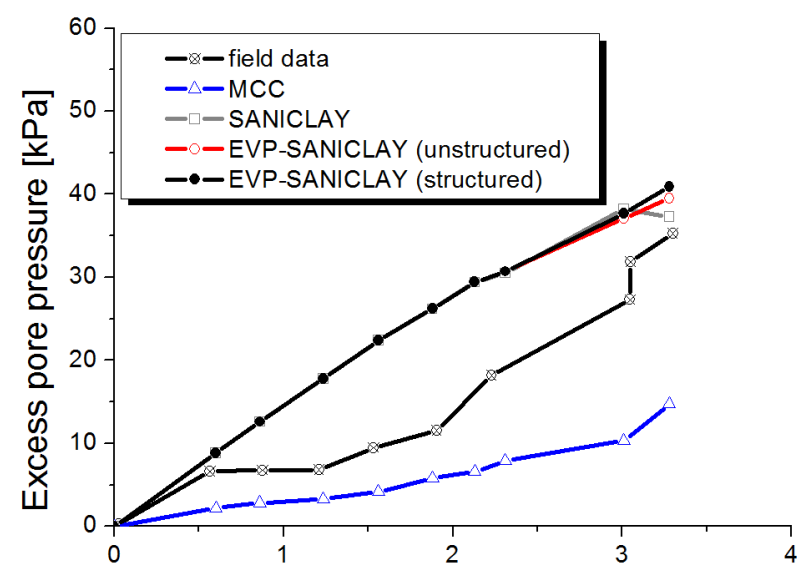

Fill height [m]

(b)

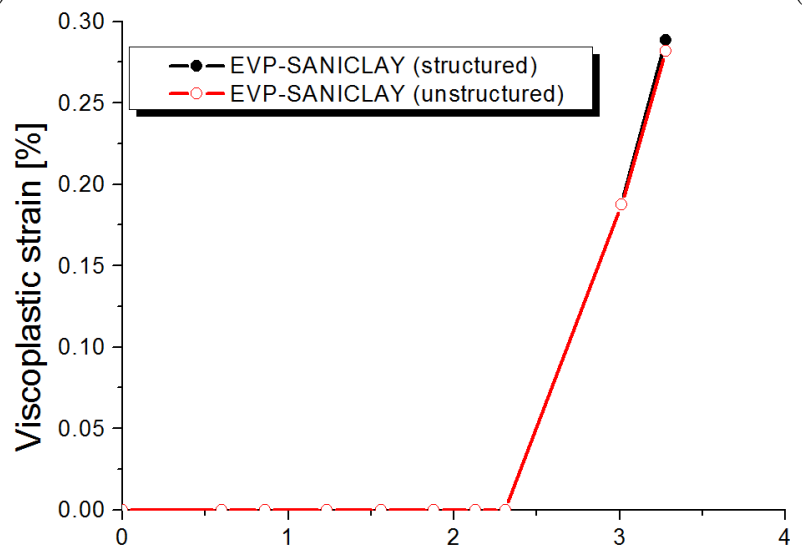

Fill height [m]

(c) 
Figure 16c shows the development of viscoplastic strains at point B under the embankment (i.e. at the position of the pneumatic piezometer considered). The figure shows that the viscoplastic strains start to develop when the embankment reaches a height of about $2.31 \mathrm{~m}$, which approximately corresponds to 509 the time when excess pore pressure generation changes its pace.

\section{Conclusions}

512 The response of natural soft soil is governed by anisotropy, structure and time-dependency. In this 513 work, in order to concurrently account for these advanced features of soil behavior a time-dependent 514 elasto-viscoplastic extension of a well-established anisotropic clay model, namely SANICLAY, has been 515 proposed. The model is numerically implemented in finite element program PLAXIS using an implicit 516 integration scheme. The performance of the model at the element-level has been validated against 517 experimental data obtained from testing four different clays at both structured and un-structured states.

518 Furthermore the time-dependent behavior of St. Alban embankment D on the well-structured Champlain 519 clay was analysed using the proposed EVP-SANICLAY model. The paper presented the results for 520 settlements, lateral deformations, and excess PWP variations during the construction and the subsequent 521 consolidation, comparing model predictions with the field measurements where available. It was observed 522 that the developed model considers the delayed excess pore pressure dissipation following the completion 523 of the embankment construction reasonably well; hence it is able to yield more realistic predictions of the 524 long-term vertical and horizontal deformations. The boundary value problem simulation results also 525 illustrated that considering clay initial structure and subsequent destructuration effects significantly 526 improve the accuracy of predictions, particularly when dealing with a highly sensitive soft clay such as 527 Champlain clay. Furthermore, the model also predicted the immediate displacements as well as the 528 development of excess pore pressures during early stages of construction with reasonable accuracy.

In general, EVP-SANICLAY proved to be able to much better predict both short- and long-term 530 behavior of natural clay behavior when compared with a commonly used critical state based model such 531 as MCC, and also the SANCILAY model. 


\section{Acknowledgements}

Support to conduct this study is provided by the University of Nottingham's Dean of Engineering award, and the Natural Sciences and Engineering Research Council of Canada (NSERC).

\section{Appendix}

For the sake of completeness of presentation, some of the key components of the SANICLAY model that are not presented in the main body of this paper are summarized here. Both stress and strain quantities are assumed positive in compression (as is common in geomechanics), and the effect of this sign convention has been considered on the model equations. All stress components in this paper should be considered as effective stress. Finally, in terms of notation, tensor quantities are denoted by bold-faced symbols and operations explained accordingly.

The hypoelastic formulation, considered for simplicity, constitutes of a shear modulus $G$, for calculating increments of elastic deviatoric strains, and a bulk modulus $K$, for calculating increments of elastic volumetric strains, where

$G=\frac{3 K(1-2 v)}{2(1+v)} ; \quad K=\frac{p(1+e)}{\kappa}$

where $v$ is the Poisson's ratio, $e$ is the void ratio, $p=(\operatorname{tr} \sigma) / 3$ is the mean effective stress (where tr stands for the trace), and $\kappa$ is the slope of elastic swelling lines in the $e-\ln p$ space.

The isotropic hardening law of the model describing the evolution of the size of structured SYS, i.e.

$p_{0}^{* S}$, is defined as

$$
\dot{p}_{0}^{* S}=\dot{S}_{l} p_{0}^{S}+S_{i} \dot{p}_{0}^{S}
$$

where $\dot{S}_{i}$ is the evolution rate of the isotropic destructuration factor (explained in the sequel), and

$\dot{p}_{0}^{s}=[(1+e) /(\lambda-\kappa)] p_{0} \dot{\varepsilon}_{v}^{v p}$ is the evolution of the size of SYS, that is a proportional to viscoplastic volumetric strain rate, with $\lambda$ indicating the slope of normal compression line.

The rotational hardening law describing the evolution of fabric anisotropy with viscoplastic staining

can be expressed in the general stress space as:

$$
\dot{\boldsymbol{\alpha}}=\left(\frac{1+e}{\lambda-\kappa}\right) C\left(\frac{p}{p_{0}}\right)^{2}\left|\dot{\varepsilon}_{v}^{v p}\right|\left[\frac{3}{2}(\boldsymbol{r}-x \boldsymbol{\alpha}):(\boldsymbol{r}-x \boldsymbol{\alpha})\right]^{1 / 2}\left(\boldsymbol{\alpha}^{b}-\boldsymbol{\alpha}\right)+\dot{\boldsymbol{\alpha}}_{f}
$$

In the above equation, $\dot{\boldsymbol{\alpha}}_{f}=\left(\dot{S}_{f} / S_{f}\right) \boldsymbol{\alpha}$ controls the contribution of destructuration over the change of 557 orientation of the yield surface $\left(\dot{S}_{f}\right.$ explained in the sequel $) ; \boldsymbol{r}=\boldsymbol{s} / p$ is the shear stress ratio; $\boldsymbol{\alpha}^{b}=$ 
$\sqrt{2 / 3} M \boldsymbol{n}_{x}$ is the bounding 'image' stress-ratio tensor, where $\boldsymbol{n}_{x}$ is an auxiliary unit tensor defined as $\boldsymbol{n}_{x}=\|(\boldsymbol{r} / x)-\boldsymbol{\alpha}\|$ and \|\| denoting the norm operator; and $\left|\dot{\varepsilon}_{v}^{v p}\right|$ is the absolute value of the viscoplastic volumetric strain rate.

In order to express the isotropic and frictional destructurations, an axillary internal variable called the destructuration viscoplastic strain rate, $\dot{\varepsilon}_{d}^{v p}$, is defined by

$\dot{\varepsilon}_{d}^{v p}=\sqrt{(1-A)\left(\dot{\varepsilon}_{v}^{v p}\right)^{2}+A\left(\dot{\varepsilon}_{q}^{v p}\right)^{2}}$

where $\dot{\varepsilon}_{v}^{v p}$ and $\dot{\varepsilon}_{q}^{v p}$ are the volumetric and deviatoric viscoplastic strain rates, respectively, and $A$ is a

model parameter could be set to 0.5 as a default value. The evolution equations for the $S_{i}$ and $S_{f}$ read

$\dot{S}_{i}=-k_{i}\left(\frac{1+e}{\lambda-\kappa}\right)\left(S_{i}-1\right) \dot{\varepsilon}_{d}^{v p}$

$\dot{S}_{f}=-k_{f}\left(\frac{1+e}{\lambda-\kappa}\right)\left(S_{f}-1\right) \dot{\varepsilon}_{d}^{v p}$

565

566

567

568

569

570

571

572

573

574

575

576

577

578

579

580

581

where $k_{i}$ and $k_{f}$ are model parameters.

As indicated in model formulation section, the critical stress-ratio is defined as a function of the Lode angle $\theta$. To regulate the variation of $M(\theta)$ between its values $M_{c}$ for compression and $M_{e}$ for extension, the expression proposed by Sheng et al. [56] has been adopted here which reads as

$M(\theta)=M_{c}\left(\frac{2 m^{4}}{1+m^{4}+\left(1-m^{4}\right) \sin 3 \theta}\right)^{1 / 4}$

where $m=M_{e} / M_{c},-\pi / 6 \leq \theta=(1 / 3) \sin ^{-1}\left[-3 \sqrt{3} J_{3} /\left(2 J_{2}{ }^{3 / 2}\right)\right] \leq \pi / 6$, with $J_{2}$ and $J_{3}$ being the second and third invariants of the modified stress deviator $\boldsymbol{s}-p \boldsymbol{\alpha}$.

\section{References}

[1] Kim DK. Comparisons of Constitutive Models for Anisotropic Soils. KSCE J Civil Eng 2004; 8(4):403409.

[2] Sekiguchi H, Ohta H. Induced anisotropy and time dependency in clays. 9th ICSMFE, Tokyo, Constitutive equations of Soils 1977; 17:229-238.

[3] Graham J, Noonan ML, Lew KV. Yield states and stress-strain relationships in a natural plastic clay. Can Geotech J 1983; 20(3):502-516.

[4] Korhonen KH, Lojander M. Yielding of Perno clay. In Proc of $2^{\text {nd }}$ International Conference on Constitutive Laws for Engineering Materials, Tucson, Arizona, Vol 2 1987: 1249-1255. 
[5] Dafalias YF. An anisotropic critical state soil plasticity model. Mech Res Commun 1986; 13(6):341347.

[6] Dafalias YF. An anisotropic critical state clay plasticity model. In Proceedings of the 2nd international conference on constitutive laws for engineering materials. Tucson, US, 1987:513-521.

[7] Thevanayagam S, Chameau JL. Modelling anisotropy of clays at critical state. J Eng Mech-ASCE 1992; 118(4):786-806

[8] Whittle AJ, Kavvadas MJ. Formulation of MIT-E3 constitutive model for overconsolidated clays. J Geotech Eng 1994; 120(1):173-198.

[9] Newson TA, Davies MCR. A rotational hardening constitutive model for anisotropically consolidated clay. Soils Found 1996; 36(3):13-20

[10] Wheeler SJ, Karstunen M, Näätänen A. Anisotropic hardening model for normally consolidated soft clay. In Proc. 7th Int. Symp. on Numerical Models in Geomechanics (NUMOG VII), Graz, 1999, 3340. A.A. Balkema.

[11] Wheeler SJ, Näätänen A, Karstunen M, Lojander M. An anisotropic elasto-plastic model for soft clays. Can Geotech J 2003; 40(2):403-418.

[12] Dafalias YF, Manzari MT, Papadimitriou AG. SANICLAY: simple anisotropic clay plasticity model. Int J Numer Anal Meth Geomech 2006; 30:1231-1257.

[13] Taiebat M, Dafalias YF, Peek R. A destructuration theory and its application to SANICLAY model. Int J Numer Anal Meth Geomech 2010; 34:1009-1040.

[14] Vaid YP, Campanella RG. Time-dependent behaviour of undisturbed clay. J Geotech Eng-ASCE 1977; 103(7):693-709.

[15] Tavenas F, Leroueil S, La Rochelle P, Roy M. Creep behavior of an undisturbed lightly overconsolidated clay. Can Geotech J 1978; 15(3):402-423.

[16] Leroueil S, Kabbaj M, Tavenas F, Bouchard R. Stress-strain-strain-rate relation for the compressibility of sensitive natural clays. Géotechnique 1985; 35(2):159-180.

[17] Lefebvre G, Leboeuf D. Rate effects and cyclic loading of sensitive clays. J Geotech Eng-ASCE 1987; 113(5):476-489.

[18] Augustesen A, Liingaard M, Lade PV. Evaluation of Time-Dependent Behavior of Soils. Int J Geomech 2004; 4(3):137-156.

[19] Vaid YP, Robertson PK, Campanella RG. Strain rate behavior of Saint-Jean-Vianney clay. Can Geotech J 1979; 16:34-42. 
[20] Díaz-Rodríguez JA, Martínez-Vasquez JJ, Santamarina JC. Strain-rate effects in Mexico City soil. J Geotech Geoenviron Eng 2009; 135(2):300-305

[21] Leroueil S. The isotache approach. Where are we 50 years after its development by Professor Šuklje? 2006 Prof. Šuklje's Memorial Lecture, XIII Danube-European Geotechnical Engineering Conference, 29th-31st May 2006, Ljubljana, Slovenia.

[22] Suklje L. The analysis of the consolidation process by the isotache method. Proc. 4th Int. Conf. on Soil Mech and Found. Engng., London 1957; 1:200-206.

[23] Naghdi PM, Murch, SA. On the mechanical behavior of viscoelastic/plastic solids. J Applied Mechanics 1963; 30(3):321-328.

[24] Perzyna P. The constitutive equations for work-hardening and rate sensitive plastic materials. In Proc. Vibration Problems Warsaw 1963; 3:281-290.

[25] Perzyna P. Fundamental problems in viscoplasticity. Adv Appl Mech 1966; 9:244-377.

[26] Adachi T, Oka F. Constitutive equations for normally consolidated clay based on elastoviscoplasticity. Soils Found 1982; 22(4):57-70.

[27] Nova R. A viscoplastic constitutive model for normally consolidated clay. In Proceedings of IUTAM Conference on Deformation and Failure of Granular Materials, Delft, The Netherlands, 1982, 287-295.

[28] Katona MG. Evaluation of Viscoplastic Cap Model. J Geotech Eng-ASCE. 1984; 110:1106-1125.

[29] Kaliakin VN, Dafalias YF. Theoretical aspects of the elastoplastic-viscoplastic bounding surface model for cohesive soils. Soils Found 1990; 30(3):11-24

[30] Yin JH, Zhu JG, Graham J. A new elastic viscoplastic model for time-dependent behaviour of normally and overconsolidated clays: theory and verification. Can Geotech J 2002; 39:157-173

[31] Yin ZY, Hicher PY. Identifying parameters controlling soil delayed behavior from laboratory and in situ pressuremeter testing. Int J Num Anal Meth Geomech 2008; 32:1515-1535

[32] Martindale H, Chakraborty T, Basu B. A Strain-Rate Dependent Clay Constitutive Model with Parametric Sensitivity and Uncertainty Quantification. Geotech Geol Eng 2013; 31:229-248

[33] Leoni M, Karstunen M, Vermeer P. Anisotropic creep model for soft soils. Géotechnique 2008; 58(3):215-226.

[34] Yin Z-Y, Karstunen M. Modelling strain-rate-dependency of natural soft clays combined with anisotropy and destructuration. Acta Mechanica Solida sinica, Vol. 24, No 3, June 2001. Published by AMSS Press, Wuhan, China. 
643 [35] Dafalias YF, Taiebat M. Anatomy of Rotational Hardening in Clay Plasticity. Geotechnique 2013;

644

645

646

647

648

649

650

651

652

653

654

655

656

657

658

659

660

661

662

663

664

665

666

667

668

669

670

671

672

673 63(16):1406-1418.

[36] Dafalias YF, Taiebat M. Rotational hardening with and without anisotropic fabric at critical state. Geotechnique 2014; 64(6): 507-511.

[37] Shahrour I, Meimon Y. Calculation of marine foundations subjected to repeated loads by means of the homogenization method. Comput Geotech 1995; 17(1):93-106.

[38] Fodil A, Aloulou W, Hicher PY. Viscoplastic behaviour of soft clay. Géotechnique 1997; 47(3):581591.

[39] Lewis RW, Schrefler BA. The Finite Element Method in the Static and Dynamic Deformation and Consolidation of Porous Media. $2^{\text {nd }}$ Ed.: John Wiley \& Sons, ISBN: 978-0-471-92809-6; 1998.

[40] Hinchberger SD. The behaviour of reinforced and unreinforced embankments on soft rate-sensitive foundation soils. Ph.D. thesis, Department of Civil Engineering, The University of Western Ontario, London, Ont. 1996.

[41] Brinkgreve RBJ, Engin E, Swolfs WM. Plaxis 2014 reference manual, Plaxis, Delft, Netherlands; 2014

[42] Nakase A, Kamei T. Influence of strain rate on undrained shear characteristics of K0-consolidated cohesive soils. Soils Found 1986; 26(1):85-95.

[43] Rangeard D. Identification des caractéristiques hydro-mécaniques d'une argile par analyse inverse des essais pressiométriques. Thèse de l'Ecole Centrale de Nantes et l'Université de Nantes, 2002.

[44] Kamei T, Sakajo S. Evaluation of undrained shear behaviour of K0-consolidated cohesive soils using elasto-viscoplastic model. Comput Geotech 1995; 17:397-417.

[45] Vermeer PA, Neher HP. A soft soil model that accounts for creep. In: Proc. Plaxis Symposium 'Beyond 2000 in Computational Geotechnic', Amsterdam 1999: 249-262.

[46] Rocchi G, Fontana M, Da Prat M. (2003). Modelling of natural soft clay destruction processes using viscoplasticity theory. Géotechnique 2003; 53(8):729-745.

[47] La Rochelle P, Trak B, Tavenas F, Roy M. Failure of a test embankment on a sensitive Champlain clay deposit. Can Geotech J 1974; 11(1):142-164.

[48] Tavenas FA, Chapeau C, La Rochelle P, Roy M. Immediate settlements of three test embankments on Champlain clay. Can Geotech J 1974; 11(1):109-141.

[49] Leroueil S, Tavenas F, Trak B, La Rochelle P, Roy M. Construction pore water pressures in clay foundations under embankments. Part I: the Saint-Alban test fills. Can Geotech J 1978; 15:54-65. 
674 [50] Karim MR, Oka F, Krabbenhoft K, Leroueil S, Kimoto S. Simulation of long-term consolidation 675 behavior of soft sensitive clay using an elasto-viscoplastic constitutive model. Int J Numer Anal Meth $676 \quad$ Geomech 2013; 37:2801-2824.

677 [51] Tavenas F, Leroueil S. Effects of stresses and time on yielding of clays. In Proceedings of the 9th 678 International Conference on Soil Mechanics and Foundation Engineering, Toyko, Japan, 1977.

679 [52] Oka F, Tavenas F, Leroueil S. An elasto-viscoplastic fem analysis of sensitive clay foundation beneath 680 embankment. In Computer Method and Advances in Geomechanics, Vol. 2, Beer G, Booker JR, 681 Carter JP (eds). Balkema: Brookfield, 6-10 May 1991; 1023-1028.

682 [53] Morissette L., St-Louis MW, McRostie GC. Empirical settlement predictions in overconsolidated 683 Champlain Sea clays. Can Geotech J 2001; 38:720-731.

684 [54] Tavenas F, Mieussens C, Bourges F. Lateral displacements in clay foundations under embankments. 685 Can Geotech J 1979; 16(3):532-550.

686 [55] Karstunen M, Rezania M, Sivasithamparam N, Yin ZY. Comparison of Anisotropic Rate-Dependent 687 Models for Modeling Consolidation of Soft Clays. Intl J Geomech 2012, DOI: 688 10.1061/(ASCE)GM.1943- 5622.0000267.

689 [56] Sheng D, Sloan SW, Yu HS. Aspects of finite element implementation of critical state models. 690 Computational mechanics 2000; 26(2):185-196.

691

692 


\title{
A viscoplastic SANICLAY model for natural soft soils
}

\author{
Mohammad Rezaniaa, Mahdi Taiebat ${ }^{b, c,},{ }^{*}$ and Elisa Poletti ${ }^{\mathrm{d}}$ \\ aDepartment of Civil Engineering, University of Nottingham, Nottingham, UK \\ bDepartment of Civil Engineering, University of British Columbia, Vancouver, BC, Canada \\ cDepartment of Civil \& Environmental Engineering, Massachusetts Institute of Technology, Cambridge, \\ MA, USA \\ ${ }^{d}$ Department of Civil Engineering, University of Minho, Azurém, Guimarães, Portugal
}

\begin{abstract}
This paper focuses on constitutive and numerical modeling of strain-rate dependency in natural clays while also accounting for anisotropy and destructuration. For this purpose the SANICLAY model that accounts for the fabric anisotropy with the additional destructuration feature that accounts for sensitivity of natural clays, is considered as the reference model. An associated flow rule is adopted for simplicity. The model formulation is refined to also account for the important feature of strain-rate dependency using the Perzyna's overstress theory. The model is then implicitly integrated in finite element program PLAXIS. Performance of the developed and implemented model is explored by comparing the simulation results of several element tests and a boundary value problem to the available experimental data. The element tests include the constant strain-rate under one-dimensional and triaxial conditions on different clays. The boundary value problem includes a test embankment, namely embankment D constructed at Saint Alban, Quebec. For comparison, the test embankment is also analysed using the Modified Cam-Clay (MCC) model, the SANICLAY model, and the viscoplastic model but without destructuration. Results demonstrate the success of the developed and implemented viscoplastic SANICLAY in reproducing the strain-rate dependent behavior of natural soft soils.
\end{abstract}

Keywords: viscoplasticity; strain-rate dependency; anisotropy; destructuration; clay

\section{Introduction}

Modeling the stress-strain response of natural soft soils constitutes a challenge in practical geotechnical engineering; it is governed by a series of factors that are not always included in conventional constitutive models. In particular, the three main inherent features that influence their response are a) anisotropy, b) destructuration (degradation of the inter-particle bonds), and c) strain-rate dependency.

${ }^{*}$ Corresponding author. Tel.: +1 6048223279.

E-mail addresses: mohammad.rezania@nottingham.ac.uk (M. Rezania), mtaiebat@civil.ubc.ca (M. Taiebat), elisapoletti@civil.uminho.pt (E. Poletti). 
Since modeling the full anisotropy of natural clay behavior is not practical due to the number of parameters involved, efforts have been mainly focused on development of models with reduced number of parameters while maintaining the capacity of the model [1]. Historically, for practical model development purposes, the initial orientation of soil fabric is considered to be of cross-anisotropic nature, which is a realistic assumption as natural soils have been generally deposited only one-dimensionally in a vertical direction. It is also a well-established fact that the yield surfaces obtained from experimental tests on undisturbed samples of natural clays are inclined in the stress space due to the inherent fabric anisotropy in the clay structure (e.g., [2-4]). Based on the above, a particular line of thought has become popular in capturing the effects of anisotropy on clayey soil behavior, by development of elasto-plastic constitutive models involving an inclined yield surface that is either fixed (e.g., [2]), or can changed it inclination by adopting a rotational hardening $(\mathrm{RH})$ law in order to simulate the development or erasure of anisotropy during plastic straining (e.g., [5-6]). For obvious reasons a model accounting for both inherent and evolving anisotropy would be more representative of the true nature of response in clays; hence, since the first proposal of such model by Dafalias [5-6] similar framework has been adopted by a number of other researchers for development of anisotropic elasto-plastic constitutive models (e.g., [7-11]). Based on the original model, Dafalias et al. [12] proposed what they called SANICLAY model, altering the original RH law and introducing a non-associated flow rule. A destructuration theory was later applied to the SANICLAY model [13] to account for both isotropic and frictional destructuration processes. In these works, the SANICLAY has been shown to provide successful simulation of both undrained and drained rate-independent behaviour of normally consolidated sensitive clays, and to a satisfactory degree of accuracy of overconsolidated clays.

Past experimental studies have also shown that soft soils exhibit time-dependent response (e.g., [1417]). Time-dependency is usually related to the soil viscosity that could lead to particular effects such as creep, stress relaxation, and strain-rate dependency of response. Time-dependency of soil response can be observed experimentally by means of creep tests, stress relaxation tests, or constant rate of strain (CRS) tests [18]. Rate-sensitivity is a particular aspect of time effect that has been investigated extensively; it influences both strength and stiffness of soils. Various studies using CRS tests have shown how faster strain rates for a certain strain level lead to higher effective stresses; also, the general observation, particularly in soft soils, is that higher undrained strengths can be achieved by increasing the loading rate (e.g., [16-17,19-20]). The reported observations from laboratory studies all imply that consideration of soil viscosity effects could be key for correct prediction of long term deformations in field conditions; although, neglecting soil viscosity seemingly provide sufficiently correct predictions in short-term [21]. Landslides or long-term deformations of tunnels and embankments on soft soils are examples of common practical problems where a sustainable remediation and/or design solution can only be achieved if time-dependent behavior of soil is taken into consideration.

In order to account for the time-dependency of soft clays' behavior, various frameworks can be found in the literature. Among a number of popular frameworks such as the isotache theory of Šuklje [22] or the non- 
stationary surface theory of Naghdi and Murch [23], the overstress theory of Perzyna [24-25] is a common framework often used in geomechanics for this purpose due to its relative simplicity. The first overstresstype viscoplastic models were based on isotropic Cam-Clay or modified Cam-Clay models (e.g., [26-32]). More recently, several models accounting for either only the fabric anisotropy (e.g., [33]), or both anisotropy and destructuration [34] have also been introduced. A shortcoming of these models is the absence of bounds for the evolution of rotational hardening variables which could eventually lead to an excessive rotation of the yield surface for loading at very high values of stress-ratio [35-36]. Furthermore, destructuration theories have so far only addressed isotropic destructuration (usually constituting a mechanism of isotropic softening of the yield surface with destructuration), neglecting frictional destructuration.

In this paper, a new Elasto-ViscoPlastic Simple ANIsotropic CLAY plasticity (EVP-SANICLAY) model is proposed. The model is a new member of the SANICLAY family of models, which are based on the classical modified Cam-Clay model and include rotational hardening and destructuration features for simulation of anisotropy and sensitivity, respectively. Perzyna's overstress theory [24-25] is employed to account for soil viscosity effects. Being based on the SANICALY model, the new viscoplastic model restricts the rotation to within bounds necessary to guarantee the existence of real-valued solutions for the analytical expression of the yield surface [12]. In the following sections, the theoretical formulation of the model will be discussed, followed by the details of its numerical implementation based on an algorithm proposed by Katona [28]. The validation of the new model is done by comparing the model simulation results against several experimental data at the element level and also field measurements for a boundary value problem. In particular, at element level the measured behavior observed from CRS and undrained triaxial tests over a number of different soft clays are used. Within these examples, determination of model parameter values is also discussed. For the boundary value problem, a well-studied test embankment, namely St. Alban embankment, is modeled and the predicted deformations using the EVP-SANICLAY model are compared with the recorded in-situ values. In order to better highlight the merits of the newly proposed constitutive model, the simulation results are also compared with those obtained using the MCC model, the SANCILAY model, and also the EVP-SANICLAY model but without the destructuration feature. Note that in this paper all stress components are effective stresses and as usual in geomechanics, both stress and strain quantities are assumed positive in compression.

\section{EVP-SANICLAY}

\subsection{Model formulation}

According to Perzyna's theory, the total strain increment, $\Delta \varepsilon$, associated with a change in effective stress, $\Delta \sigma$, during a time increment of $\Delta t$, is additively decomposed to elastic and viscoplastic parts

$$
\Delta \boldsymbol{\varepsilon}=\Delta \boldsymbol{\varepsilon}^{e}+\Delta \boldsymbol{\varepsilon}^{v p}
$$
where the superscripts $e$ and $v p$ represent the elastic and the viscoplastic components, respectively. The 
irreversible and time-dependent. Adopting the isotropic hypoelastic relations for simplicity [12], the elastic part of the total strain can be shown as

$$
\Delta \boldsymbol{\varepsilon}^{e}=\boldsymbol{D}^{-1}: \Delta \boldsymbol{\sigma}
$$

where $\boldsymbol{D}$ is the elastic stiffness matrix with more details presented in the Appendix, and symbol : in implies the trace of the product of two tensors.

The time-dependent viscoplastic strain increment is evaluated as

$$
\Delta \boldsymbol{\varepsilon}^{v p}=\dot{\boldsymbol{\varepsilon}}^{v p} \cdot \Delta t
$$

where $\dot{\boldsymbol{\varepsilon}}^{v p}$ is the viscoplastic strain rate tensor (a superposed dot denotes the time derivative), and following the original proposal by Perzyna [24-25], it can be defined as

$$
\dot{\boldsymbol{\varepsilon}}^{v p}=\mu \cdot\langle\Phi(F)\rangle \cdot \frac{\partial g}{\partial \boldsymbol{\sigma}}
$$

where $\mu$ is referred to as the fluidity parameter, $g$ is the viscoplastic potential function represented by the dynamic loading surface (DLS - explained in the sequel), and $\Phi(F)$ is the so-called overstress that is the normalised distance between the current static yield surface (SYS) and the DLS (see Figure 1). The application of Macauley brackets in Equation (4) ensures that

$$
\langle\Phi(F)\rangle= \begin{cases}0 & \text { for } \Phi(F) \leq 0 \\ \Phi(F) & \text { for } \Phi(F)>0\end{cases}
$$

Several different relationships for $\Phi(F)$ have been proposed in the literature (e.g. [26,37]). In this work the following exponential function proposed by Fodil et al. [38] is employed

$$
\Phi(F)=\exp (F)-1=\exp \left[N\left(\frac{p_{0}^{d}}{p_{0}^{s}}-1\right)\right]-1
$$

where $p_{0}^{s}$ and $p_{0}^{d}$ are the size of the SYS and the DLS, respectively (see Figure 1), $N$ is the strain-rate coefficient that together with $\mu$ are the two viscous parameters of this model.

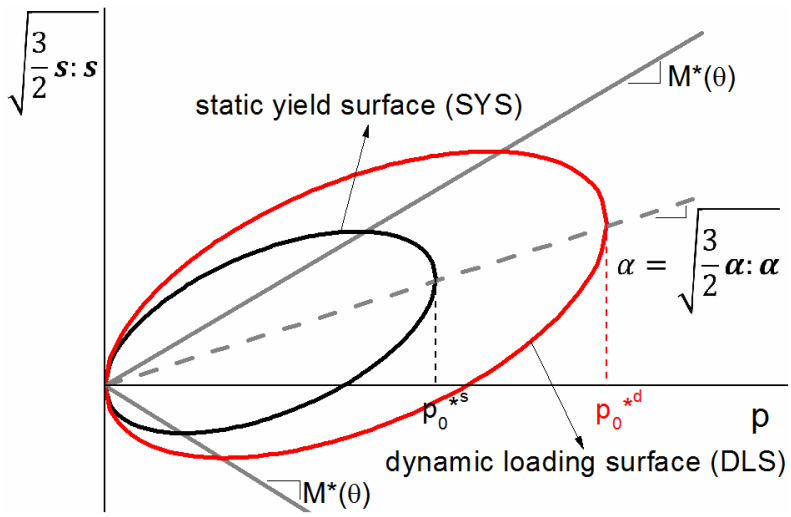

Figure 1. Graphical representation of the EVP-SANICLAY model in the stress space

This specific choice of $\Phi(F)$ ensures that its value is always greater or equal to zero. Thus, from Equation (7) it is evident that if the stress state lies on or inside the SYS, the soil response would be purely elastic. If the 
stress state lies outside the SYS, viscoplastic strain will be developed proportional to its distance from the current SYS.

In this work the elliptical surface of the SANICLAY model [12] is adopted as the SYS. The SANICLAY model was originally proposed with a non-associated flow rule; however, for simplicity purposes an associated flow rule is adopted here for its elastic-viscoplastic extension. In the general stress space, the SYS function can be expressed as

$$
f^{s}=\frac{3}{2}(\boldsymbol{s}-p \boldsymbol{\alpha}):(\boldsymbol{s}-p \boldsymbol{\alpha})-\left(M^{*}(\theta)^{2}-\frac{3}{2} \boldsymbol{\alpha}: \boldsymbol{\alpha}\right)\left(p_{0}^{* s}-p\right) p=0
$$

In the above expression, $\boldsymbol{s}=\boldsymbol{\sigma}-\boldsymbol{p} \boldsymbol{I}$ is the deviatoric component of stress tensor $\boldsymbol{\sigma}$ ( $\boldsymbol{I}$ being the fourth order identity tensor). $\boldsymbol{\alpha}$ is the deviatoric fabric tensor that accounts for anisotropy by coupling the deviatoric and volumetric plastic strain rates. $p_{0}^{* S}=S_{i} p_{0}^{S}$ defines the size of the structured SYS where $S_{i} \geq 1$ is an isotropic destructuration factor and $p_{0}^{S}$ is the size of the intrinsic SYS. $M^{*}(\theta)=S_{f} M(\theta)$ where $S_{f} \geq 1$ is a frictional destructuration factor and $M(\theta)$ is the critical stress-ratio that in the general stress space its value is interpolated between $M_{c}$ and $M_{e}$ by means of a Lode angle $\theta$. In the stress space illustrated in Figure 1 the scalar $\alpha=\sqrt{(3 / 2) \alpha: \alpha}$ defines the rotation of the SYS and DLS. As shown in Figure 1, the DLS has the same shape and orientation as the smaller SYS, and following the adoption of associate flow rule it coincides the viscoplastic potential surface too. A summary of the hardening equations and the Lode angle formulation are presented in the Appendix for the sake of completeness.

The model constants of EVP-SANICLAY can be divided into 4 categories: (1) the elasticity constants $\kappa$ and $v$ and the critical state constants $M_{c}, M_{e}$ and $\lambda$ which are the same as those in the MCC model (with the exception that in MCC we have $M_{e}=M_{c}$ ); (2) the rotational hardening (RH) constants $C$ and $x$, which are specific to the SANICLAY model; (3) the destructuration constants $k_{i}, k_{f}$ and $A$; and (4) the viscosity parameters $N$ and $\mu$, which constitute the two new additional parameters of the EVP-SANICLAY and they can be determined as discussed in Yin and Hicher [31]. Furthermore, similar to the SANICLAY, $\alpha$ and $p_{0}^{s}$ constitute the hardening internal variables in the EVP-SANICLAY model. It should be noted that despite the large number of model parameters, they have clear physical meaning and can be determined following straightforward processes. The detailed procedure for evaluating the initial values of the model state variables, and hardening and destructuration parameters can be found in Taiebat et al. [13].

\subsection{Numerical Integration}

The numerical solution algorithm for the elasto-viscoplastic model can be developed by using a step-bystep time integration algorithm with a Newton-Raphson iteration procedure [28]. In this scheme it is assumed at the beginning of a certain defined time interval and strain increment, the values of stresses, strains, and state variables are known. The objective is to determine the subsequent elastic and viscoplastic strain components, which in turn allow finding the subsequent stresses and internal variables. From Equations $(1,2)$ the incremental constitutive relationship for a time step can be expressed as 


$$
\Delta \boldsymbol{\sigma}=D\left(\Delta \boldsymbol{\varepsilon}-\Delta \boldsymbol{\varepsilon}^{v p}\right)
$$

For approximation of $\Delta \varepsilon^{v p}$, a finite difference scheme is employed as:

$$
\Delta \boldsymbol{\varepsilon}^{v p}=\Delta t\left[(1-\beta) \dot{\boldsymbol{\varepsilon}}_{t}^{v p}+\beta \dot{\boldsymbol{\varepsilon}}_{t+\Delta t}^{v p}\right]
$$

where $\dot{\varepsilon}_{t}^{v p}$ is the value of viscoplastic strain rate at time $t$, and $\beta$ is a time interpolation parameter $(0 \leq \beta \leq$ 1); $\beta=0$ represents an explicit forward (Euler) interpolation, $\beta=0.5$ represents central (Crank-Nicolson) interpolation, and $\beta=1$ implies an implicit backward interpolation. Lewis and Schrefler [39] showed that in this scheme the solution is conditionally stable for $0 \leq \beta<0.5$ and $\beta=1$, and unconditionally stable for $0.5 \leq \beta<1$. Substituting Equation (9) into Equation (8) and rearranging the terms give:

$$
D^{-1} \boldsymbol{\sigma}_{t+\Delta t}+\Delta t \cdot \beta \cdot \dot{\boldsymbol{\varepsilon}}_{t+\Delta t}^{v p}=\Delta \boldsymbol{\varepsilon}-\Delta t \cdot(1-\beta) \dot{\boldsymbol{\varepsilon}}_{t}^{v p}+D^{-1} \boldsymbol{\sigma}_{t}
$$

where the terms on the right hand side are known (at time $t$ ), while the left hand side terms are unknowns (at time $t+\Delta t$ ) and they are to be solved in an iterative procedure. A Modified Newton-Raphson approach is used for the iterative solution of Equation (10). To do this, a limited Taylor series is applied to the unknown quantities $\boldsymbol{\sigma}_{t+\Delta t}$ and $\dot{\boldsymbol{\varepsilon}}_{t+\Delta t}^{v p}$ :

$$
\left\{\begin{array}{c}
\sigma_{t+\Delta t}=\sigma_{i}+d \sigma_{i} \\
\dot{\varepsilon}_{t+\Delta t}^{v p}=\dot{\varepsilon}_{i}^{v p}+\frac{\partial \dot{\varepsilon}_{i}^{v p}}{\partial \boldsymbol{\sigma}} d \boldsymbol{\sigma}_{i}
\end{array}\right.
$$

Note that subscript $i$ refers to the $i$-th iteration at the current time step. Substituting Equations (11a) and (11b) into Equation (10) and successive rearrangements result in the following form for computation of stress increment:

$$
d \boldsymbol{\sigma}_{i}=\left[\boldsymbol{D}^{-1}+\Delta t \cdot \beta \cdot \frac{\partial \dot{\varepsilon}_{i}^{v p}}{\partial \boldsymbol{\sigma}}\right]^{-1}:\left[\left(\Delta \boldsymbol{\varepsilon}-\Delta t \cdot(1-\beta) \dot{\boldsymbol{\varepsilon}}_{t}^{v p}+\boldsymbol{D}^{-1}: \boldsymbol{\sigma}_{t}\right)-\left(\boldsymbol{D}^{-1} \boldsymbol{\sigma}_{i}+\Delta t \cdot \beta \cdot \dot{\boldsymbol{\varepsilon}}_{i}^{v p}\right)\right]
$$

If it is assumed that function $K$ represents the term $\left(\Delta \boldsymbol{\varepsilon}-\Delta t \cdot(1-\beta) \dot{\boldsymbol{\varepsilon}}_{t}^{v p}+\boldsymbol{D}^{-1} \boldsymbol{\sigma}_{t}\right)$ with known quantities remaining constant during the iteration, and that function $U$ represents the iterative term $\left(\boldsymbol{D}^{-1} \boldsymbol{\sigma}_{i}+\Delta t \cdot \beta \cdot \dot{\boldsymbol{\varepsilon}}_{i}^{v p}\right)$, then Equation (12) can be presented in a short form as:

$d \boldsymbol{\sigma}_{i}=\left[\frac{\partial U}{\partial \boldsymbol{\sigma}}\right]^{-1} \cdot\left[K_{t}-U_{i}\right]$

The most efficient solution scheme for continuum problems using overstress-type elasto-viscoplastic constitutive equations can be obtained with $\beta=0.5$ [40]; hence, this value is adopted for the time interpolation parameter in the present work. For the solution algorithm, at every time step Equation (13) is iteratively solved. At each iteration $d \sigma_{i}$ is calculated and subsequently $\boldsymbol{\sigma}_{i}$ is updated as $\boldsymbol{\sigma}_{i}=\boldsymbol{\sigma}_{i-1}+d \boldsymbol{\sigma}_{i}$. When convergence is achieved (i.e. when $d \sigma_{i}<$ tolerance $\sim 10^{-7}$ ), the iterative procedure stops and the incrementally accumulated stress values will become the stresses at the corresponding time step (i.e., $\sigma_{t+\Delta t}$ ); subsequently, viscoplastic strain tensor can be calculated as $\varepsilon_{t+\Delta t}^{v p}=\boldsymbol{\varepsilon}_{t+\Delta t}-\boldsymbol{D}^{-1} \boldsymbol{\sigma}_{t+\Delta t}$. The implementation makes it possible to apply the whole strain increment through a number of sub-increments, not all at once. After the completion of the integration process at a time increment the procedure advances to the next time step. 
The EVP-SANICLAY model has been implemented into PLAXIS finite element program as a user-defined soil model in order to be used for both element level and boundary value problem simulations. In the following, first the performance of the model is validated by simulation of a number of element test data on various clays. The model is then used for settlement study of a real instrumented test embankment and the simulation results are discussed in detail. The embankment simulation also aims to compare details of the predicted response using the proposed model and also using an isotropic and rate-independent model that is often used in practice.

\section{Model validation based on element level tests}

For the element test simulations the implemented user-defined model has been employed through the PLAXIS Soil Test application [41] to simulate several undrained triaxial shear and CRS test data on four different soft soils reported in the literature, namely Kawasaki clay, Haney clay, St. Herblain clay, and Batiscan clay $[14,16,42-43]$. The values of model constants and state variables used for the four soil types analysed in this paper are summarised in Tables 1 and 2. In accordance with the natural or reconstituted state of the clay sample being simulated the destructuration feature of the model has been switched on or off by setting respective values to the structuration parameters.

Table 1. Constants of the EVP-SANICLAY model adopted for four types of clays

\begin{tabular}{lccccc}
\hline Model constant & & Kawasaki & Haney & St. Herblain & Batiscan \\
\hline Elasticity & $\kappa$ & 0.021 & 0.05 & 0.022 & 0.037 \\
Critical state & $v$ & 0.2 & 0.25 & 0.3 & 0.3 \\
Rotational hardening & $M_{C}\left(M_{e}\right)$ & $1.65(1.24)$ & 1.28 & 1.25 & 0.98 \\
& $\lambda$ & 0.16 & 0.32 & 0.41 & 0.41 \\
Destructuration & $C$ & 12 & 12 & 10 & 12 \\
& $x$ & 2.6 & 2.4 & 1.5 & 1.7 \\
Viscosity & $k_{i}$ & 0 & 1.5 & 0 & 1.4 \\
& $k_{f}$ & 0 & 1.4 & 0 & 1.3 \\
& $A$ & 0 & 0.3 & 0 & 0.5 \\
& $N$ & 12 & 17 & 9 & 12 \\
& $\mu\left[\mathrm{s}^{-1}\right]$ & $7 \times 10^{-6}$ & $5 \times 10^{-11}$ & $5 \times 10^{-9}$ & $2 \times 10^{-9}$ \\
\hline
\end{tabular}

Table 2. Initial values of state variables adopted for four types of clays

\begin{tabular}{lccccc}
\hline Model state variable & & Kawasaki & Haney & St. Herblain & Batiscan \\
\hline Initial void ratio & $e$ & 1.07 & 2 & 2.26 & 1.92 \\
Initial size of the SYS & $p_{0}[\mathrm{kPa}]$ & 250 & 340 & 30 & 50 \\
Initial rotation of the SYS & $\alpha$ & 0.60 & 0.43 & 0.46 & 0.36 \\
Initial isotropic & $S_{i}$ & 1 & 6 & 1 & 3 \\
structuration factor & $S_{f}$ & 1 & 1.3 & 1 & 1.5 \\
Initial frictional & & & & & \\
structuration factor & & & & & \\
\hline
\end{tabular}




\subsection{Kawasaki clay}

To evaluate the strain-rate dependency, Nakase and Kamei [42] performed undrained triaxial compression and extension tests with various shearing rates on anisotropically consolidated reconstituted Kawasaki clay specimens. The index properties of Kawasaki clay samples were reported as plasticity index $I_{P}=29.4$, specific gravity $G_{S}=2.69$, liquid limit $w_{L}=55.3 \%$, plastic limit $w_{P}=25.9 \%$, and clay content 22.3\%. All tests were conducted under a vertical effective consolidation pressure of $392 \mathrm{kPa}$ with a backpressure of $196 \mathrm{kPa}$ in the consolidation stage. The samples were consolidated under a $K_{0}$ value of 0.42 , and then the samples were sheared in both compression and extension with axial strain rates of $0.7,0.07$, and $0.007 \% / \mathrm{min}$.

Kamei and Sakajo [44] reported the values of conventional soil parameters, such as $\kappa, \lambda, M$ and initial void ratio, for the samples of Kawasaki clay. Based on the test data, the critical stress ratio in triaxial compression and extension were measured as 1.65 and 1.24, respectively. Rotational hardening parameters were determined according to Dafalias et al. [12]. For the simulations, the destructuration feature of the model was switched off by setting $S_{i}=S_{f}=1$, as the soil specimens were reconstituted. Viscosity parameters were determined through calibration based on data from tests at only two strain-rates.

Figure 2 shows the comparison between experimental and numerical results obtained using the EVPSANICLAY model. The tests were simulated considering the consolidation stage. As it is seen in the figure, the response during triaxial compression has been captured very well by the model, while for the extension part the results are less accurate, even though the Lode angle dependency was considered in order to better reproduce the clay behavior in extension. As illustrated in Figure 3 of Taiebat et al. [13] this could be in part due to adoption of an associated flow rule in the EVP model.

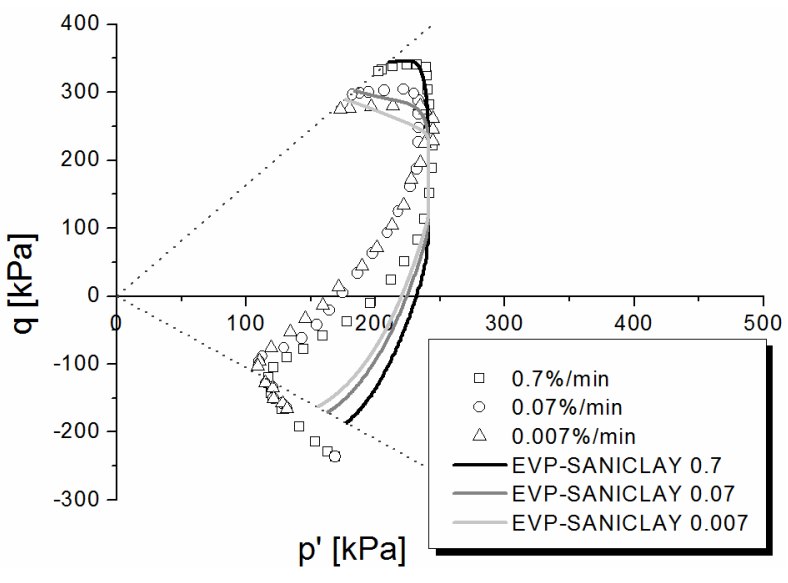

(a)

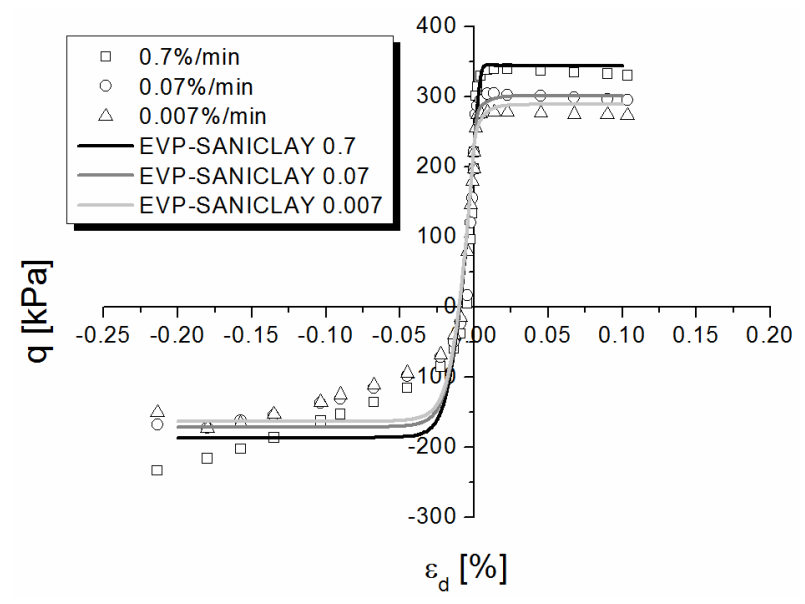

(b)

Figure 2. Undrained triaxial test: (a) effective stress path; (b) deviator stress versus axial strain

It can be noted that in triaxial compression, a better comparison between experimental and numerical results is achieved for higher strain rates. As the strain rate decreases, the numerical stress paths tend to be 
more lenient towards the critical state. As no destructuration was considered for this simulation and also associated flow rule was employed, the modeling results did not reproduce a noticeable softening behavior (Figure 2b). This is observed in both compression and extension. The initial stiffness of the curve was also well represented. The Lode angle dependency of the model allows capturing the anisotropy in strength as it was observed by Nakase and Kamei [42].

\subsection{Haney clay}

Vaid and Campanella [14] carried out undrained triaxial tests on undisturbed saturated sensitive marine clay known as Haney clay. It is a silty clay with $w_{L}=44 \%, w_{P}=26 \%$ and a sensitivity within the range of 6 to 10. All test samples were normally consolidated, with an all-around confining pressure of $515 \mathrm{kPa}$. Consolidation was allowed for a period of $36 \mathrm{hr}$ after which the samples were left undrained for $12 \mathrm{hr}$ under the consolidation stresses prior to shearing. In order to study the rate dependency of undisturbed clay response, the undrained shearing stage of the tests was performed at different constant strain rates, varying from $10^{-3}$ to $1.1 \%$ /min.

Values of conventional soil parameters listed in Tables 1 and 2 were reported by Vermeer and Neher [45]. After determination of the initial value of $\alpha$, the values of anisotropy constants, $C$ and $x$, were obtained via curve fitting. Destructuration parameter values were also calibrated via trial runs. Structuration factor and destructuration constants influence the softening behavior after peak strength, and to a lesser degree, the shear strength achieved. Figure $3 \mathrm{a}$ and $3 \mathrm{~b}$ show the influence of frictional destructuration in soft clay behavior. An increase of the frictional structuration factor leads to a larger softening behavior and a noticeable decrease in shear strength (Figure 3a).

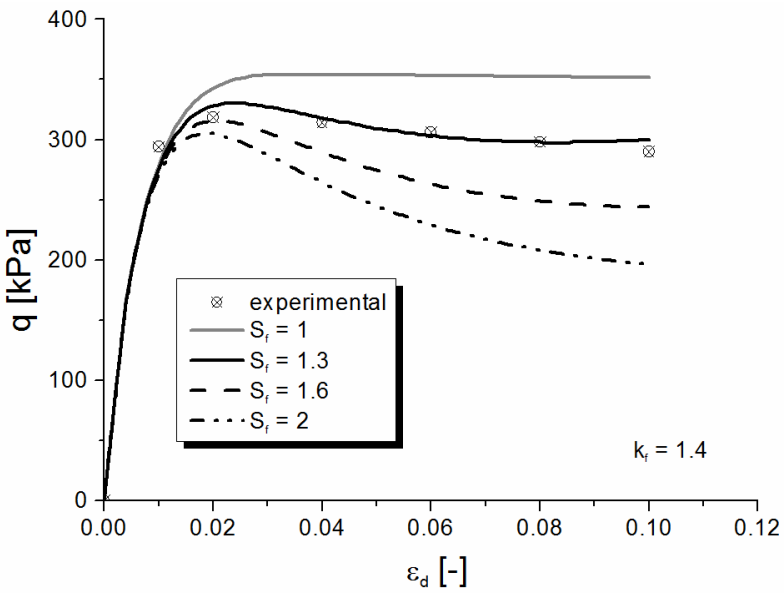

(a)

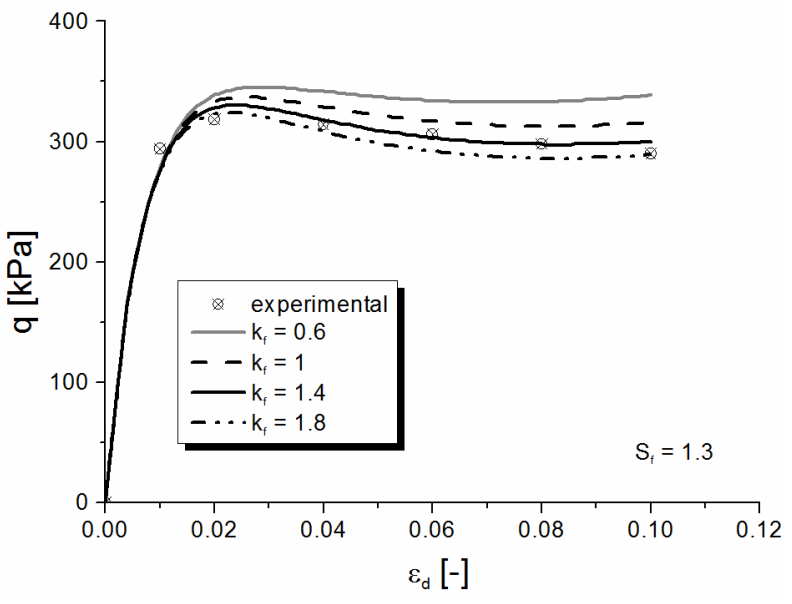

(b) 


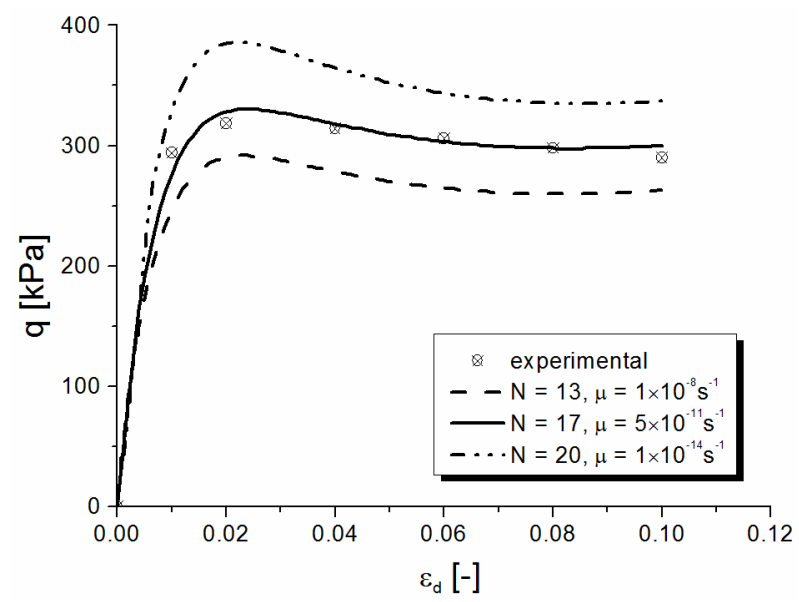

(c)

Figure 3. Calibration of structuration and viscosity parameters for Haney clay: (a) influence of frictional structuration parameter $S_{f}$ for a constant rate $k_{f}=1.4$; (b) influence of rate of frictional destructuration $k_{f}$ for a constant value of $S_{f}=1.3$; (c) combined influence of viscosity parameters $N$ and $\mu$

A similar, if less marked, behavior is seen in relation to the rate of frictional destructuration (Figure $3 \mathrm{~b}$ ), with larger softening observed for higher destructuration rates. Viscosity parameter values were calibrated based on the results of two tests (i.e. at two strain rates) only. As it is shown in Figure 3c, viscosity parameters play an important role in the overall calibration of the model, particularly with regards to the shear strengths achieved. In order to obtain an improved match with the experimental results, instead of the default value of 0.5 , a value of 0.3 was adopted for the destructuration parameter $A$.

For model simulations using EVP-SANICLAY, three specific strain rates, at $0.00094 \% / \mathrm{min}, 0.15 \% / \mathrm{min}$ and $1.1 \% / \mathrm{min}$, have been taken into account to reproduce the observed shear stress-shear strain curves. Also the peak strengths achieved at different strain rates were considered to evaluate the model performance. The experimental versus numerical results are shown in Figure 4. It can be seen from the figure that the model simulations compare very well with the observed behavior. The model, with its destructuration function on, is able to simulate the softening behavior of natural clay response after peak (Figure 4a). Also Figure 4b indicates that the model provides a reasonably good representation for the variations of maximum shear strength with loading rate. 


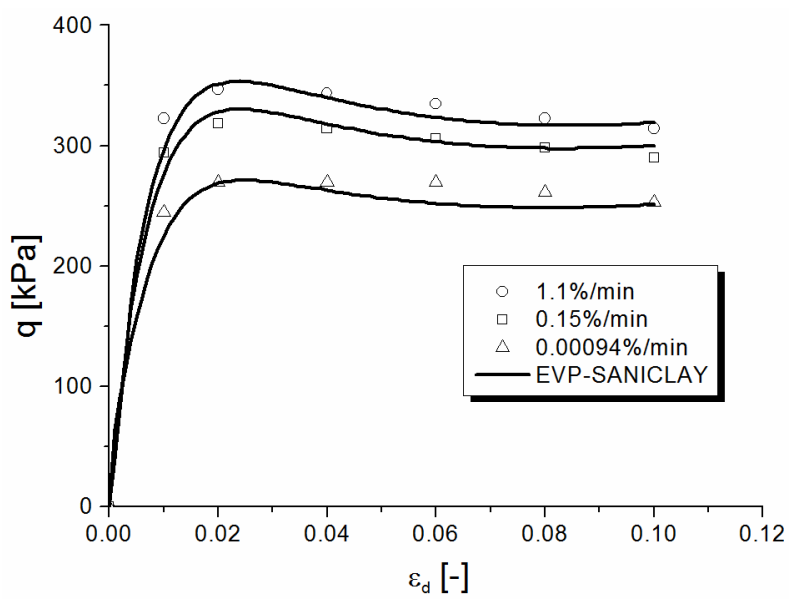

(a)

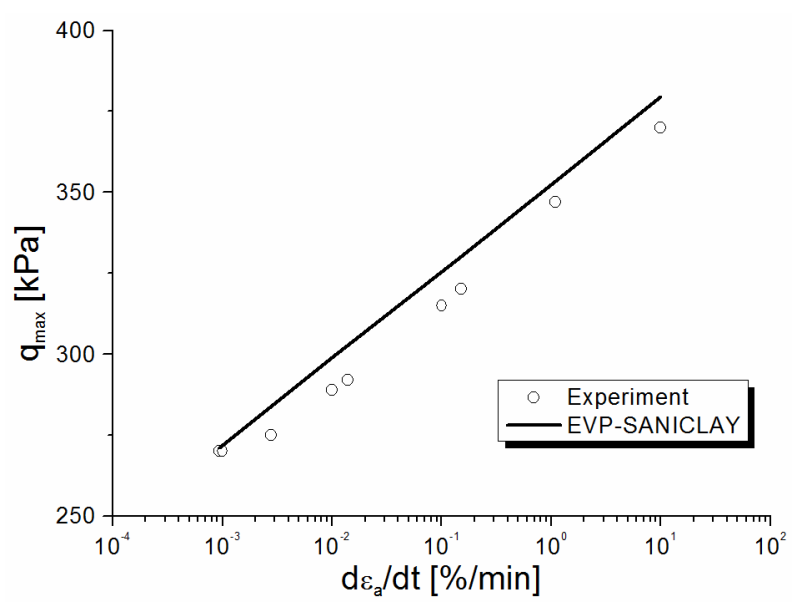

(b)

Figure 4. Undrained triaxial compression tests: (a) deviator stress versus axial strain; (b) evolution of maximum deviator stress with strain rate

\subsection{St. Herblain clay}

A particular CSR oedometer test was performed by Rangeard [43] on St. Herblain clay, a clayey river alluvial deposit. Two different strain rates were considered during the test. The test was started with a strain rate of $3.3 \times 10^{-6} \mathrm{~s}^{-1}$ until an axial strain of $12 \%$, at this strain the loading rate was lowered to a strain rate of $6.6 \times 10^{-7} \mathrm{~s}^{-1}$ and was kept at that until a vertical strain of $15.5 \%$, then again the rate was switched back to the initial strain rate and was kept constant until the end of the test.

Soil parameter values, obtained from oedometer and triaxial tests, were also reported by Rangeard [43]. The clay sample used for the experiments was taken from a depth of 6.5-7.5 m, it had a bulk unit weight $\gamma=14.85 \mathrm{kN} / \mathrm{m}^{3}$ and a water content of $87 \%$. A vertical pre-consolidation pressure of $52 \mathrm{kPa}$ was determined from the oedometer tests. The model parameters adopted are summarised in Tables 1 and 2.

Given that the clay was slightly structured, for the simulations the destructuration feature of the model was switched off. Figure 5 shows the experimental data versus simulation results. It can be seen that the model predictions are in good agreement with the data, particularly with regards to vertical stresses. The model also captures the indentation due to the change in strain-rate during the test. 


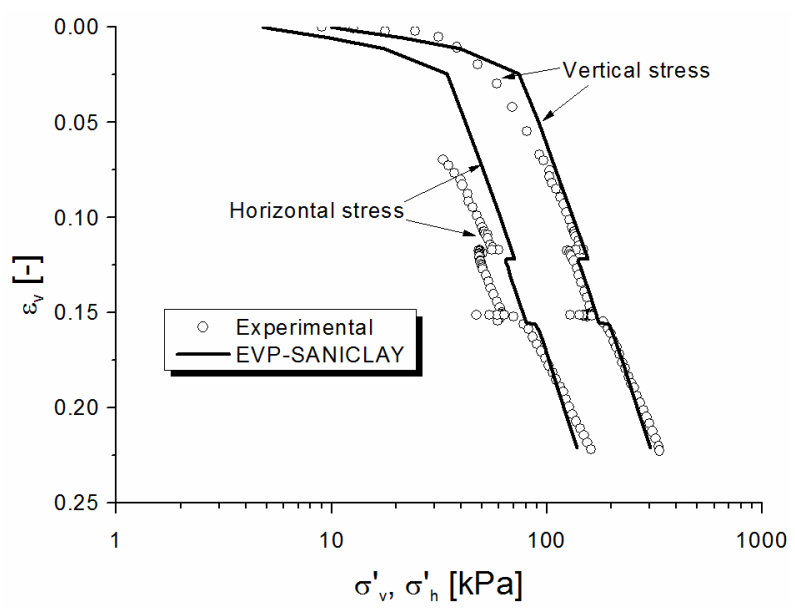

Figure 5. Simulations of CRS oedometer test results over St. Herblain clay

\subsection{Batiscan clay}

CSR oedometer tests were performed on Batiscan clay by Leroueil et al. [16]. The clay samples were taken from a depth of $7.25-7.46 \mathrm{~m}$; the samples reportedly had a water content of $80 \%$, liquidity index $I_{L}=$

$2942.7, I_{P}=21$, and $\gamma=17.5 \mathrm{kN} / \mathrm{m}^{3}$. The pre-consolidation pressure, determined from conventional oedometer

295 tests, was evaluated as $88 \mathrm{kPa}$. The strain-rates for the CRS tests varied between $1.7 \times 10^{-8} \mathrm{~s}^{-1}$ and $4 \times 10^{-5} \mathrm{~s}^{-1}$.

296 The initial vertical effective stress was taken equal to $65 \mathrm{kPa}$, corresponding to a size of the initial yield surface of $50 \mathrm{kPa}$. Conventional soil parameter values reported in Tables 1 and 2 were obtained from Leroueil et al. [16] and Rocchi et al. [46].

Combinations of initial degree of structuration and rate of destructuration have been studied and the best coupled values were chosen for the numerical simulations. As it is shown in Figure 6a, larger values of initial structuration $S_{\mathrm{i}}$ result in a larger reduction of final vertical stress due to the higher softening occurring. For a constant value of $S_{i}$, the value of the rate of destructuration does not appear to have as much influence, but it follows the same trend (Figure 6b), with higher rates leading to a higher vertical stress reduction.

304 Viscosity parameters are typically obtained from long-term oedometer tests via curve fitting. The calibration 305 of the coupled values is showed in Figure 6c. Note that viscosity parameters greatly change the stress value at 306 the end of the initial stiff elastic regime. The calibrated model parameter values are summarised in Tables 1 307 and 2 . 


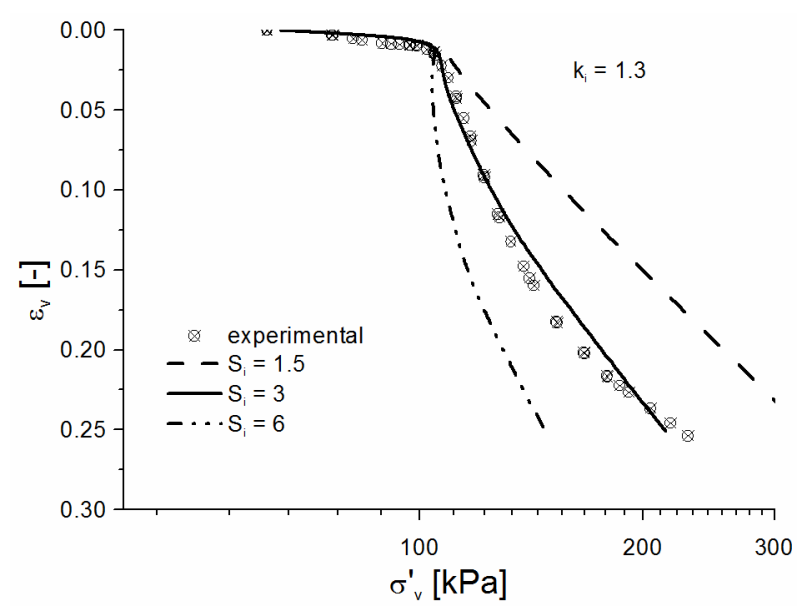

(a)

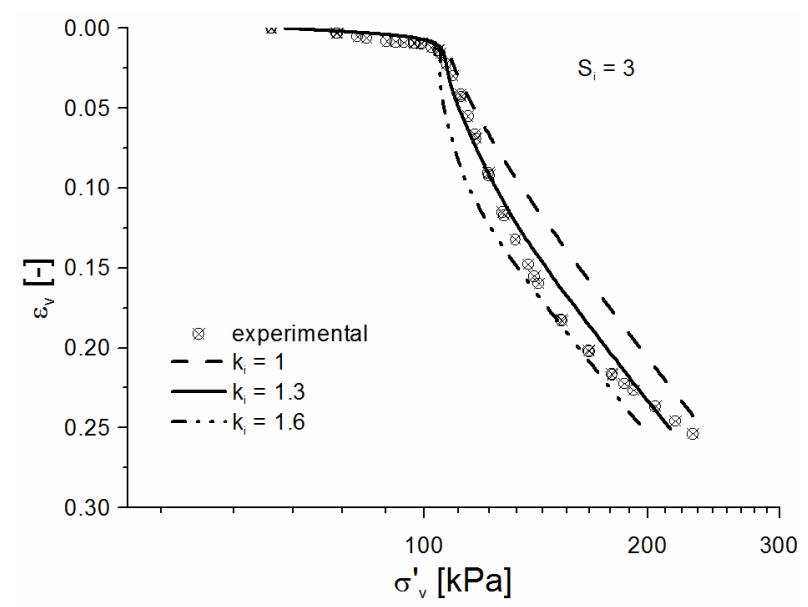

(b)

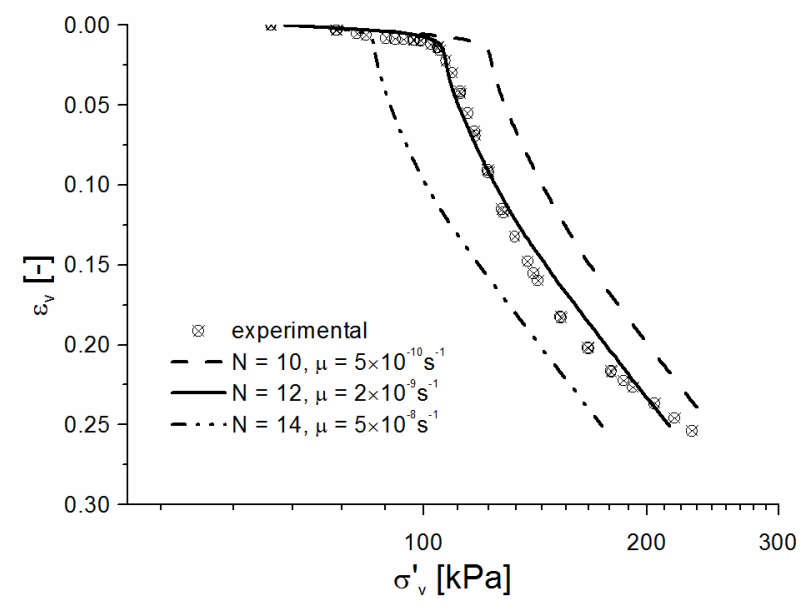

(c)

Figure 6. Calibration of structuration and viscosity parameters for Batiscan clay: (a) influence of isotropic structuration factor $S_{i}$ for a constant rate $k_{i}=1.3$; (b) influence of rate of isotropic destructuration $k_{i}$ for a constant structuration value of $S_{i}=3$; (c) combined influence of viscosity parameters $N$ and $\mu$

Model simulations using EVP-SANICLAY are shown in Figure 7. It is seen that a good correlation is obtained between the numerical results and experimental data. Also clearly the strain-rate effects are well captured; the exponential trend of the curves indicates the progress of destructuration at large strains. 


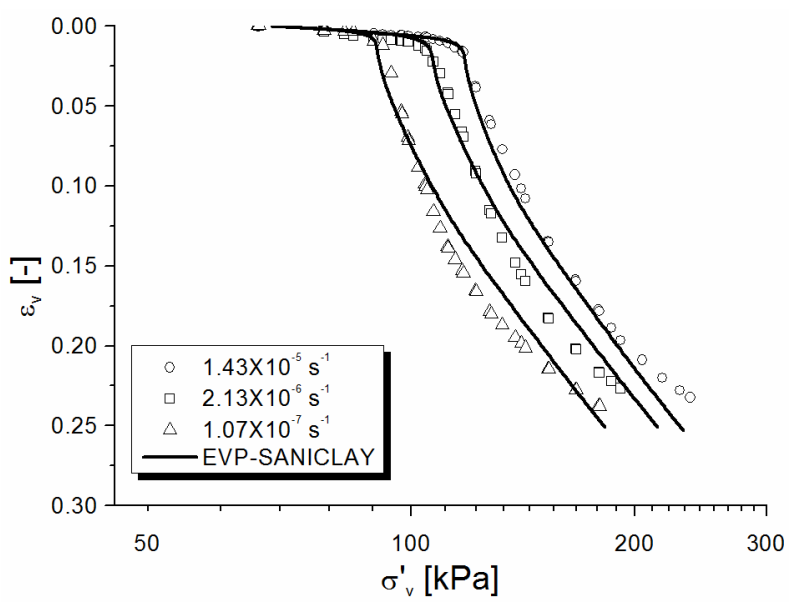

Figure 7. Oedometer test results: vertical strain versus vertical stress

Considering that all above element test simulations performed using EVP-SANICLAY, it appears that in addition to the anisotropy and destructuration effects, the model is able to reasonably capture the strain-rate dependency in behavior of natural clays. Also for the simulations preformed above, the model implementation proved to be sufficiently robust.

\section{Boundary value level modeling}

In order to study the performance of the proposed elasto-viscoplastic constitutive model at the boundary value level, the simulation of a test embankment was carried out. In particular, embankment D of a set of four test embankments built on a soft, sensitive and cemented clay in Saint-Alban, Quebec, Canada was selected [47-48]. This is a well-known and well-instrumented embankment for which soil parameters are readily available in the literature.

\subsection{Model description}

Embankment D has a height of $3.28 \mathrm{~m}$, a uniform crest width of $7.6 \mathrm{~m}$ and slope angles of $13.75^{\circ}$. The embankment material consists of uniform medium sand compacted to a unit weight of $18.56 \mathrm{kN} / \mathrm{m}^{3}$. It was constructed on 13.7 m deep natural clay deposit known as Champlain clay, underlain by a dense fine to medium sand layer down to a depth of $24.4 \mathrm{~m}$ [49]. The soft deposit is overlain by approximately $1.5 \mathrm{~m}$ thick weathered crust. In order not to disturb the very soft and sensitive clay deposit at the site, the embankment was built directly on the existing natural ground, without excavating the thin dry crust layer at the top. In this work a two-dimensional plane strain finite element model of the embankment was created using PLAXIS AE [41], and taking advantage of the symmetry, only half of the embankment was modeled. A finite element mesh with 1723 15-noded triangular elements (Figure 8.a) was used for the analyses. Each element has pore water pressure (PWP) degrees of freedom at corner nodes. Mesh sensitivity studies were carried out to ensure that the mesh was dense enough to produce accurate results. The geometry of the finite element model is shown 
341 in Figure 8a. The far right boundary of the model was assumed at distance of $40 \mathrm{~m}$ from the embankment

342 centerline. The bottom boundary of the clay deposit was assumed to be completely fixed in both horizontal

343 and vertical directions, whereas, the left and right vertical boundaries were only restrained horizontally.

344 Drainage was allowed at the ground level, while the bottom boundary was considered impermeable.

345 Impermeable drainage boundaries were also assigned to the lateral boundaries. Based on ground data, the

346 water table was assumed at $0.7 \mathrm{~m}$ depth.

347 The embankment was built in stages, with an initial layer of $0.6 \mathrm{~m}$ and after 6 days the normal 348 construction began (Figure 8.b), with an average rate of $0.24 \mathrm{~m} /$ day [48]. The same construction pace was

349 adopted in the numerical model. For the calculation phases, plastic analyses were carried out corresponding

350 to the construction process of the embankment, after which the consolidation analysis was performed.

For the numerical analysis, the embankment itself was modeled with the simple linear elastic-perfectly plastic Mohr-Coulomb model using the following reported values for the embankment material: Young's modulus $E=40,000 \mathrm{kPa}$, Poisson's ratio $v=0.3$, friction angle $\phi=44^{\circ}$, and cohesion $c=0 \mathrm{kPa}$. The dry crust layer above the water table was also modeled with the Mohr-Coulomb model using shear modulus $G=880$ $\mathrm{kPa}$, Poisson's ratio $v=0.3, \phi=27^{\circ}, c=1 \mathrm{kPa}$. Unit weight $\gamma=19 \mathrm{kN} / \mathrm{m}^{3}$ is used for both [47,50]. The sensitive Champlain clay deposit below the water table was modeled using the implemented user-defined EVP-SANICLAY model, with a unit weight $\gamma=16 \mathrm{kN} / \mathrm{m}^{3}$ [47]. 


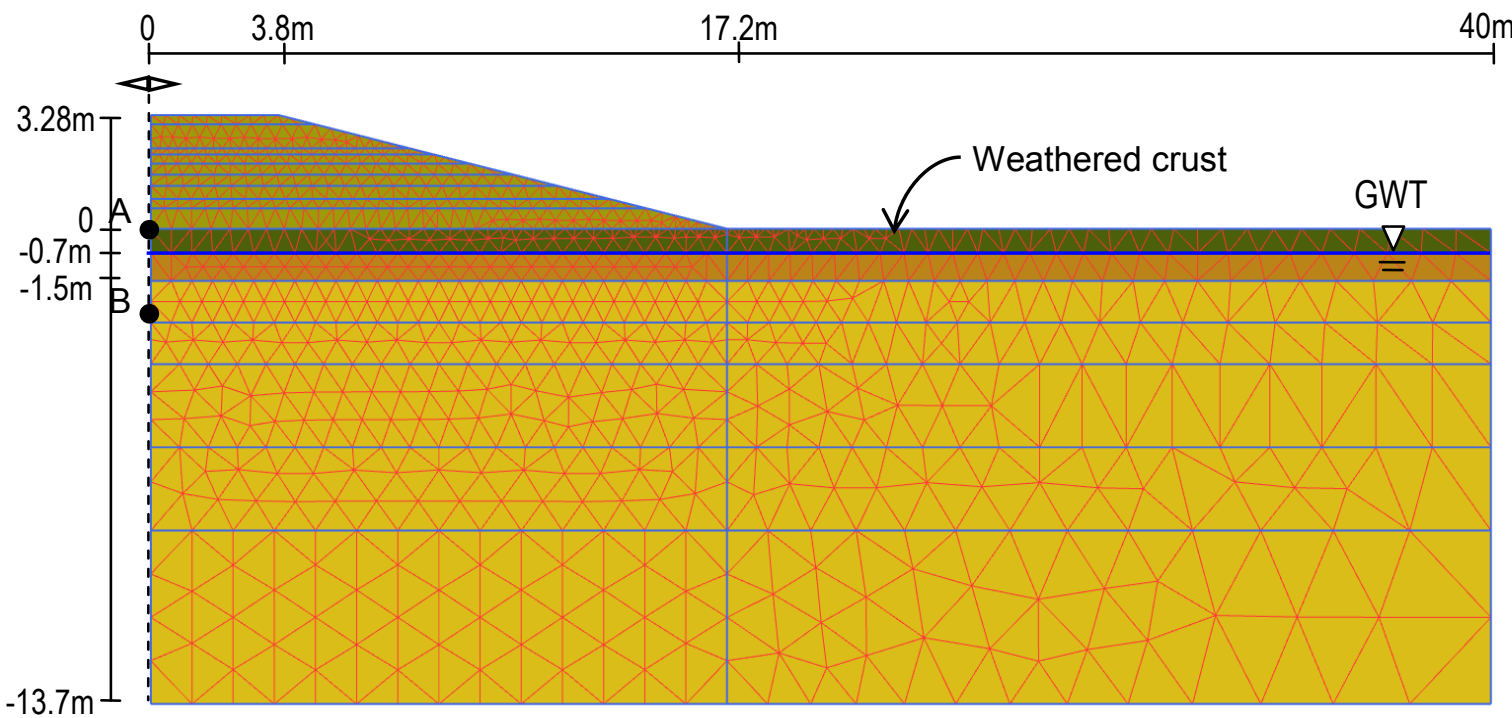

(a)

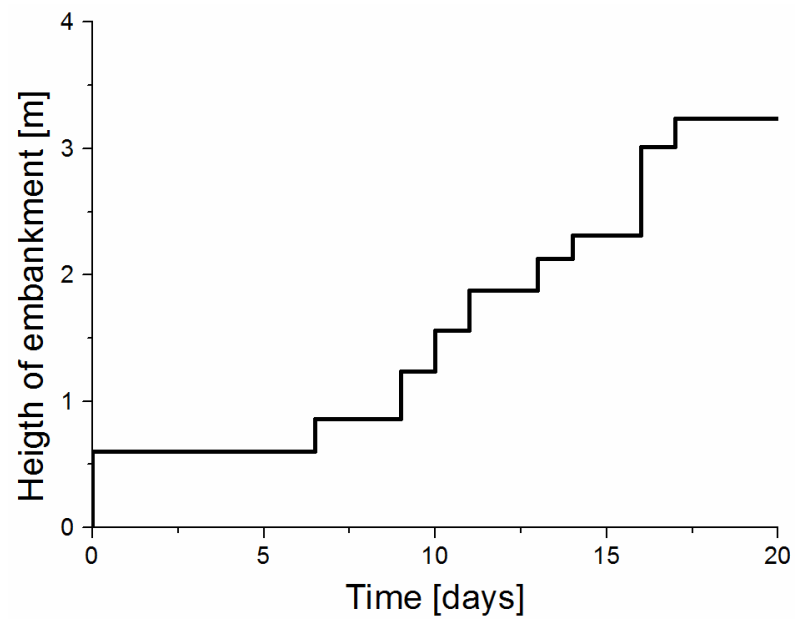

(b)

Figure 8. (a) Geometry of the model embankment and the finite element mesh adopted; (b) construction history of the St. Alban embankment D

The material parameter values for the Champlain clay layers were determined using the available data obtained from testing of samples taken at a depth of $6 \mathrm{~m}$ below the ground surface [15]. Conventional parameter values were derived from existing studies based on soil element test results [47-48,50]. Similar to the section on element level simulations, the anisotropy parameter values were determined following the approach proposed by Dafalias et al. [12]. The destructuration parameters were calibrated against experimental data available for undrained triaxial compression tests over samples of Champlain clay taken 
367 from a depth of approximately 3m [51]. For three tests presented in Figure 9 the samples were first 368 isotropically consolidated up to three different pre-consolidation pressures of $44,66.6$ and $77 \mathrm{kPa}$, and 369 subsequently sheared. Figure 9 shows a good agreement between the experimental data and the numerical 370 simulations both in terms of stress-strain response and of stress paths. The destructuration trend after peak 371 strengths was also well captured.

372

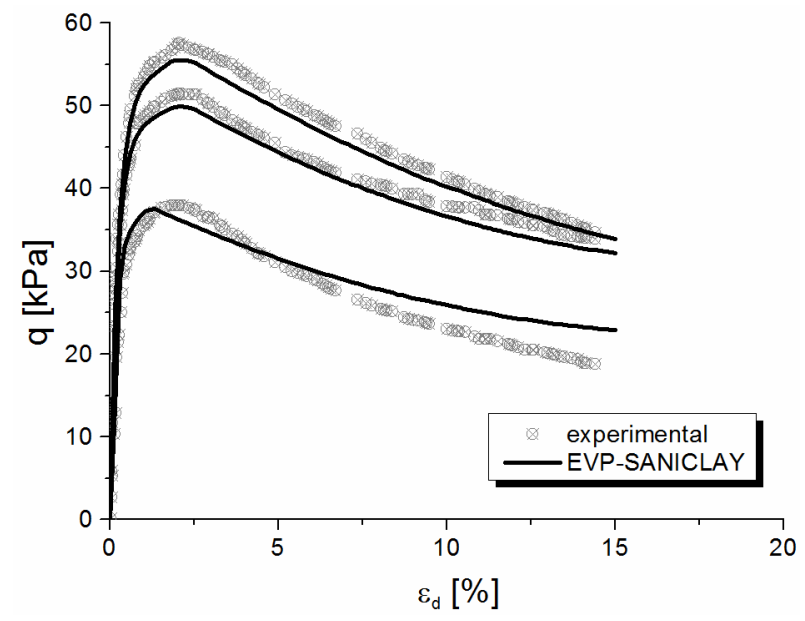

(a)

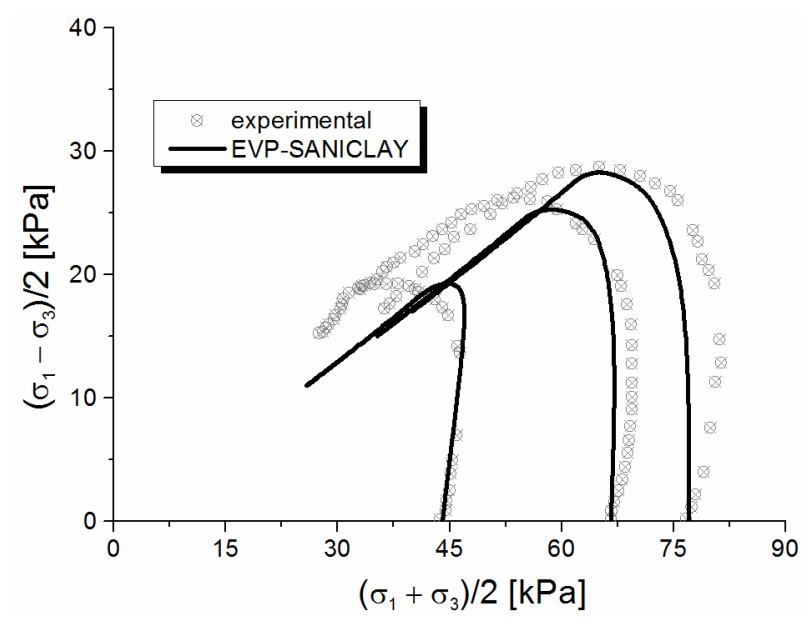

(b)

Figure 9. Validation of numerical simulations versus experimental results for undrained triaxial compression tests: (a) deviator stress versus axial strain; (b) effective stress paths

In the absence of appropriate soil test data, such as long-term oedometer tests with at least two different strain rates, viscosity parameters were calibrated using trial runs. 
Table 3 summarises the soil and state parameters adopted for the simulation of St. Alban test

381 embankment, and Table 4 lists the calibrated anisotropy and destructuration parameter values. The 382 permeability, $k$, of the clay, assumed to be isotropic, was reported to be equal to $3.46 \times 10^{-4} \mathrm{~m} /$ day. It should

383 also be added that the initial state of stress was generated by adopting $K_{0}$-procedure [41] where the reported $384 K_{0}$ value of 0.8 was employed [52]. Results from oedometer tests performed on Champlain clay reported that 385 over-consolidation ratio (OCR) varied between 1.8 and 2.2 [47]; a mean value of 2.0 was assumed for the 386 analyses performed here.

387

388 
Table 3 - Constants of the EVP-SANICLAY model adopted for St. Alban test embankment D

\begin{tabular}{lccc}
\hline Model constant & \multicolumn{2}{c}{$\begin{array}{c}\text { Top Champlain clay } \\
\text { layer }(0.7-1.5 \mathrm{~m})\end{array}$} & $\begin{array}{c}\text { Bottom Champlain clay } \\
\text { layer }(1.5-13.7 \mathrm{~m})\end{array}$ \\
\hline Elasticity & $\kappa$ & 0.012 & 0.013 \\
& $v$ & 0.3 & 0.3 \\
Critical state & $M_{c}$ & 1.07 & 1.07 \\
\multirow{3}{*}{ Rotational hardening } & $\left(M_{e}\right)$ & 0.36 & 0.25 \\
& $\lambda$ & 10 & 10 \\
Destructuration & $C$ & 1.7 & 1.7 \\
& $x$ & 1.5 & 1.5 \\
\multirow{3}{*}{ Viscosity } & $k_{i}$ & 1.4 & 1.4 \\
& $k_{f}$ & 0.5 & 0.5 \\
& $A$ & 13 & 13 \\
& $N$ & $5 \times 10^{-9}$ & $5 \times 10^{-9}$ \\
\hline
\end{tabular}

Table 4 - Initial values of state variables adopted for St. Alban test embankment D

\begin{tabular}{lccc}
\hline Model state variable & & $\begin{array}{c}\text { Top Champlain clay } \\
\text { layer } \\
(0.7-1.5 \mathrm{~m})\end{array}$ & $\begin{array}{c}\text { Bottom Champlain } \\
\text { clay layer } \\
(1.5-13.7 \mathrm{~m})\end{array}$ \\
\hline Initial void ratio & $e$ & 1.7 & 1.8 \\
Overconsolidation ratio & OCR & 2.0 & 2.0 \\
Initial rotation of the SYS & $\alpha$ & 0.41 & 0.41 \\
Initial isotropic & $S_{i}$ & 4.5 & 4.5 \\
structuration factor & & 1.2 & 1.2 \\
Initial frictional & $S_{f}$ & & \\
structuration factor & & &
\end{tabular}

In order to assess the performance of EVP-SANICLAY model, the finite element analysis of the embankment was repeated twice where instead of the EVP-SANICLAY model the MCC model and the EVPSANICLAY model without destructuration (i.e., with $S_{i}=S_{f}=1$ ) were used.

\subsection{Simulations results}

The results from numerical analyses were compared with the available field measurement data for the time period following the construction $[47,50,53]$. Figure 10 shows settlement predictions versus time at the node on the centerline at the base of the embankment (point A in Figure 8a), using different models. From the figure it is clear that the proposed EVP-SANICLAY model gives a rather good prediction when compared to the in-situ measurements. When destructuration is switched off, the model significantly underestimates the settlement over time. The underestimation of settlement is even more pronounced with the MCC and SANICLAY models; in this case the predicted settlement reaches an approximately constant value after 400 days, pointing out that the model is clearly time-independent. 


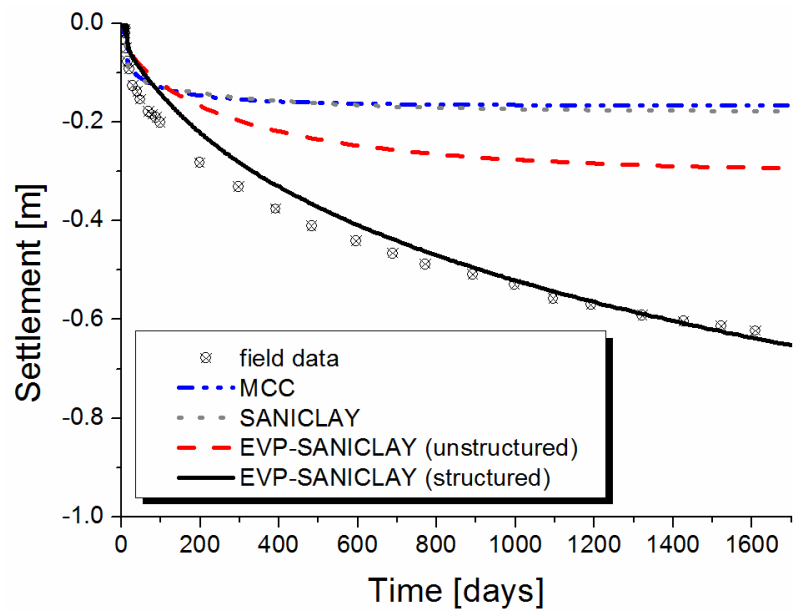

No additional field data is available for surface settlements recorded at different times, but a comparison

410 between the numerical results adopting different soil constitutive models can be made. Such numerical

411 simulation results are shown in Figure 11. Generally they all show a typical behavior, with the main vertical

412 settlements at the centerline of the embankment and diminishing values at larger distances from the

413 centerline. However, as consideration of soil viscosity during plastic deformation delays the consolidation

414 process, settlements through using EVP-SANICLAY (Figure 11d) represent more realistic deformation pattern

415 with time. The simulation performed using the MCC and SANICLAY (Figure 11a,b) clearly shows that with the

416 time-independent models the consolidation process completes rapidly after which the vertical deformation

417 stops. When the effect of soil structure is ignored (Figure 11c) a behavior similar to the complete EVP-

418 SANICLAY model is obtained, but with significantly lower values for the vertical settlement. This is expected, 419 given that Champlain clay is highly structured clay with a sensitivity value of about of 22 [15]. 


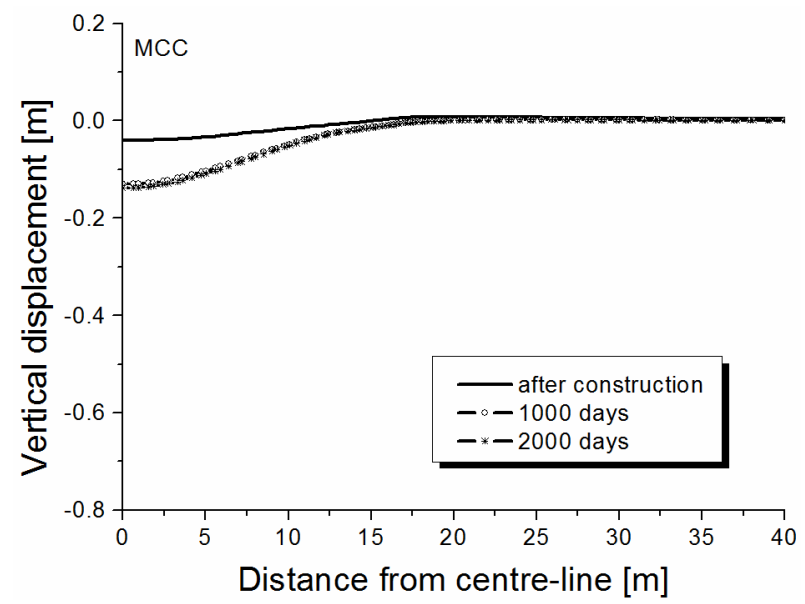

(a)

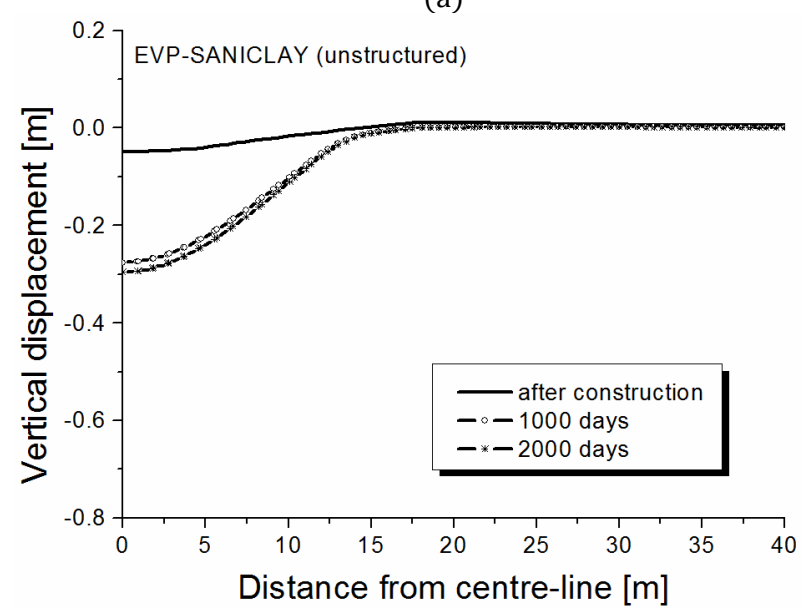

(c)

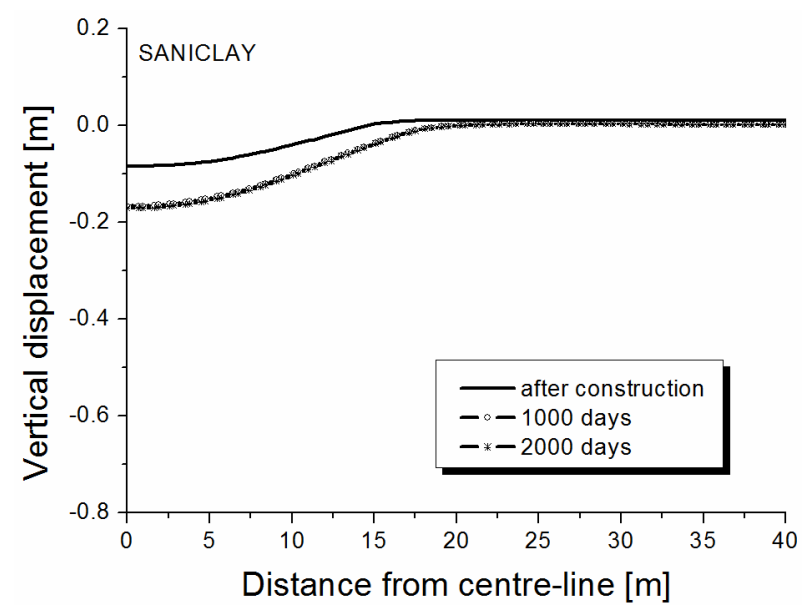

(b)

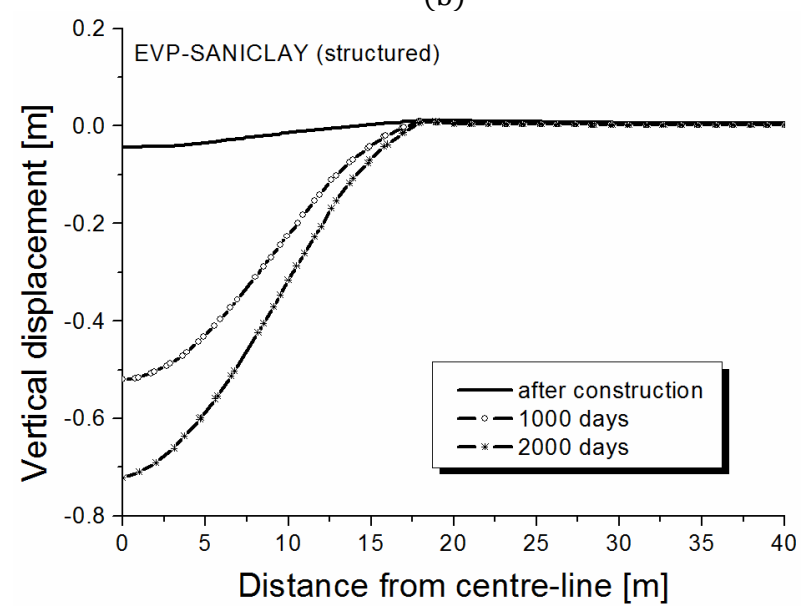

(d)

Figure 11. Numerical simulation results for surface settlement using: (a) MCC model; (b) SANICLAY model;

(c) EVP-SANICLAY model without structure; (d) EVP-SANICLAY model

Pneumatic piezometers were installed at different depths underneath the embankment to monitor the excess pore water pressure variations with time [48,50]. Figure 12 shows the in-situ measurements related to a piezometer located on the centerline at a depth of $2.6 \mathrm{~m}$ under the base of the embankment (point $B$ in Figure 8a). The excess PWP initially increased during the embankment construction and then gradually dissipated with time. The figure also shows the results of numerical simulations with the models. As it can be seen, a better approximation of the excess PWP variation is obtained with the EVP-SANICLAY model, in comparison with the MCC, SANICLAY, and the anisotropic EVP model without structure. Interestingly, for the SANICLAY and both of the EVP-SANICLAY model simulations, with and without structure, the maximum PWP value is reasonably close to the field measurement, but when the initial structure and degradation of bonds are not taken into consideration, a faster dissipation of excess PWP is observed. MCC model underestimates the maximum excess PWP immediately after the construction; additionally, after the construction excess PWP 
is dissipated very quickly, contrary to the observed in-situ scenario. The observed delayed pore pressure dissipation can be captured only when the viscosity of soil behavior is taken into consideration.

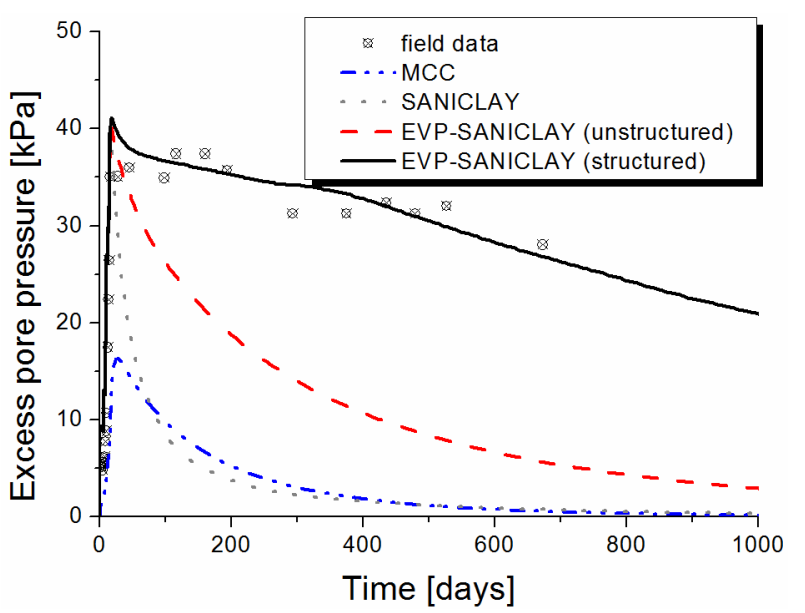

Figure 12. Excess PWP predictions at point B in Figure 8a

Field data for lateral displacements at depth are not available for the embankment [54]; therefore, simulation results presented in Figure 13, for the lateral deformation profiles at the toe of the embankment, could not be compared with the actual measurements. From Figure 13d, EVP-SANICLAY model simulations show deformation profiles similar in shape to what was reported for other embankment sites. For example in case of St. Alban embankment B, the maximum lateral displacement was reported to have more than doubled during the initial 4.5 years of consolidation [54], and the maximum value was at a depth of about $1 \mathrm{~m}$. The MCC and SANCILAY models led to smaller lateral displacement near the surface (Figure 13a,b). For the EVP simulations in Figure 13c,d, the lateral displacements increased near the surface, and delayed deformation became more pronounced. When structure effects were ignored in the EVP model (Figure 13c), the general shape of the lateral deformation profiles did not change much compared to Figure $13 \mathrm{~d}$ but the predicted values became smaller, without noticeable difference between the profiles at 1000 and 2000 days. Clearly consideration of the soil initial structure and its degradation result in a greater pace of viscoplastic strain developments. For example, monitoring the development of viscoplastic strains at point B under the embankment, i.e. the position of the piezometer, it can be seen in Figure 14 that after an initial elastic response, the viscoplastic strains begin to develop while still in the construction phase, and then continue to evolve with consolidation progress. It is particularly apparent how ignoring soil structure effects lead to significantly lower viscoplastic strain accumulation, a trend also observed in previous figures. 


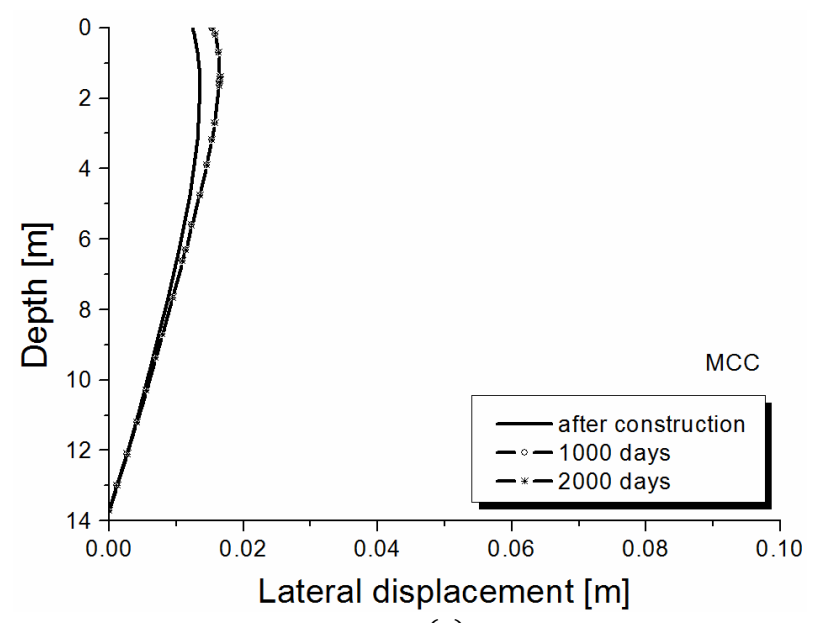

(a)

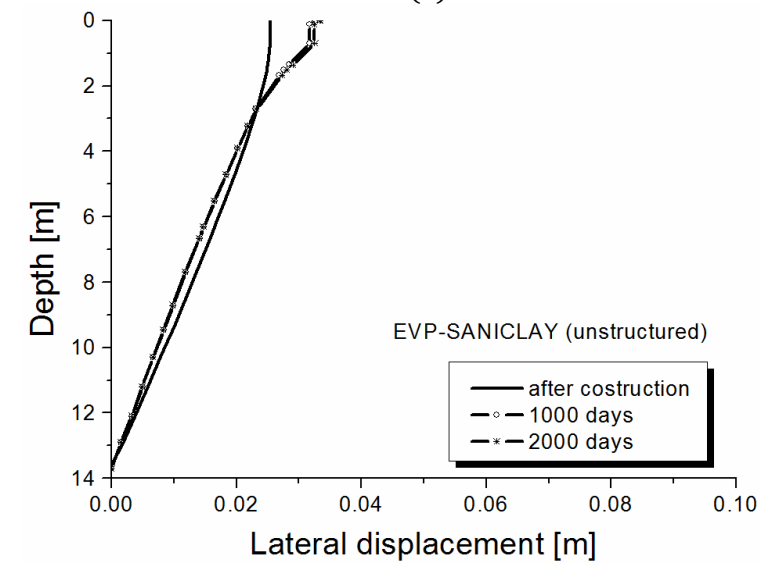

(c)

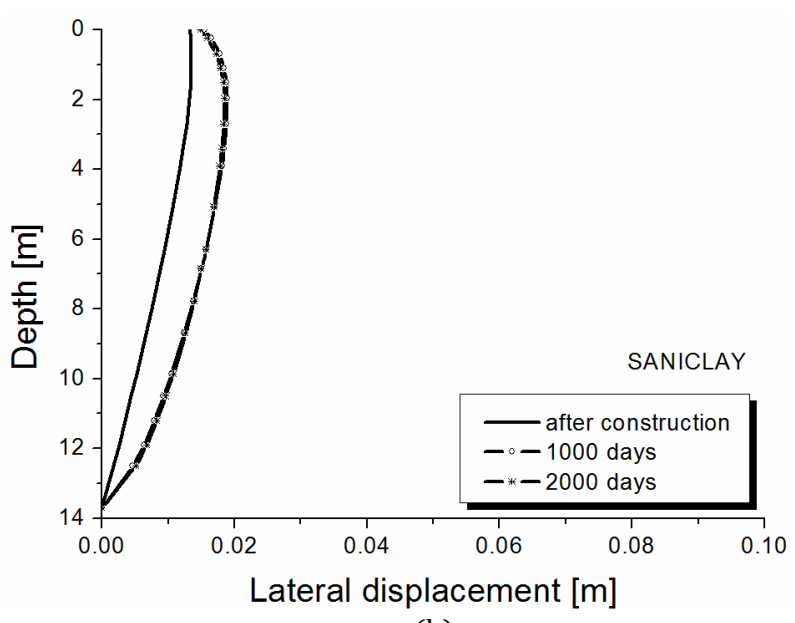

(b)

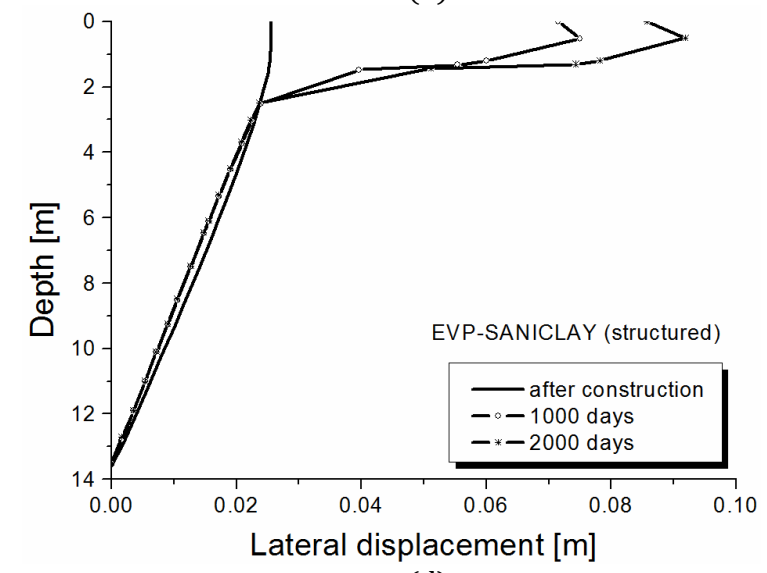

(d)

Figure 13. Numerical simulation results for lateral displacement under the toe using: (a) MCC model; (b) SANICLAY model; (c) EVP-SANICLAY model without structure; (d) EVP-SANICLAY model

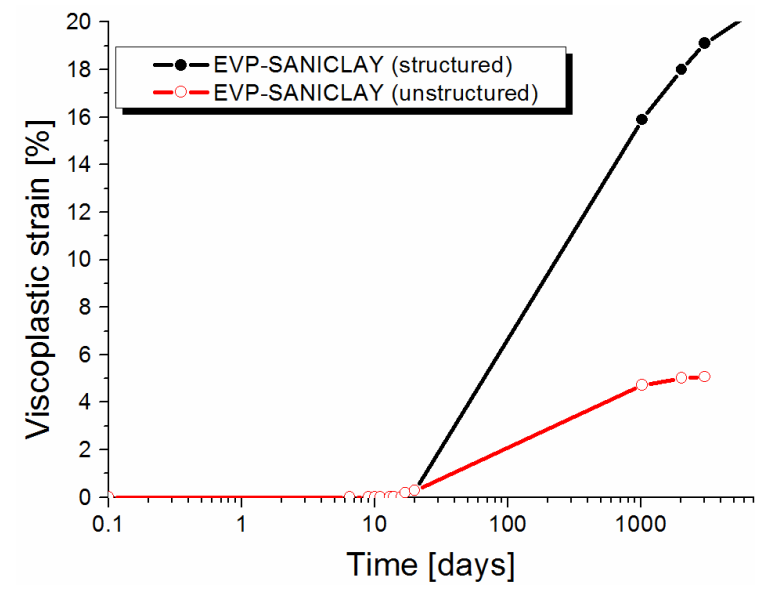

Figure 14. Development of viscoplastic strains at point B in Figure 8a

\subsection{Non-uniqueness of viscosity parameters}

As already mentioned, calibration of viscosity parameters $N$ and $\mu$ has been done directly on the embankment model as no appropriate test data has been available for the foundation soil. It should be 
pointed out that the Perzyna-type viscosity parameters for a particular clay are not necessarily a unique set and more than one combination of the two viscosity parameters can be found for a clay, depending on how one wants to fit the experimental data [55]. Figure 15 shows an example of how for three different sets of viscosity parameter values it is still possible to obtain a good approximation of the field observation for settlements at point A under the embankment. For these particular sets, a maximum difference of only $3 \%$ was found among the vertical settlement results, and similar minor variations were observed among the corresponding lateral displacement and excess PWP predictions.

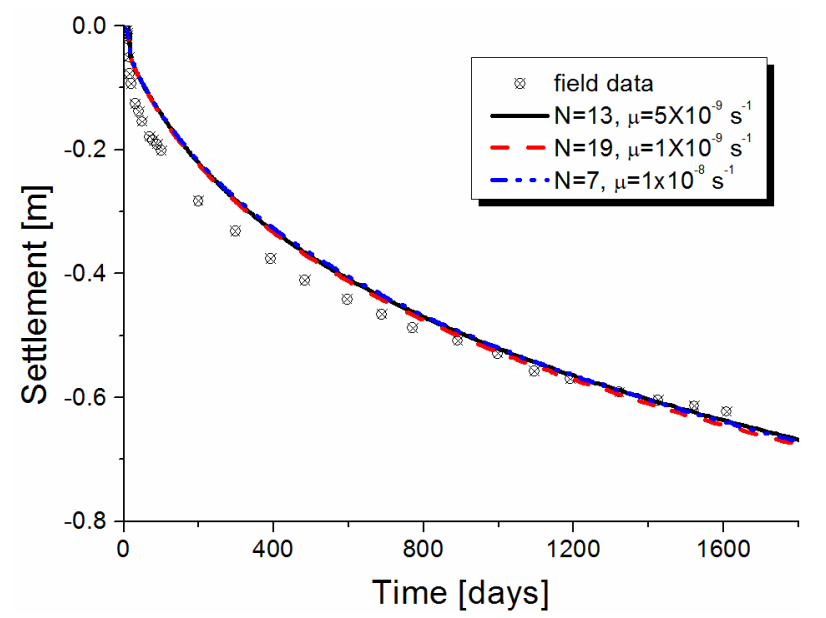

Figure 15. Illustrating the non-uniqueness of viscosity parameters for prediction of time-settlement at point $\mathrm{A}$ in Figure 8a

\subsection{Discussion on behavior during construction}

Additional field measurement data on settlement and excess pore pressure generation during embankment construction process is also available [48]. The data could be used to assess the performance of the developed model in reproducing the short-term response of the embankment. Simulation results during the construction are shown in Figure 16.

Figure 16a shows that at point A in Figure 8a, EVP-SANICLAY model somewhat underestimates the results; although, as it was observed in Figure 7a, it is then able to gain accuracy during consolidation. MCC and SANCILAY, on the contrary, overestimates short-term settlements during the construction. In terms of excess PWP at point B in Figure 8a, EVP-SANICLAY is able to give a good prediction of the pore pressure generation during the embankment construction (Figure 16b). Based on EVP-SANICLAY predictions, PWP develops rapidly during the construction until embankment reaches a height of approximately $2.31 \mathrm{~m}$ (corresponding to 16 days after the start of construction) when the excess PWP generation slightly decelerates. From the figure, it is clear that the MCC model underestimates excess PWP generation during the construction. Compared to the full EVP model, EVP-SANICLAY without structure provides lower predictions of excess PWP generation after the stage at which the embankment reaches a height of $2.31 \mathrm{~m}$. 


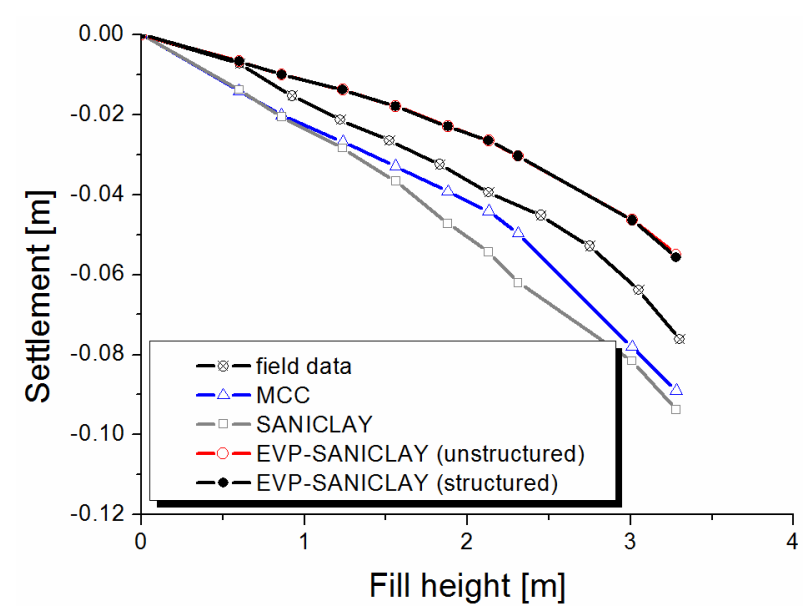

(a)

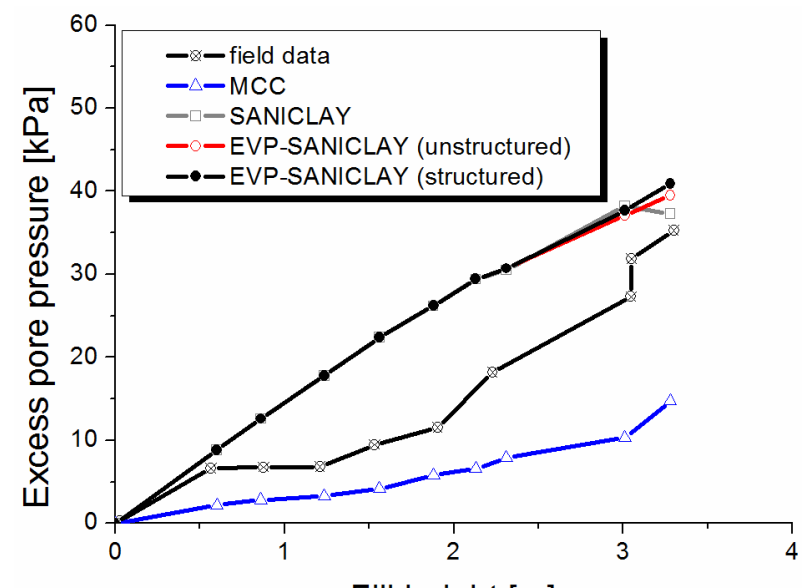

Fill height [m]

(b)

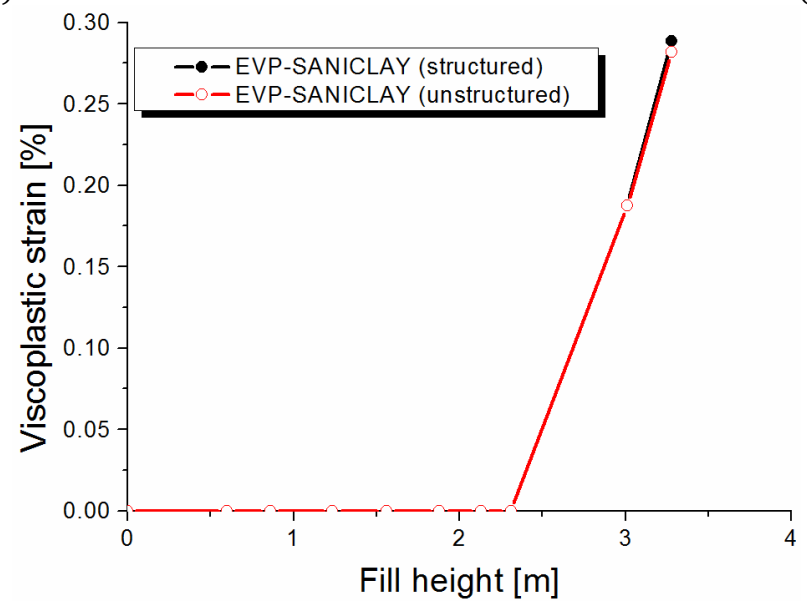

(c)

Figure 16. Field measurements versus numerical simulation results for the duration of construction: (a) settlements at point A in Figure 8a; (b) excess pore water pressure at point B in Figure 8a; (c) development of viscoplastic strains at point B in Figure 8a

Figure 16c shows the development of viscoplastic strains at point B under the embankment (i.e. at the position of the pneumatic piezometer considered). The figure shows that the viscoplastic strains start to develop when the embankment reaches a height of about $2.31 \mathrm{~m}$, which approximately corresponds to the time when excess pore pressure generation changes its pace.

\section{Conclusions}

The response of natural soft soil is governed by anisotropy, structure and time-dependency. In this work, in order to concurrently account for these advanced features of soil behavior a time-dependent elastoviscoplastic extension of a well-established anisotropic clay model, namely SANICLAY, has been proposed. The model is numerically implemented in finite element program PLAXIS using an implicit integration scheme. The performance of the model at the element-level has been validated against experimental data 
obtained from testing four different clays at both structured and un-structured states. Furthermore the timedependent behavior of St. Alban embankment D on the well-structured Champlain clay was analysed using the proposed EVP-SANICLAY model. The paper presented the results for settlements, lateral deformations, and excess PWP variations during the construction and the subsequent consolidation, comparing model predictions with the field measurements where available. It was observed that the developed model considers the delayed excess pore pressure dissipation following the completion of the embankment construction reasonably well; hence it is able to yield more realistic predictions of the long-term vertical and horizontal deformations. The boundary value problem simulation results also illustrated that considering clay initial structure and subsequent destructuration effects significantly improve the accuracy of predictions, particularly when dealing with a highly sensitive soft clay such as Champlain clay. Furthermore, the model also predicted the immediate displacements as well as the development of excess pore pressures during early stages of construction with reasonable accuracy.

In general, EVP-SANICLAY proved to be able to much better predict both short- and long-term behavior of natural clay behavior when compared with a commonly used critical state based model such as MCC, and also the SANCILAY model.

\section{Acknowledgements}

Support to conduct this study is provided by the University of Nottingham's Dean of Engineering award, and the Natural Sciences and Engineering Research Council of Canada (NSERC).

\section{Appendix}

For the sake of completeness of presentation, some of the key components of the SANICLAY model that are not presented in the main body of this paper are summarized here. Both stress and strain quantities are assumed positive in compression (as is common in geomechanics), and the effect of this sign convention has been considered on the model equations. All stress components in this paper should be considered as effective stress. Finally, in terms of notation, tensor quantities are denoted by bold-faced symbols and operations explained accordingly.

The hypoelastic formulation, considered for simplicity, constitutes of a shear modulus $G$, for calculating increments of elastic deviatoric strains, and a bulk modulus $K$, for calculating increments of elastic volumetric strains, where

$G=\frac{3 K(1-2 v)}{2(1+v)} ; \quad K=\frac{p(1+e)}{\kappa}$

where $v$ is the Poisson's ratio, $e$ is the void ratio, $p=(\operatorname{tr} \sigma) / 3$ is the mean effective stress (where tr stands for the trace), and $\kappa$ is the slope of elastic swelling lines in the $e-\ln p$ space. 
The isotropic hardening law of the model describing the evolution of the size of structured SYS, i.e. $p_{0}^{* S}$, is defined as

$$
\dot{p}_{0}^{* S}=\dot{S}_{\imath} p_{0}^{S}+S_{i} \dot{p}_{0}^{S}
$$

542

543

544

545

546

547

548

549

550

551

552

553

$$
\dot{\varepsilon}_{d}^{v p}=\sqrt{(1-A)\left(\dot{\varepsilon}_{v}^{v p}\right)^{2}+A\left(\dot{\varepsilon}_{q}^{v p}\right)^{2}}
$$

where $\dot{\varepsilon}_{v}^{v p}$ and $\dot{\varepsilon}_{q}^{v p}$ are the volumetric and deviatoric viscoplastic strain rates, respectively, and $A$ is a model parameter could be set to 0.5 as a default value. The evolution equations for the $S_{i}$ and $S_{f}$ read

$\dot{S}_{i}=-k_{i}\left(\frac{1+e}{\lambda-\kappa}\right)\left(S_{i}-1\right) \dot{\varepsilon}_{d}^{v p}$

$\dot{S}_{f}=-k_{f}\left(\frac{1+e}{\lambda-\kappa}\right)\left(S_{f}-1\right) \dot{\varepsilon}_{d}^{v p}$

where $k_{i}$ and $k_{f}$ are model parameters.

As indicated in model formulation section, the critical stress-ratio is defined as a function of the Lode angle $\theta$. To regulate the variation of $M(\theta)$ between its values $M_{c}$ for compression and $M_{e}$ for extension, the

$$
M(\theta)=M_{c}\left(\frac{2 m^{4}}{1+m^{4}+\left(1-m^{4}\right) \sin 3 \theta}\right)^{1 / 4}
$$

where $m=M_{e} / M_{c},-\pi / 6 \leq \theta=(1 / 3) \sin ^{-1}\left[-3 \sqrt{3} J_{3} /\left(2 J_{2}{ }^{3 / 2}\right)\right] \leq \pi / 6$, with $J_{2}$ and $J_{3}$ being the second and third invariants of the modified stress deviator $\boldsymbol{s}-p \boldsymbol{\alpha}$. 


\section{References}

565 [1] Kim DK. Comparisons of Constitutive Models for Anisotropic Soils. KSCE J Civil Eng 2004; 8(4):403-409.

566 [2] Sekiguchi H, Ohta H. Induced anisotropy and time dependency in clays. 9th ICSMFE, Tokyo, Constitutive 567 equations of Soils 1977; 17:229-238.

568

[3] Graham J, Noonan ML, Lew KV. Yield states and stress-strain relationships in a natural plastic clay. Can Geotech J 1983; 20(3):502-516.

570

[4] Korhonen KH, Lojander M. Yielding of Perno clay. In Proc of $2^{\text {nd }}$ International Conference on Constitutive Laws for Engineering Materials, Tucson, Arizona, Vol 2 1987: 1249-1255.

572 [5] Dafalias YF. An anisotropic critical state soil plasticity model. Mech Res Commun 1986; 13(6):341-347.

573 [6] Dafalias YF. An anisotropic critical state clay plasticity model. In Proceedings of the 2nd international conference on constitutive laws for engineering materials. Tucson, US, 1987:513-521.

575 [7] Thevanayagam S, Chameau JL. Modelling anisotropy of clays at critical state. J Eng Mech-ASCE 1992; 118(4):786-806

[8] Whittle AJ, Kavvadas MJ. Formulation of MIT-E3 constitutive model for overconsolidated clays. J Geotech Eng 1994; 120(1):173-198.

579

[9] Newson TA, Davies MCR. A rotational hardening constitutive model for anisotropically consolidated clay. Soils Found 1996; 36(3):13-20

[10] Wheeler SJ, Karstunen M, Näätänen A. Anisotropic hardening model for normally consolidated soft clay. In Proc. 7th Int. Symp. on Numerical Models in Geomechanics (NUMOG VII), Graz, 1999, 33- 40. A.A. Balkema.

[11] Wheeler SJ, Näätänen A, Karstunen M, Lojander M. An anisotropic elasto-plastic model for soft clays. Can Geotech J 2003; 40(2):403-418.

586 [12] Dafalias YF, Manzari MT, Papadimitriou AG. SANICLAY: simple anisotropic clay plasticity model. Int J Numer Anal Meth Geomech 2006; 30:1231-1257.

588

[13] Taiebat M, Dafalias YF, Peek R. A destructuration theory and its application to SANICLAY model. Int J Numer Anal Meth Geomech 2010; 34:1009-1040.

[14] Vaid YP, Campanella RG. Time-dependent behaviour of undisturbed clay. J Geotech Eng-ASCE 1977; 103(7):693-709.

592 [15] Tavenas F, Leroueil S, La Rochelle P, Roy M. Creep behavior of an undisturbed lightly overconsolidated clay. Can Geotech J 1978; 15(3):402-423.

[16] Leroueil S, Kabbaj M, Tavenas F, Bouchard R. Stress-strain-strain-rate relation for the compressibility of sensitive natural clays. Géotechnique 1985; 35(2):159-180.

596 [17] Lefebvre G, Leboeuf D. Rate effects and cyclic loading of sensitive clays. J Geotech Eng-ASCE 1987; 113(5):476-489. 
[18] Augustesen A, Liingaard M, Lade PV. Evaluation of Time-Dependent Behavior of Soils. Int J Geomech 2004; 4(3):137-156.

[19] Vaid YP, Robertson PK, Campanella RG. Strain rate behavior of Saint-Jean-Vianney clay. Can Geotech J $1979 ; 16: 34-42$.

[20] Díaz-Rodríguez JA, Martínez-Vasquez JJ, Santamarina JC. Strain-rate effects in Mexico City soil. J Geotech Geoenviron Eng 2009; 135(2):300-305

[21] Leroueil S. The isotache approach. Where are we 50 years after its development by Professor Šuklje?. 2006 Prof. Šuklje's Memorial Lecture, XIII Danube-European Geotechnical Engineering Conference, 29th31st May 2006, Ljubljana, Slovenia.

[22] Šuklje L. The analysis of the consolidation process by the isotache method. Proc. 4th Int. Conf. on Soil Mech and Found. Engng., London 1957; 1:200-206.

[23] Naghdi PM, Murch, SA. On the mechanical behavior of viscoelastic/plastic solids. J Applied Mechanics 1963; 30(3):321-328.

[24] Perzyna P. The constitutive equations for work-hardening and rate sensitive plastic materials. In Proc. Vibration Problems Warsaw 1963; 3:281-290.

[25] Perzyna P. Fundamental problems in viscoplasticity. Adv Appl Mech 1966; 9:244-377.

[26] Adachi T, Oka F. Constitutive equations for normally consolidated clay based on elasto-viscoplasticity. Soils Found 1982; 22(4):57-70.

[27] Nova R. A viscoplastic constitutive model for normally consolidated clay. In Proceedings of IUTAM Conference on Deformation and Failure of Granular Materials, Delft, The Netherlands, 1982, 287-295.

[28] Katona MG. Evaluation of Viscoplastic Cap Model. J Geotech Eng-ASCE. 1984; 110:1106-1125.

[29] Kaliakin VN, Dafalias YF. Theoretical aspects of the elastoplastic-viscoplastic bounding surface model for cohesive soils. Soils Found 1990; 30(3):11-24

[30] Yin JH, Zhu JG, Graham J. A new elastic viscoplastic model for time-dependent behaviour of normally and overconsolidated clays: theory and verification. Can Geotech J 2002; 39:157-173

[31] Yin ZY, Hicher PY. Identifying parameters controlling soil delayed behavior from laboratory and in situ pressuremeter testing. Int J Num Anal Meth Geomech 2008; 32:1515-1535

[32] Martindale H, Chakraborty T, Basu B. A Strain-Rate Dependent Clay Constitutive Model with Parametric Sensitivity and Uncertainty Quantification. Geotech Geol Eng 2013; 31:229-248

[33] Leoni M, Karstunen M, Vermeer P. Anisotropic creep model for soft soils. Géotechnique 2008; 58(3):215226.

[34] Yin Z-Y, Karstunen M. Modelling strain-rate-dependency of natural soft clays combined with anisotropy and destructuration. Acta Mechanica Solida sinica, Vol. 24, No 3, June 2001. Published by AMSS Press, Wuhan, China.

[35] Dafalias YF, Taiebat M. Anatomy of Rotational Hardening in Clay Plasticity. Geotechnique 2013; 63(16):1406-1418. 
[36] Dafalias YF, Taiebat M. Rotational hardening with and without anisotropic fabric at critical state. Geotechnique 2014; 64(6): 507-511.

[37] Shahrour I, Meimon Y. Calculation of marine foundations subjected to repeated loads by means of the homogenization method. Comput Geotech 1995; 17(1):93-106.

[38] Fodil A, Aloulou W, Hicher PY. Viscoplastic behaviour of soft clay. Géotechnique 1997; 47(3):581-591.

[39] Lewis RW, Schrefler BA. The Finite Element Method in the Static and Dynamic Deformation and Consolidation of Porous Media. $2^{\text {nd }}$ Ed.: John Wiley \& Sons, ISBN: 978-0-471-92809-6; 1998.

[40] Hinchberger SD. The behaviour of reinforced and unreinforced embankments on soft rate-sensitive foundation soils. Ph.D. thesis, Department of Civil Engineering, The University of Western Ontario, London, Ont. 1996.

[41] Brinkgreve RBJ, Engin E, Swolfs WM. Plaxis 2014 reference manual, Plaxis, Delft, Netherlands; 2014.

[42] Nakase A, Kamei T. Influence of strain rate on undrained shear characteristics of $\mathrm{K} 0$-consolidated cohesive soils. Soils Found 1986; 26(1):85-95.

[43] Rangeard D. Identification des caractéristiques hydro-mécaniques d'une argile par analyse inverse des essais pressiométriques. Thèse de l'Ecole Centrale de Nantes et l'Université de Nantes, 2002.

[44] Kamei T, Sakajo S. Evaluation of undrained shear behaviour of K0-consolidated cohesive soils using elasto-viscoplastic model. Comput Geotech 1995; 17:397-417.

[45] Vermeer PA, Neher HP. A soft soil model that accounts for creep. In: Proc. Plaxis Symposium 'Beyond 2000 in Computational Geotechnic', Amsterdam 1999: 249-262.

[46] Rocchi G, Fontana M, Da Prat M. (2003). Modelling of natural soft clay destruction processes using viscoplasticity theory. Géotechnique 2003; 53(8):729-745.

[47] La Rochelle P, Trak B, Tavenas F, Roy M. Failure of a test embankment on a sensitive Champlain clay deposit. Can Geotech J 1974; 11(1):142-164.

[48] Tavenas FA, Chapeau C, La Rochelle P, Roy M. Immediate settlements of three test embankments on Champlain clay. Can Geotech J 1974; 11(1):109-141.

[49] Leroueil S, Tavenas F, Trak B, La Rochelle P, Roy M. Construction pore water pressures in clay foundations under embankments. Part I: the Saint-Alban test fills. Can Geotech J 1978; 15:54-65.

[50] Karim MR, Oka F, Krabbenhoft K, Leroueil S, Kimoto S. Simulation of long-term consolidation behavior of soft sensitive clay using an elasto-viscoplastic constitutive model. Int J Numer Anal Meth Geomech 2013; 37:2801-2824.

[51] Tavenas F, Leroueil S. Effects of stresses and time on yielding of clays. In Proceedings of the 9th International Conference on Soil Mechanics and Foundation Engineering, Toyko, Japan, 1977.

[52] Oka F, Tavenas F, Leroueil S. An elasto-viscoplastic fem analysis of sensitive clay foundation beneath embankment. In Computer Method and Advances in Geomechanics, Vol. 2, Beer G, Booker JR, Carter JP (eds). Balkema: Brookfield, 6-10 May 1991; 1023-1028.

[53] Morissette L., St-Louis MW, McRostie GC. Empirical settlement predictions in overconsolidated Champlain Sea clays. Can Geotech J 2001; 38:720-731. 
671 [54] Tavenas F, Mieussens C, Bourges F. Lateral displacements in clay foundations under embankments. Can 672 Geotech J 1979; 16(3):532-550.

673 [55] Karstunen M, Rezania M, Sivasithamparam N, Yin ZY. Comparison of Anisotropic Rate-Dependent Models 674 for Modeling Consolidation of Soft Clays. Intl J Geomech 2012, DOI: 10.1061/(ASCE)GM.1943$675 \quad 5622.0000267$.

676 [56] Sheng D, Sloan SW, Yu HS. Aspects of finite element implementation of critical state models. 677 Computational mechanics 2000; 26(2):185-196.

678

679 